\title{
VIABILITY OF ALTERNATIVE GENETIC IMPROVEMENT STRATEGIES USING WHOLE GENOME SELECTION ON COMMERCIAL DAIRY OPERATIONS
}

\author{
A Thesis \\ presented to \\ the Faculty of California Polytechnic State University, \\ San Luis Obispo
}

\begin{abstract}
In Partial Fulfillment
of the Requirements for the Degree

Master of Science in Agriculture,

Specialization in Animal Science
\end{abstract}

by

Levi William Morgan Gassaway

June 2009 
(C)2009

Levi William Morgan Gassaway

ALL RIGHTS RESERVED 


\section{COMMITTEE MEMBERSHIP}

TITLE:

AUTHOR:

DATE SUBMITTED:

COMMITTEE CHAIR:

COMMITTEE MEMBER:

COMMITTEE MEMBER:
Viability of Alternative Genetic Improvement Strategies Using Whole Genome Selection on Commercial Dairy Operations

Levi William Morgan Gassaway

June 2009
Dr. Bruce L. Golden, Department Head Dairy Science

Dr. Stanley L. Henderson, Professor Dairy Science

Dr. Dan G. Peterson, Professor Animal Science 


\begin{abstract}
Viability of Alternative Genetic Improvement Strategies Using Whole Genome Selection on Commercial Dairy Operations
\end{abstract}

\title{
Levi William Morgan Gassaway
}

The objective of this thesis was to determine the viability of alternative genetic improvement strategies (GIS). Each alternative GIS combined the use of whole genome selection (WGS) with common reproductive methods (non-sexed semen artificial insemination (AI), sexed semen AI, embryo transfer utilizing non-sexed semen AI) that can be found on a commercial dairy operation. The viability of each GIS was determined using a discounted gene flow model, designed with parameters of a typical western dairy operation, to evaluate the following variables: reproductive method, selection intensity, accuracy of prediction and female age-class. Of the GIS investigated, a heifer-based strategy that used embryo transfer with $11 \%$ selection intensity and $85 \%$ accuracy was viable. This GIS generated 2.7 million dollars in present value of cumulative gross marginal returns. Despite such encouraging results, at the current prices for genotyping, reproductive methods and achievable prediction accuracy levels, all other GIS resulted in negative returns. Whole genome selection could be a powerful genetic improvement tool for the commercial dairy industry if high accuracy genotyping solutions and reproductive methods that allowed for high selection intensity were combined and priced less than $\$ 379.07$ per individual.

(Keywords: genomics, whole genome selection, dairy cattle, genetic improvement strategy) 


\section{ACKNOWLEDGEMENTS}

I would like to acknowledge Cal Poly San Luis Obispo and its faculty of dedicated educators.

I would also like to thank my committee members. Dr. Golden, I am grateful that you allowed me this opportunity to further my education and to pursue my passion in genomics and animal breeding. Dr. Henderson, I thank you for imparting to me the idea that even though we are animal scientists that we must still remember the beneficiaries of our work, the producers. Dr. Peterson, I appreciate your efforts in helping me to learn how to temper my determination with patience and knowledge.

And to my family and friends for being my sounding boards even when it did not make sense and you did not want to hear about it anymore. 


\section{TABLE OF CONTENTS}

Table of Contents $\quad$ Page

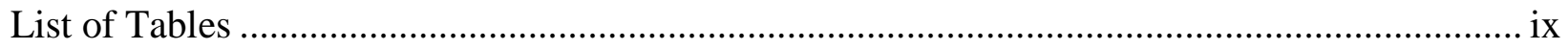

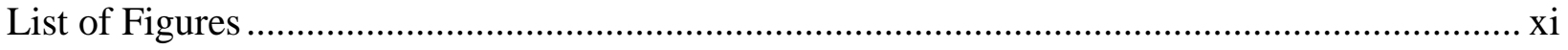

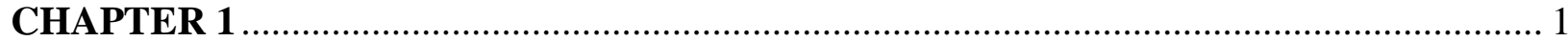

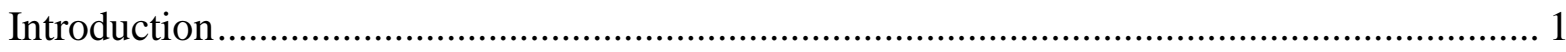

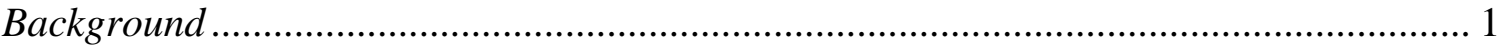

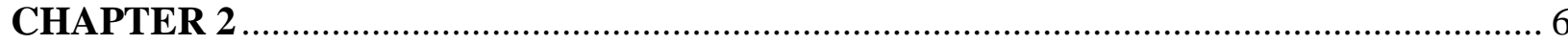

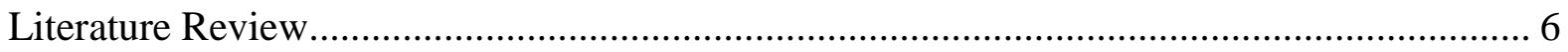

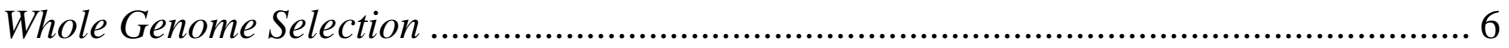

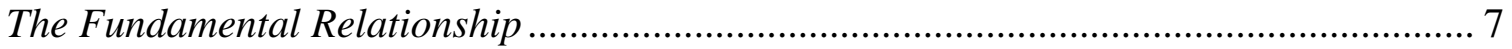

The Correlation between SNP and Quantitative Trait Loci ............................................ 7

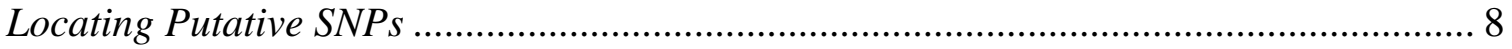

The Validation of a SNP as an Associative Marker or QTN ......................................... 10

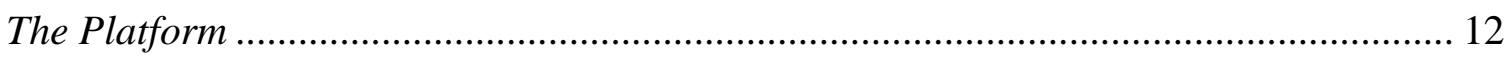

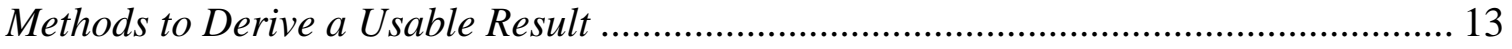

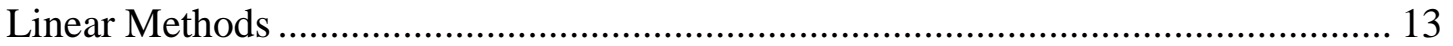

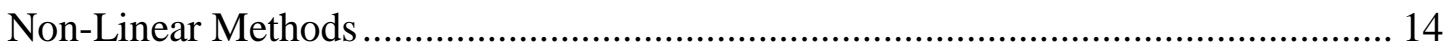

Methods to Compute Genomic Predictions from BovineSNP50 Bead Chip.................... 15

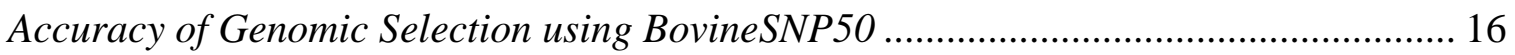

Common Application Strategies for Whole Genome Selection ....................................... 18

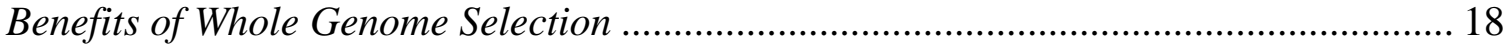

Discounted Gene Flow Model .................................................................................. 19

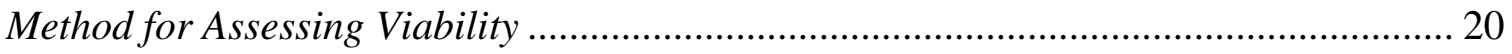

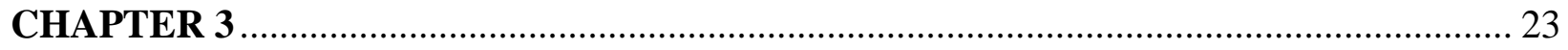

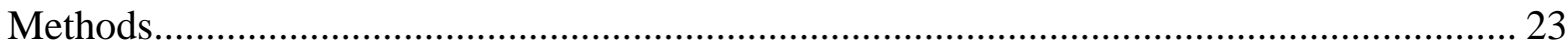

Heifer-based Genetic Improvement Strategies ......................................................... 24

Cow-based Genetic Improvement Strategies ........................................................... 25

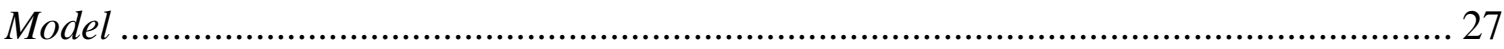

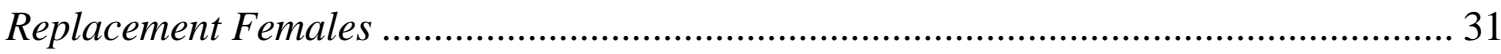

Quantity of Replacement Females Produced Annually .............................................. 31 


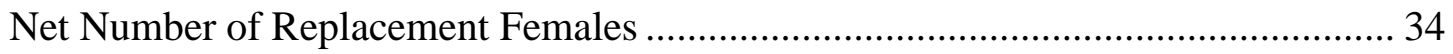

Selection Percentage for Heifer-based Genetic Improvement Strategies......................... 35

Number of Donor Heifers Required when Using a Single Flush ................................ 36

Number of Donor Heifers Required when Using a Double Flush................................ 37

Selection Percentage for Cow-based Genetic Improvement Strategies ........................... 35

Number of Donor Cows Required when Using a Single Flush .................................. 37

Number of Donor Cows Required when Using a Double Flush .................................. 38

Genomic Esitmated Breeding Value Accuracy Levels .................................................. 38

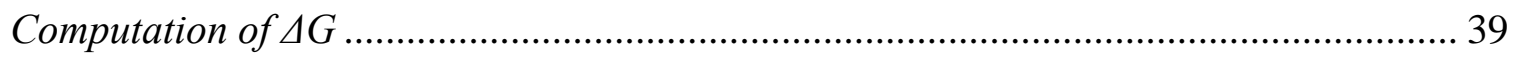

Determination of Present Value ................................................................................ 40

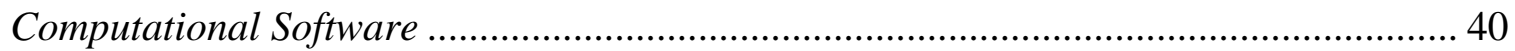

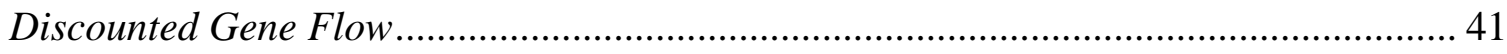

Present Value of Total Marginal Cost for Each Genetic Improvement Strategy ............. 52

Present Value of Total Marginal Costs for Heifer and Cow-based Genetic Improvement Strategies Utilizing Artificial Insemination ........................................ 52

Present Value of Total Marginal Costs for Heifer-based Genetic Improvement Strategies Utilizing Embryo Transfer .................................................................. 53

Present Value of Total Marginal Costs for Cow-based Genetic Improvement Strategies Utilizing Embryo Transfer ………………………………………..... 53

Present Value of Total Marginal Cost Per Dollar Increase in $\Delta G$............................... 53

Break Even Cost .................................................................................................. 54

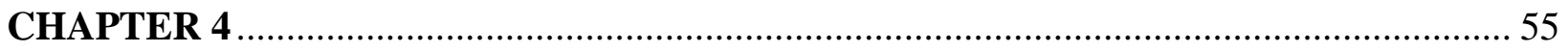

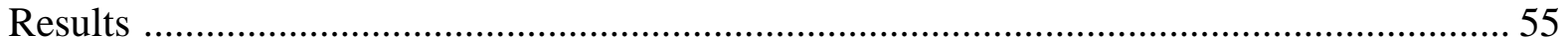

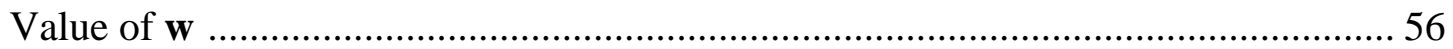

Estimated $\Delta G$ per Year …………………………….......................................... 57

Present Value of Gross Marginal Returns ................................................................ 58

Present Value of Gross Marginal Returns for Heifer-based Genetic Improvement Strategies.

Present Value of Gross Marginal Returns for Cow-based Genetic Improvement

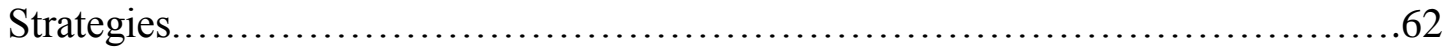

Present Value of Cumulative Gross Marginal Returns .................................................. 64

Present Value of Cumulative Gross Marginal Returns for Heifer-based Genetic Improvement Strategies 
Present Value of Cumulative Gross Marginal Returns for Cow-based Genetic

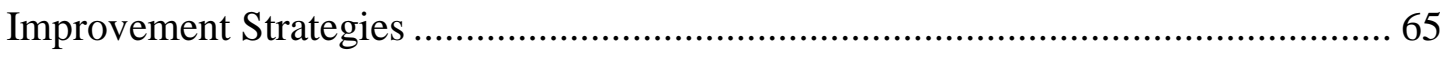

Present Value of Total Marginal Cost for Each Genetic Improvement Strategy ............ 66

Present Value of Total Marginal Cost per Dollar Increase in the Present Value of $\triangle G 67$

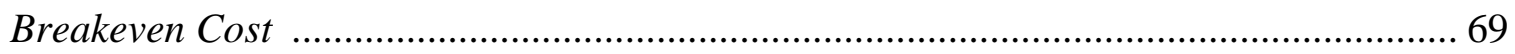

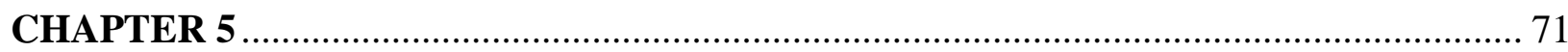

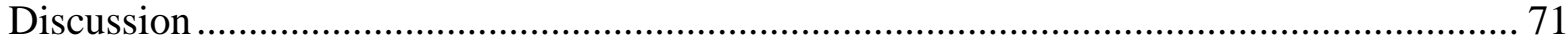

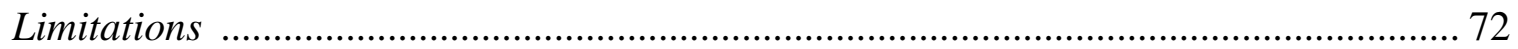

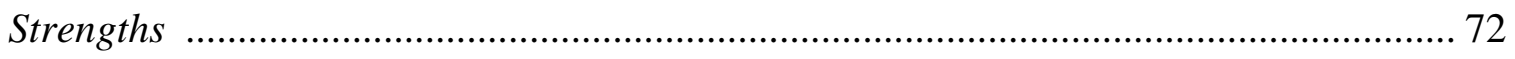

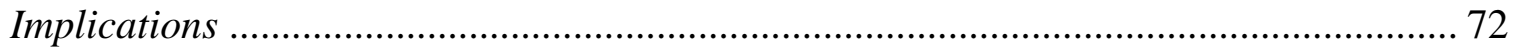

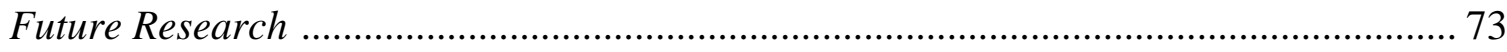

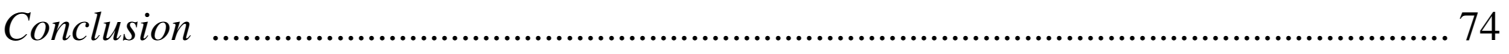

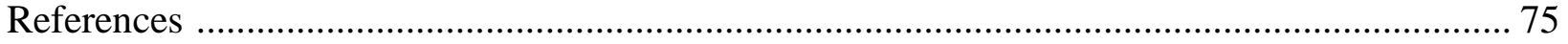

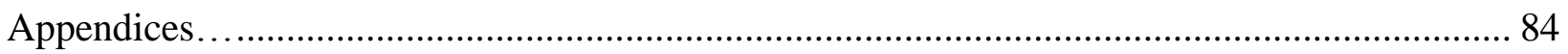




\section{LIST OF TABLES}

List of Tables

Page

1. Table 2.1: Accuracy of estimated breeding values (EBVs) and $\mathrm{R}^{2}$ between EBV and true

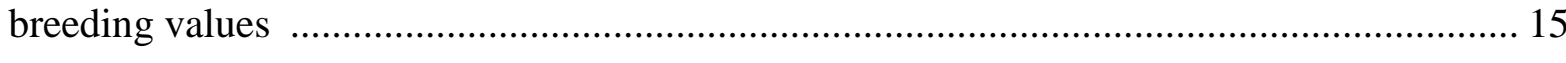

2. Table 3.1: Description of heifer-based genetic improvement strategies ............................ 25

3. Table 3.2: Description of cow-based genetic improveent strategies .................................. 26

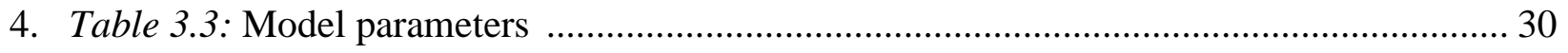

5. Table 3.4: $\mathbf{P}$ where the columns correspond to years one through twenty .......................... 44

6. Table 3.5: $\mathbf{Q}$ where the columns correspond to years one through twenty ......................... 45

7. Table 3.6: $\mathbf{R}$ where the columns correspond to years one through twenty .......................... 46

8. Table 3.7: $\mathbf{d}$ where each row corresponds to years one through twenty ............................. 47

9. Table 3.8: $\mathbf{n}$ for heifer-based genetic improvement strategies .......................................... 48

10. Table 3.9: $\mathbf{v}$ for heifer-based genetic improvement strategies ......................................... 49

11. Table 3.10: $\mathbf{n}$ for cow-based genetic improvement strategies .......................................... 50

12. Table 3.11: v for cow-based genetic improvement strategies ......................................... 51

13. Table 4.1: Selection level, breeding and calving number for each heifer-based genetic

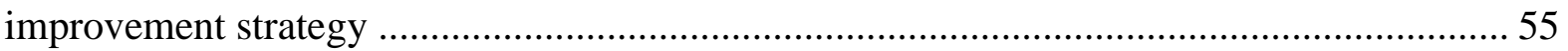

14. Table 4.2: Selection level, breeding and calving number for each cow-based genetic

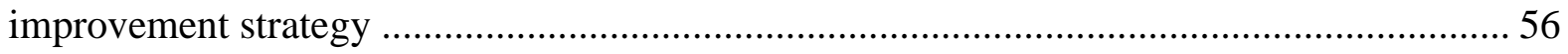

15. Table 4.3: Values of $\mathbf{w}$ elements for heifer-based genetic improvement strategies .............. 56

16. Table 4.4: Values of $\mathbf{w}$ elements for cow-based genetic improvement strategies ................. 57

17. Table 4.5: $\Delta \mathrm{G}$ per generation and $\Delta \mathrm{G}$ per year for heifer-based genetic improvement

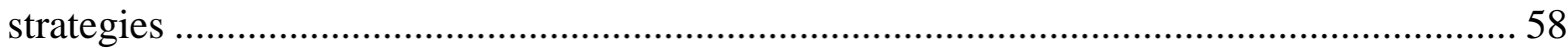

18. Table 4.6: $\Delta \mathrm{G}$ per generation and $\Delta \mathrm{G}$ per year for cow-based genetic improvement

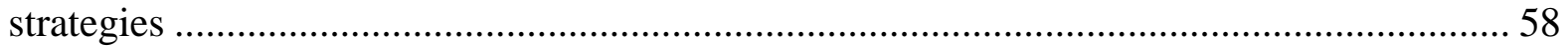

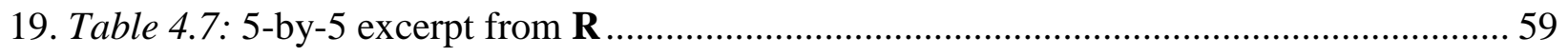

20. Table 4.8: Present value of total marginal cost for each heifer-based genetic improvement

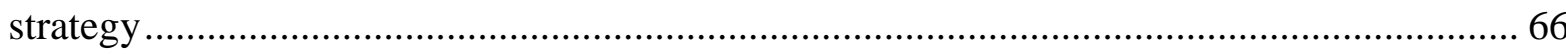

21. Table 4.9: Present value of total marginal cost for each cow-based genetic improvement strategy

22. Table 4.10: Present value of total marginal cost per dollar increase in the present value of $\Delta \mathrm{G}$ per year for heifer-based genetic improvement strategies 68 
23. Table 4.11: Present value of total marginal cost per dollar increase in the present value of $\Delta \mathrm{G}$ per year for cow-based genetic improvement strategies 68

24. Table 4.12: Cumulative marginal returns for heifer-based genetic improvement strategies.. 69

25. Table 4.13: Cumulative marginal returns for cow-based genetic improvement strategies .... 70 


\section{LIST OF FIGURES}

List of Figures

Pages

1. Figure 2.1: Model illustrating a putative SNP within an electrophoresis gel ...................... 9

2. Figure 2.2: Model illustrating a putative SNP within an electrophoreogram ....................... 9

3. Figure 2.3: Validation path for SNP markers causality ............................................... 10

4. Figure 4.1: Present value of gross marginal returns for heifer-based genetic improvement

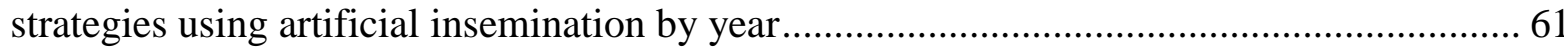

5. Figure 4.2: Present value of gross marginal returns for heifer-based genetic improvement strategies using embryo transfer by year

6. Figure 4.3: Present value of gross marginal returns for cow-based genetic improvement strategies by year.

7. Figure 4.4: Present value of cumulative gross marginal returns for each heifer-based genetic improvement strategy over a 20-year time horizon

8. Figure 4.5: Present value of cumulative gross marginal returns for each cow-based genetic improvement strategy over a 20 -year time horizon 66 


\section{CHAPTER 1}

\section{INTRODUCTION}

The objective of this thesis was to determine the viability of alternative genetic improvement strategies (GIS). The alternative GIS combined the use of whole genome selection (a selection process that used genotypic information) with common reproductive methods used on a commercial dairy operation. To determine the viability of each GIS, a discounted gene flow model was designed using parameters of typical western dairy operations to evaluate the following variables: reproductive method, selection intensity, accuracy of prediction and the ageclass of females.

The discounted gene flow model was a matrix-based method that accounted for gene flow, aging, number of selected animals, value of a selected trait and a discounting rate (Hill, 1974; Gibson and Dekkers, 2008). The present value of gross marginal and cumulative gross marginal returns that resulted from the implementation of proposed GIS were determined by using the discounted gene flow model. Following the computation of gross marginal and cumulative gross marginal returns for all GIS, the strategy capable of creating the greatest amount of genetic change per dollar invested and greatest cumulative gross marginal returns was identified as a topic to be investigated further.

\section{Background}

The breeding of selected individuals that expressed a preferred trait was an ancient methodology. A practical example in Genesis (the first book of the Old Testament) recounted the story of Jacob, a shepherd that bred sheep and goats for both strength and coat color (Genesis, 
$\sim 1500$ BC). This approach has been repeated throughout the world with a variety of species and breeds with few new developments until the last half of the $20^{\text {th }}$ century.

In 1900, Hugo de Vries, Carl Correns, and Erich von Tschermark independently rediscovered Gregor Mendel's work on the fundamentals of heredity. In his foundation work, Mendel summarized the two principles of meiosis, segregation and independent assortment (National Human Genome Research Institute, 2009). In 1902, William Sutton proposed the Chromosomal Theory of Heredity. Sutton described that in the process of meiosis; only one-half of an individual's genes were included into a gamete, which validated Mendel's theories (National Human Genome Research Institute, 2009). In 1905, William Bateson coined the name "genetics" for this new science that investigated the principles of heredity and inheritance (National Human Genome Research Institute, 2009).

Concurrent with the rediscovery of genetics, cow-testing associations were developed. Early record keeping organizations set forth the standards by which an individual cow's production could be recorded and compared to other cows throughout a herd or testing association region. Over time, these local testing associations evolved into nationally based programs such as the United States Dairy Herd Improvement Association (DHIA) (Voelker, 1981).

With the rediscovery of genetics in conjunction with development testing organizations, conditions were perfect for the modernization of animal breeding philosophies. To benefit the industry, one of the first changes dairy breeders made was the implementation of progeny testing. Progeny testing, utilized in Denmark as early as 1902, has spread throughout the world evolving considerably since its inception (Johansson, 1959). 
Progeny testing was used to evaluate a sire's transmitting ability. Over the past 100 years, the United States Department of Agriculture (USDA) adopted the following models that utilized information collected from official dairy records to determine sire quality:

1) Dam-daughter Comparison: In 1935, the dam-daughter comparison method was adopted by the USDA Bureau of Dairy Industry as the official method of sire evaluation (Freeman, 1991). This model determined the transmitting ability of a sire by comparing the average production levels of his female progeny with the average production levels of their dams (Putnam et al., 1943).

2) Herd-mate Comparison: In 1952, Johannson and Robertson proposed the first contemporary comparison method in the United Kingdom (Freeman, 1991). In 1954, C.R. Henderson of the United States developed his own version of a herd-mate comparison. Henderson's method accounted for herd-year-season effects by regressing a sire's daughter's production against her herd-mates' average production (Van Vleck, 1963; Freeman, 1991). The USDA Agriculture Research Service replaced the dam-daughter comparison with the more accurate herd-mate comparison method in 1962 (Freeman, 1991).

3) Modified Contemporary Comparison: This method accounted for variables not previously considered such as genetic differences among herd-mates, daughter distribution, pedigree information, number of herd-mates, and the number and average repeatability of herd-mates' sires (Norman et al., 1976). The modified contemporary comparison replaced the herd-mate comparison method in 1974.

4) Animal Model: The Animal Model has been in use since 1989 (Powell and Norman, 2006). The Animal Model differed from previous methods as it considered the 
additive genetic relationships of all animals that contributed to an individual animal's evaluation (Wiggans and Misztal, 1987). The inclusion of this additional information improved the overall accuracy of evaluation and avoided any bias created by nonrandom mating and female selection, which was an inherent weakness of previous sire based progeny testing methods (Wiggans and Misztal, 1987).

Progeny testing alone did not significantly affect the dairy industry. Foote (2002) noted that sire selection and validation using natural service proofs had disappointing results. It was not until artificial insemination (AI) became commercially used that progeny testing began to achieve impressive results. Progeny testing worked in synergy with AI. Progeny testing enabled AI to have the single greatest effect of any biotechnology on the dairy industry to date (Foote, 2002). The combination of AI and progeny testing resulted in a substantial amount of genetic gain, as illustrated by the average production level of cows nearly doubling since 1950 (Butler, 2002).

Since the development of commercial AI, the dairy industry drastically changed. In 1959, Jay Lush stated, "other things being equal the higher producing cow will make her owner more profit (or at least will cause him less loss) than the low producing one." This statement remained true for several decades. However, in the volatile economic environment of this new century, fluid milk did not necessarily mean money. Modern animal breeders and dairymen have recognized the importance of non-production traits such as productive life, daughter pregnancy rate, somatic cell score, foot and leg score, and udder score in the development of long living and profitable cattle. 
The genetic quality of animals for traits, (i.e. daughter pregnancy rate and productive life), were not known for an inordinate amount of time. Until recent years, it was not possible to overcome this barrier to producing more efficient cattle. Contemporary developments in biotechnology have made it possible for the genetic selection of superior cattle.

Beckman and Soller (1983) laid the foundation for using genetic markers to select breeding stock. The researchers hypothesized that polymorphic genetic markers had the potential to evaluate genetic loci that influenced economic traits. In addition, the authors theorized that marker-based selection could be used to propagate and manage beneficial alleles within a breeding population (Beckman and Soller, 1983). The evaluation of genetic markers, specifically single nucleotide polymorphisms (SNPs), to select breeding stock became known as markerassisted selection (Lande and Thompson, 1990).

With continued research and developments, marker-assisted selection advanced to the next level, whole genome selection. The implementation of whole genome selection served as the focus of this thesis. 


\section{CHAPTER 2}

\section{LITERATURE REVIEW}

Whole genome selection (WGS), an extension of marker-assisted selection, was based on the assumption that all quantitative trait loci (QTL) (a chromosomal region believed to contain a gene or genes that influenced a phenotype of interest) were in linkage disequilibrium with at least one single nucleotide polymorphism marker (SNP) (Goddard and Hayes, 2007). Meuwissen et al. (2001) proposed the concept of WGS and investigated the strategy's potential for generating accurate genomic estimated breeding values. From the investigators' research, WGS had the potential to produce high accuracy estimated breeding values (Meuwissen et al., 2001). The development of dense genetic marker maps for bovine, more affordable genotyping technologies and efficient methods to compute estimated genomic breeding values have resulted in the opportunity to use WGS (van der Beek, 2007).

\section{Whole Genome Selection}

Lambert (2008) stated, "the result of a biological system is hardly ever definite.” This uncertainty was due to the two laws of Medelian inheritance, segregation and independent assortment. These laws described the random nature of gamete formation, from the separation of gene copies to the non-associative grouping of gene copies, within gametes.

The primary objective of WGS was to establish an accurate method to estimate the genetic quality of breeding animals. Animals selected based on their genomic estimated breeding values inherited chromosomal segments that influenced the phenotypes of interest (Meuwissen et al., 2001; Schaefer, 2006; VanRaden, 2008). Proposed plans for WGS implementation have focused on using genotypic information in combination with traditional parental averages to pre- 
select superior individuals as parents for subsequent generations (Meuwissen et al., 2001, Schaefer, 2006, VanRaden, 2008).

\section{The Fundamental Relationship}

Interrogating the bovine genome to locate genes that affected economic traits was not a recently developed concept. In 1995, the first successful bovine genome analysis was made in an attempt to map the QTL that affected milk production in dairy cattle (Georges et al., 1995). The underlying principle to WGS was the relationship between a SNP and QTL (Ron and Weller, 2007). Single nucleotide polymorphisms were the most abundant form of genetic variation and were commonly found in non-coding regions (Wiltshire et al., 2003; Snelling et al., 2005). Single nucleotide polymorphisms were determined to be ideal for the detection of markertrait/gene association due to their low mutation rates and ease of genotyping (Hinds et al., 2005; Kolbehdari et al., 2008).

\section{The Correlation between SNP and Quantitative Trait Loci}

Single nucleotide polymorphism markers have been associated with a causative mutation; in rare cases, a SNP marker has been the causal mutation (quantitative trait nucleotide). The level of relation between a SNP marker and a quantitative trait nucleotide was of extreme importance when considering SNP markers for inclusion in genomic assays.

Linkage disequilibrium, measured in terms of $\mathrm{R}^{2}$, was used to describe the level of the association between a SNP marker and a QTL (Grisart et al., 2004; de Roos et al., 2008). The correlation coefficient, $\mathrm{R}^{2}$, was calculated by performing a regression between marker genotype and a corresponding phenotype. This regression method was simpler than other strategies as the exact location of marker was not required (Kolbehdari et al., 2008). 


\section{Locating Putative SNPS}

Locating SNPs throughout the genome was accomplished using traditional sequencing as well as in silico analysis of candidate QTL (Ron and Weller, 2007). Sanger Sequencing and Sanger Cycle Sequencing (a primarily automated method) characterized traditional sequencing techniques. These methods determined a DNA sample's sequence by allowing single stranded DNA fragments to synthesize a complimentary strand until the addition of a dideoxynucleotide. Samples from dideoxyreactions were electrophoresed on polyacrylimide gels to separate the DNA fragments by size. Photographs were taken of the gels and the DNA sample's sequence was determined from the resulting images (Slatko et al., 2001). Putative SNPs were then recognized by comparing the gels of the same genetic region from other individuals (Figure 2.1).

The automated cycle sequencing method used machines to decode the light emitted from labeled dideoxynucleotides within the DNA fragments in gels to produce electrophoreograms (Figure 2.2). SNPs have been identified from electrophoreograms by sequencing multiple individuals for the same DNA region and locating any non-congruent peaks (Ron and Weller, 2007) (Figure 2.2). 


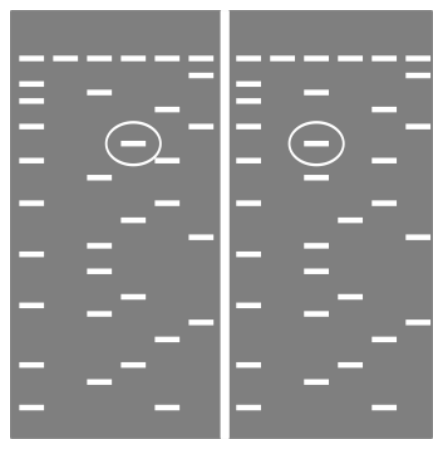

Figure 2.1: Model illustrating a putative SNP within an electrophoresis gel.

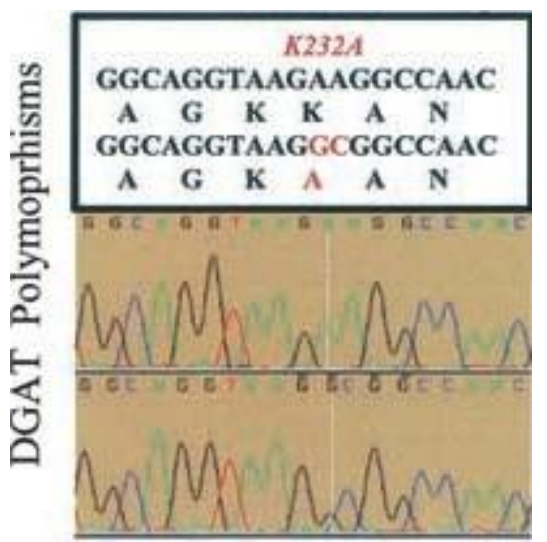

Figure 2.2: Model illustrating a putative SNP within an electrophoreogram (source: Grisart et al., 2002).

When DNA samples from multiple individuals were analyzed, putative SNPs were simple to identify. However, visually inspecting gels was a time consuming process. Sequencing methods that used automated systems and computer analysis programs became preferred tools. This combination of classical biology with advanced computational methods characterized in silico biology. In silico methods utilized powerful computing systems to design and apply new mathematical methods and computer programs to efficiently locate and validate SNP markers (in silico Biology, 2008). Since the primary sequencing of the bovine genome in 2004, in silico analysis tools (i.e. the Interactive Bovine in silico SNP database) have contributed to the increasing number of identified SNPs (Hawken et al., 2004; Ron and Weller, 2007; Human Genome Sequencing Center, 2009). 


\section{The Validation of a SNP as an Associative Marker or QTN}

The process of validating a SNP marker as a quantitative trait nucleotide (QTN) has been a costly and time consuming proposition (Yalcin et al. 2005; Ron and Weller, 2007).

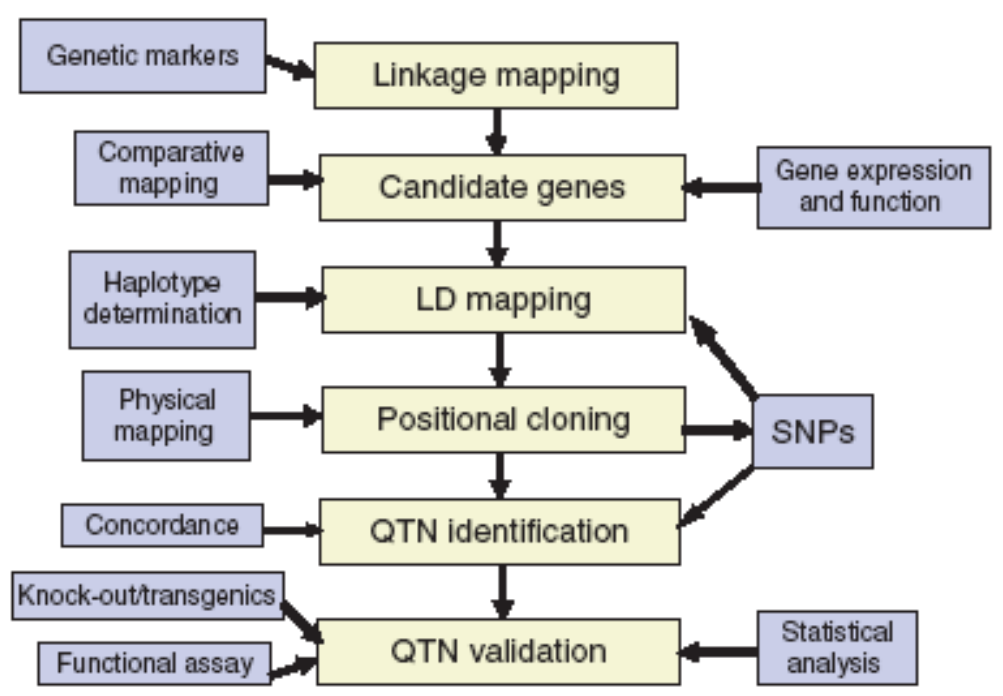

Figure 2.3: Validation path for SNP markers causality (source: Ron and Weller, 2007).

The validation pathway for SNP markers relied on linkage mapping regions of the genome specific to a putative QTL within a well-ordered pedigree (Figure 2.3). Linkage mapping was utilized to determine the level of linkage disequilibrium between a QTL and putative SNP markers (Ron and Weller, 2007). The selection of genes for further analysis relied on four main principles:

- the gene affected the phenotype of interest; 
- the gene was validated as affecting the phenotype by using knock-outs, selective mutations, and transgenics;

- the gene was expressed in organs related to the phenotype of interest;

- and the gene was expressed at the proper time (i.e. during maturation or lactation) (Ron and Weller, 2007).

Linkage disequilibrium mapping was used to further reduce the size of a putative QTL. Employing the logic that a polymorphism within a QTL was due to a single mutation, all carriers of the mutant allele should have been a descendant of the first mutant; consequently, each descendant should have had similar haplotypes (blocks of markers) surrounding a QTL (Riguet et al., 1999; Ron and Weller, 2007). Therefore, the essential QTL region would have contained the smallest common haplotype unit (Ron and Weller, 2007).

The arrangement of genes within a QTL was determined by positional cloning procedures (Ron and Weller, 2007). Positional cloning used information from all genomic resources such as whole genome sequences, comparative maps, and gene indices (Ron and Weller, 2007).

Before a SNP marker was validated as a QTN the marker must have met the following requirements:

- all individuals that were homozygous for the QTL were homozygous for the polymorphism;

- all individuals that were heterozygous for the QTL were heterozygous for the polymorphism;

- and the same QTL allele was linked to the putative QTN for heterozygous animals (Ron and Weller, 2007). 
If a SNP marker satisfied the aforementioned statements, the marker would be in complete concordance.

If a polymorphism met all the requirements for association, functional methods including statistical evaluations, knock-outs/transgenics and functional assays were used to validate if a SNP was the causal mutation for a phenotype (Ron and Weller, 2007). To validate a polymorphism as a QTN, the results of all functional methods should have conferred the same positive result. The failure of one or more tests would imply that the SNP marker was not a causal mutation. To date, DGAT1 was the only bovine SNP marker validated as a quantitative trait nucleotide. DGAT1 directly affected milk composition, as confirmed by multiple functional assays (Grisart et al., 2002).

\section{The Platform}

Illumina ${ }^{\circledR}$ Incorporated, in conjunction with the USDA-ARS Beltsville, University of Missouri and the USDA-ARS Clay Center formed the iBMC cooperative in an effort to develop a high-density SNP marker analysis platform for the bovine. The iBMC's BovineSNP50 bead chip consisted of 3-micron beads coated with a marker specific set of oligonucleotides, randomly distributed 5.7-microns apart on silica slides (Illumina, 2008; VanRaden, 2008a). The BovineSNP50 was designed on the Infinium ${ }^{\circledR}$ bead chip platform (Illumina, 2008; VanRaden, 2008a). McKay et al. (2008) speculated that at least 30k to 50k markers would be required to conduct a whole genome analysis. The BovineSNP50 contained more than 54k evenly spaced marker probes, of which approximately 40k were informative for the Holstein breed (VanRaden, 2008a; Illumina Inc., 2008). On average, the probes utilized in this bead chip were 51.5kb apart with median distance of $37.3 \mathrm{~kb}$ (Illumina Inc., 2008). Consequently, most markers included on 
the chip were within $40 \mathrm{~kb}$, a range hypothesized to allow for high levels of linkage disequilibrium with a causal mutation (McKay et al., 2007).

\section{Methods to Derive a Usable Result}

Methods (least Squares, best linear unbiased prediction (BLUP), Bayesian A and Bayesian B) were investigated to derive an estimated breeding value from genomic information. Meuwissen et al. (2001) sought to determine which statistical method obtained the greatest accuracy in predicting breeding values when using WGS. This study was conducted as a simulation with the following elements. The simulated population had an effective size of $\mathrm{N}_{\mathrm{e}}=100$ with a genome that consisted of ten chromosomes of $100 \mathrm{cM}$ each and a QTL in the center where a mutation could occur. Markers were located every $0.5 \mathrm{cM}$, totaling 101 markers per chromosome and 1010 markers per genome. A mutation rate of $2.5^{*} 10^{-5}$ per locus was imposed. The simulation population reached mutation drift balance after 1000 generations. Twenty-two hundred individuals were then genotyped for approximately 50K haplotypes (Meuwissen et al. 2001).

Linear Methods. The least squares method was used in a stepwise procedure so that all effects could be approximated simultaneously. When utilizing the least squares procedure, the effects of each gene were individually determined only for those that were deemed statistically significant. The effects of non-significant genes were set to zero. The effects of all statistically significant genes were summed to derive an estimated breeding value (Meuwissen et al. 2001).

Best linear unbiased prediction (BLUP) method considered the effects of alleles as random rather than fixed effects. A single variance of the allele effects was estimated. The single 
variance estimation resulted in an unrealistic assumption that the effect variance was the same for all alleles (Meuwissen et al. 2001).

Non-Linear Methods. Both Bayesian methods (A and B) were similar to BLUP with the main difference being that the estimated variance of allele effects were not considered equal for alleles. However, Bayesian A and Bayesian B are not equivalent; these methods differ in how they determined a prior distribution of each allele's variance.

1) Bayesian A: To determine the allelic variance, information from data itself and a prior distribution of the allele effect variance was combined. The result of this was a posterior distribution of the variance, $\operatorname{post}\left(\sigma_{\mathrm{g} i}^{2} \mid \mathbf{g}_{\mathrm{i}}\right)=\chi^{2}\left(\nu+\mathrm{n}_{\mathrm{i}} \mathrm{S}+\mathbf{g}_{\mathrm{i}}{ }^{\prime} \mathbf{g}_{\mathrm{i}}\right)$, where $\mathbf{g}$ was a vector of allele effects, $n_{i}$ was the number of allele effects at a particular loci (i), $\sigma_{\text {gi }}^{2}$ was the variance individual effects, $\mathrm{S}$ was a scale parameter, and $v$ was the degrees of freedom. However, this posterior distribution was incapable of directly estimating the variance because the elucidation of its solution was dependant on $\mathbf{g}_{\mathrm{i}}$ being unknown. Therefore, Gibbs Sampling algorithm was used, which was designed for posterior distributions with conditional effects (Meuwissen et al. 2001).

2) Bayesian B: This method utilized a prior distribution of greater density, $\pi$. The prior distribution of Bayesian B would appear as follows: $\rho\left(\sigma_{\text {gi }}^{2}, \mathbf{g}_{\mathrm{i}} \mid \mathbf{y}^{*}\right)=\rho\left(\sigma_{\mathrm{gi}}^{2} \mid \mathrm{Y}^{*}\right) * \rho\left(\mathbf{g}_{\mathrm{i}} \mid \sigma_{\mathrm{gi}}^{2}\right.$, $\left.y^{*}\right)$, where $y^{*}$ equaled y corrected for all genetic effects, except for $\mathbf{g}$. Bayesian B did not have any conditional restrictions placed onto $\mathbf{g}$. Therefore, the Metropolis-Hastings algorithm was used (Meuwissen et al. 2001).

The authors determined the accuracy of predicted breeding values. From these results, non-linear methods, specifically Bayesian B, were more accurate than the linear methods (Table 
2.1). Based on these findings, the authors concluded that it was feasible to estimate the breeding values of animals accurately with dense marker maps. If implemented, animals selected using estimated breeding values derived from marker analysis could have a substantial affect on genetic gain.

Table 2.1. Accuracy of estimated breeding values (EBVs) and regression between EBV and true breeding values.

\begin{tabular}{|c|c|c|}
\hline & \multicolumn{2}{|c|}{ Mean $( \pm$ SE $)$} \\
\hline Method & Accuracy & Regression between EBV and TBV \\
\hline LS & $0.318( \pm 0.018)$ & $0.285( \pm 0.024)$ \\
\hline BLUP & $0.732( \pm 0.030)$ & $0.896( \pm 0.045)$ \\
\hline BayesianA & 0.798 & 0.827 \\
\hline BayesianB & $0.848( \pm 0.012)$ & $0.946( \pm 0.018)$ \\
\hline
\end{tabular}

(Meuwissen et al., 2001)

\section{Methods to Compute Genomic Predictions from BovineSNP50 Bead Chip}

The methodologies presented in Meuwissen et al. (2001) were further investigated by VanRaden (2008). The investigator's objective was to determine which of several numerical methods computed the most accurate genomic predictions. Each method was tested with data from actual pedigrees and genomic data from the newly designed BovineSNP50 bead chip (VanRaden, 2008).

VanRaden (2008) evaluated three linear methods to analyze the reliability of estimated breeding values from genomic data: 
- iteration to solve for individual allele effects, followed by the summation of all allele effects across all loci (Meuwissen et al., 2001);

- a BLUP method that utilized a selection index comprised of both genomic and traditional genetic evaluation information such as pedigrees;

- and a BLUP method that utilized the inverse of the genomic relationship matrix instead of the inverse of the additive relationship matrix (Garrick, 2007).

The Bayesian method utilized the iterative solving of the genotypic data, followed by non-linear regressions of the marker deviations, which was also used (Meuwissen et al., 2001; VanRaden 2008).

The findings from this paper concurred with those of Meuwissen et al. (2001). The predictions made using the non-linear methods were highly correlated with the true breeding value of an individual (VanRaden, 2008). The Bayesian non-linear method produced greater levels of reliability compared to linear methods, 66 percent to 63 percent, respectively. Furthermore, estimated breeding values from non-linear methods significantly improved upon the 32 percent reliability obtained from using traditional parental averages (VanRaden, 2008). When used to measure the genetic quality of a young sire, the accuracy of genomic predictions were equivalent to 20 daughter equivalents (VanRaden, 2008).

\section{Accuracy of Genomic Selection using BovineSNP50}

To calculate the predictive power of genomic analysis, VanRaden (2008b) conducted two studies to determine the reliability of genomic estimated breeding values (GEBVs). The first study used a cooperative set of information comprised of American and Canadian genetics. 
This cooperative study used historical information from 3,576 sires born prior to 1999 to calculate the GEBVs for 1,759 sires born between 1999 to 2002 and to test the established genomic predictions (VanRaden et al., 2008b). The researchers estimated GEBVs for 623 young sires and 29 heifers from the genetic and phenotypic data (VanRaden et al., 2008b). The regression between genomic predictions and current daughter deviations were found to be significantly $(\mathrm{P}<0.0001)$ better than that of parental averages, for all of the 27 traits evaluated (VanRaden et al., 2008b). The average $\mathrm{R}^{2}$ was 0.37 for genomic predictions compared to 0.19 for that of parental averages (VanRaden et al., 2008b).

The investigators determined that the size of the predictor population heavily influenced the reliability of predictions because a larger data set allowed for a more accurate estimation of each SNP's effect (VanRaden et al., 2008b). The trend in the gain of reliability was linear increasing with the number of predictor bulls (VanRaden et al., 2008b). As shown in the research, 1151, 2130, 2609, and 3576 predictor bulls generated a 4, 9, 13, and 17 percentage point gain in $\mathrm{R}^{2}$, respectively (VanRaden et al., 2008b). Similarly, the $\mathrm{R}^{2}$ was also affected by the marker density with 25,26 , and 28 percentage point gain for $10 \mathrm{~K}, 20 \mathrm{~K}$, and $40 \mathrm{~K}$ markers, respectively (VanRaden et al., 2008b). The authors determined that the level of reliability derived for net merit dollar was equal to 0.53 , a 23 percent gain in the reliability of breeding values (VanRaden et al., 2008b).

Assuming that the number of genotyped animals will grow rapidly in the immediate future, VanRaden (2008b) utilized a larger data set supplied by Interbull for sires born between years 1995 to 1997. Analysis of this data followed the same methods used with the smaller data set. A total of 15,197 older sires were used to predict 5,987 young sires. In terms of net merit dollars, the resulting reliability was greater than 65 percent (VanRaden et al., 2008b). When 
calculated using non-linear genomic prediction, the average reliability for all traits was 74.7 percent, 0.4 percent greater than linear genomic predictions (VanRaden et al., 2008b).

\section{Common Application Strategies for Whole Genome Selection}

Most implementation strategies for WGS in the dairy industry have focused on the development of AI sires. The dairy industry has extensively utilized AI, which accounted for 85 percent of all dairy breedings annually (Sonstegard, 2008). The sire to sire pathway of selection has been subject to the greatest levels of selection, which naturally lent it to the greatest rate of genetic change in spite of long generation intervals caused by progeny testing (Rendel and Robertson, 1950).

Progeny testing methods have been fiscally inefficient. Approximately ten percent of sires pass progeny testing. The cost of the progeny testing process was often greater than 250,000 dollars per proven sire (Sonstegard, 2008).

\section{Benefits of Whole Genome Selection}

The potential benefits of WGS were two-fold. Greater rates of genetic gain across all levels of production can be achieved. As estimated by VanRaden et al. (2008b), genetic progress could increase by as much as 50 percent, if:

- $\quad$ sires for AI were selected with 60 percent reliability for total merit at one year of age;

- the utilization of young sires were increased to 90 percent of all breedings;

- and 80 percent of females used to produce sires were heifers.

Additionally, increased accuracy of predictions could allow for the more efficient and affordable production of AI sires. Sires' dams could have been accurately selected as heifers 
rather than cows and sires for the AI market could also be identified at a young age. If the accuracy of genomic estimated breeding values were great enough, current progeny testing methods could be streamlined or replaced.

\section{Discounted Gene Flow Model}

In 1974, W. Hill proposed the Discounted Gene Flow model as a method to investigate the financial ramifications that resulted from the diffusion of genes in a population over several generations (Gibson and Dekkers, 2008). As stated by Gibson and Dekkers (2008), the discounted gene flow model was used to:

- evaluate the cost-benefits of a selection or a breeding decision;

- develop operational breeding goals;

- analyze and optimize breeding programs;

- and identify genetic lags and determine ways to eliminate or reduce them.

Essential to the understanding of a gene flow model was that animal operations (i.e. dairies) were complex. The genetic quality of females was not known for almost three years. A cow's life was unpredictable, with varied lactation lengths, calving intervals and life spans. Male calves were removed from the gene pool shortly after birth, reared to be natural service sires or progeny tested, which resulted in a lag period of 18 months to six years. The gene flow method allowed for the tracking of genes through the convoluted pathways, even taking into account the lag periods that existed in each path (Gibson and Dekkers, 2008).

Fundamental to the economic aspect of discounted gene flow was the idea of a discounting factor, which was applied to all expenditures and returns for every year investigated. The determination of this value allowed for the calculation of present value. The conversion of 
both expenditures and returns to a present value allowed for economic values of an investment to be compared throughout the time horizon (between ten and twenty years) (Gibson and Dekkers, 2008).

The determination of the discount rate was critical to the analysis of the effects of breeding or selection decision over time. Commonly an eight percent discount rate was used for the financial evaluation of animal breeding strategies (Bird and Mitchell, 1980; Gibson and Dekkers, 2008). However, Bird and Mitchell (1980), as well as Gibson and Dekkers (2008), recommended a low discount rate of approximately five percent, which maintained a pattern of high implementation costs and low yet, constant returns congruent with livestock systems (Gibson and Dekkers, 2008). Once a discount rate was selected, the discounted economic response from the implementation of proposed breeding strategies or management tools could be determined by using simple matrix calculations.

\section{Method for Assessing Viability}

Modeling used mathematical equations to simulate the use of new techniques or technologies within an animal system (Dumas et al., 2008). Modeling has been an invaluable tool for animal breeders and the dairy industry. Dairy cattle had extensive management and maintenance requirements with long generation intervals, which made it impractical to investigate untested methodologies in vivo. Modeling made it possible to assess the viability and potential profitability of a new method or technology before it was implemented within the industry.

Since the early 1970s, modeling has been used to evaluate the effects of breeding and management programs (Harris and Newman, 1994). Modeling allowed for increased insight into 
the application of a breeding program in terms of genetic improvement and monetary returns (Harris and Newman, 1994). In the past, modeling was used to investigate the potential gains that resulted from the implementation of artificial insemination and sexed-semen AI (Everett, 1975; Van Vleck and Everett, 1975). In recent history, modeling was used to theorize the levels of accuracy possible from the implementation of WGS (Meuwissen et al., 2001).

As stated previously, a model was a mathematical depiction of a biological system (Aubertot, 2008). Models were used to forecast the reaction of a biological system when changes were made to input variables, such as the implementation of new breeding or selection plan (Aubertot, 2008). The process of creating a model was outlined with the following universal steps:

1) define the purpose of the model;

2) consider the system the model was to represent;

3) identify who would be using the model;

4) design the models conceptual framework;

5) select a mathematical form for the model;

6) choose a programming environment (Excel, $\mathrm{C} / \mathrm{C}++, \mathrm{R}$, Mapple,...);

7) collect all available information regarding the system to define input variables;

8) devise equations for the model that will associate input variables to the desired output variable (Makowski, 2008);

9) estimate the system's parameters;

10) and utilize the model (Aubertot, 2008). 
A finished model was represented by the following general equation:

$$
\mathbf{Z}=\boldsymbol{f}(\chi, \theta)
$$

Where:

$\mathrm{Z}=\quad$ the desired output variables from the model, such as $\Delta \mathrm{G}$ or discounted returns

$f=\quad$ the mathematical expression, which connects the output to the inputs

$\chi=\quad$ the input variables, such as the accuracy of genomic prediction (r), were determined before the model was executed

$\theta=\quad$ the parameters, herdsize, pre-weaning death loss percent, or culling rate, etc.

(Makowski, 2008)

Complete models have been used to efficiently and affordably investigate desired scenarios, improbable situations and even to speculate the value of factors that were difficult to determine (Aubertot, 2008). For these reasons, modeling served as the method for the evaluation of the viability of WGS implementation. 


\section{CHAPTER 3}

\section{METHODS}

The objective of this thesis was to determine the viability of alternative genetic improvement strategies (GIS). Each GIS was designed to use whole genome selection (WGS) in conjunction with commonly used reproductive methods (non-sexed semen artificial insemination (AI), sexed semen AI, and embryo transfer using non-sexed semen AI). One reproductive method was utilized for each of the proposed GIS.

The GIS were designed to reflect commonly used dairy reproduction methods. The only dissimilarities between current dairy reproduction methods and the proposed GIS was the use of WGS for the identification and selection of genetically superior females. The first reproductive method investigated was non-sexed semen AI. Non-sexed semen, used in commercial AI for both heifers and cows for over 50 years, has remained the most prevalent form of AI used. Nonsexed semen, less expensive than sexed semen, has achieved greater pregnancy rates due to decreased semen handling and larger insemination dosages.

Created in the 1970s, semen sorting machines allowed for the rapid and accurate separation of X and Y sperm. Most AI companies have offered female gender selected semen. Artificial insemination companies recommended using sexed semen in heifers and not in cows because heifers have uncompromised reproductive tracts, which allowed them to achieve comparatively greater pregnancy rates.

Embryo transfer has been extensively researched for over 30 years. The use of embryo transfer has now become common outside of multiple ovulation embryo transfer herds. Many 
commercial dairy operations have used embryo transfer to foster the proliferation of genetics from superior producing cows within their herd.

\section{Heifer-based Genetic Improvement Strategies}

The heifer-based selection utilizing non-sexed semen AI (HNS) GIS corresponded to management methods currently used on dairy operations. Genetic improvement strategy HNS100 (100 percent of replacement females were kept) served as the baseline for all heiferbased GIS (Table 3.1).

Sexed semen has gained in popularity for use on commercial dairies. Sexed semen increased the certainty that a replacement female would be produced from a breeding nine times out of ten. Even though there was an increased cost for the use of sexed semen, many producers considered the increased production of replacement females worth the extra cost. The greater number of replacement females produced could have allowed for increased selection of replacement females in later generations. In addition, sexed semen also reduced the incidence of dystocia because female calves were generally smaller than males. Due to the potential for increasing selection intensity in later generations, a heifer-based selection utilizing sexed semen (HSS; the use of sexed semen combined with WGS) was included for comparison (Table 3.1).

Prior to the development of WGS, selecting top-quality females, without any pedigree information or production records, as embryo donors for average quality females was a challenge. The advent of WGS created the opportunity for animal breeders and dairy producers to confidently select replacement females for use as embryo donors long before their actual production performance was known. Heifer-based embryo transfer utilizing non-sexed semen 
(HETNS; the use of embryo transfer combined with non-sexed semen) was included for comparison with the other GIS (Table 3.1).

Embryo transfer using sexed semen, for either replacement females or cows, was not considered as it resulted in fewer transferable embryos per flush compared to using non-sexed semen, which made the use of sexed semen with embryo transfer cost prohibitive.

Table 3.1. Description of heifer-based genetic improvement strategies.

\begin{tabular}{|l|l|l|}
\hline \multicolumn{1}{|c|}{$\begin{array}{c}\text { GIS } \\
\text { Acronym }\end{array}$} & Reproduction Method & \multicolumn{1}{c|}{ Description } \\
\hline HNS100 & Non-sexed Semen & $\begin{array}{l}\text { All replacement females were bred using non-sexed semen AI. This } \\
\text { method served as the baseline for the comparison of heifer-based GIS. }\end{array}$ \\
\hline HNS & Non-sexed Semen & $\begin{array}{l}\text { WGS was used to select replacement females to be bred using non-sexed } \\
\text { semen for AI. }\end{array}$ \\
\hline HSS & Sexed Semen & $\begin{array}{l}\text { WGS was used to select replacement females to be bred using sexed } \\
\text { semen for AI. }\end{array}$ \\
\hline HETNS & $\begin{array}{l}\text { Embryo Transfer/Non- } \\
\text { Sexed Semen }\end{array}$ & $\begin{array}{l}\text { WGS was used to select replacement females to be used as embryo } \\
\text { donors for the remaining replacement heifer group. This strategy was } \\
\text { investigated at two selection intensity levels corresponding to a donor } \\
\text { being flushed once or twice. }\end{array}$ \\
\hline
\end{tabular}

\section{Cow-based Genetic Improvement Strategies}

The cow-based GIS that utilized non-sexed semen AI (CNS) corresponded to management methods currently used on a dairy operation. The CNS100 GIS (100 percent of replacement females that completed their first lactation and not culled were kept) represented the baseline for cow-based GIS. If selection had occurred, the number of replacement females produced annually would have decreased, reducing the program's sustainability (Table 3.2). 
A cow-based GIS that utilized sexed semen was not studied because this reproductive method was not designed for use in cows. Due to calving, cows have compromised reproduction tracts, which limited their fertility when inseminated with sexed semen (Dalton, 2007). When compared to heifers, cows required on average one extra service per conception. Considering the added cost of using sexed semen, its use was not financially viable (Table 3.2).

Once a replacement heifer entered the production string, the dairyman or animal breeder had some idea as to the quality of that individual. However, the certainty of knowing the genetic quality of an animal was dependent on the number of observed lactations. With up to thirty-five percent of producing cows removed annually and cows having had an average lifespan of 2.8 lactations, there was little time for the identification of quality cows over several lactations. The cow-based embryo transfer method (CETNS) was proposed as a method to foster the genes of young cows of superior potential by using the replacement female cohort as a recipient group. This method was included for comparison among cow-based GIS (Table 3.2).

Table 3.2. Description of cow-based genetic improvement strategies.

\begin{tabular}{|l|l|l|}
\hline $\begin{array}{c}\text { GIS } \\
\text { Acronym }\end{array}$ & Reproduction Method & \multicolumn{1}{c|}{ Description } \\
\hline CNS100 & Non-Sexed Semen & $\begin{array}{l}\text { All first lactation cows were bred using non-sexed semen for AI. This } \\
\text { method served as the baseline for the comparison of cow-based GIS. }\end{array}$ \\
\hline CETNS & $\begin{array}{l}\text { Embryo Transfer/Non- } \\
\text { Sexed Semen }\end{array}$ & $\begin{array}{l}\text { WGS was used to select replacement females to be used as embryo donors } \\
\text { for the remaining replacement heifer group. This strategy was investigated } \\
\text { at two selection intensity levels corresponding to donor being flushed once } \\
\text { or twice }\end{array}$ \\
\hline
\end{tabular}




\section{Model}

A discounted gene flow model was developed to determine the present value of gross marginal and cumulative gross marginal returns from the implementation of alternative GIS. The model was parameterized using the values from published literature (Table 3.3). These parameters described a typical western dairy operation for the evaluation and comparison of proposed GIS. Constraints for this model included:

- all bovine on the dairy were of the Holstein breed;

- the dairy was to maintain a production herd size of 1,000 head including both milking and dry cows, but excluding heifers;

- the parity percentages were to remain similar to those prior to GIS implementation;

- $\quad$ and the model did not reflect any one Holstein dairy operation.

Published research and industry periodicals were evaluated to determine a representative production herd size, parity demographic, average productive life and culling rates. From The California Department of Food and Agriculture Cost of Production Report (2007), a realistic model herd size was determined. In 2007, an average California dairy consisted of 958 cows. This model used a production herd size of 1,000 cows.

Hare et al. (2006) compiled herd information over a 14-year period to estimate the survival rates and productive life of American dairy cattle. From this research, the following values were identified: the average percentage of each parity group; the percentage of primiparous and multiparous cows; and a female's average productive life.

To establish the average pregnancy rates for each of the reproduction methods, research by Hasler (2001), Seidel (2003) and a review article from Western Dairy News were used. 
Hasler (2001) investigated factors that affected frozen and fresh embryo transfer rates in cattle. Hasler (2001) estimated the pregnancy rates for frozen and fresh embryos in both heifers and cows using surgical and non-surgical transfers. Pregnancy rates for frozen non-surgical embryo transfers were used. Seidel (2003) investigated the financial ramifications resulting from the use of sexed semen in heifers. Seidel (2003) defined pregnancy rates for both non-sexed and sexed semen, the gender bias of each semen type, as well as the cost of each method. Western Dairy News compared the effectiveness of sexed semen use in cows. In this article both non-sexed and sexed semen pregnancy rates for cows were listed (Dalton, 2007).

Grimes (2008) discussed the cost of embryo transfer in beef cattle. The use of embryo transfer in beef heifers would be similar to that of dairy heifers for costs including collection fees (drugs, flushing, etc.), semen and freezing fees. Additionally, Grimes (2008) utilized a pregnancy rate identical to that of dairy heifers (Siedel, 2003). For the aforementioned reasons, I used values published in this article to develop an approximate cost for embryo transfer on a per calf basis for dairy heifers.

Pieppo et al. (2008) conducted research to better understand the difference between embryo production in super-ovulated Holstein heifers and cows using both non-sexed and sexed semen. The number of embryos produced from both heifers and cows inseminated with nonsexed semen were used as parameters for this model.

Meyer et al. (2001) studied the incidence of stillbirth in the United States Holstein population between the years of 1985 to 1996. Identified in this research was the stillbirth percentage for primiparous and multiparous cows. These values made it possible to calculate the number of calves surviving their first 24 hours of life. 
The United States Department of Agriculture-Animal and Plant Health Inspection Service (USDA-APHIS) (2007) published an information sheet outlining the United States dairy industry's health and management practices. The USDA-APHIS publication included operation type, productivity, heifer management, cow management and biosecurity. Among the information discussed, regarding heifer management, were the pre-weaning and post-weaning death loss percents for dairy females.

VanRaden (2004) discussed the implications of selecting for net merit dollar. In this article, $\$ 191.00$ was stated as being the genetic standard deviation of the true transmitting ability for net merit dollar in dairy cattle. This value was used to calculate the rate of genetic change $(\Delta \mathrm{G})$ for each of the proposed GIS. 
Table 3.3: Model parameters.

\begin{tabular}{|c|c|}
\hline Herd Size & 1,000 total cows, lactating plus dry \\
\hline \multicolumn{2}{|l|}{ Parity Demographics ${ }^{\text {E.Hare et al., } 2006}$} \\
\hline - $\quad 1^{\text {st }}$ Lactation & $35.4 \%$ \\
\hline - $2^{\text {nd }}$ Lactation & $25.6 \%$ \\
\hline - $3^{\text {rd }}$ Lactation & $17.1 \%$ \\
\hline - $4^{\text {th }}$ Lactation & $10.5 \%$ \\
\hline - $5^{\text {th }}$ Lactation & $6.0 \%$ \\
\hline - $6^{\text {th }}$ Lactation & $3.1 \%$ \\
\hline - $7^{\text {th }}$ Lactation & $1.5 \%$ \\
\hline - $8^{\text {th }}$ Lactation & $0.8 \%$ \\
\hline \multicolumn{2}{|l|}{ Culling Rates and Mean Productive Life } \\
\hline - $\quad$ Percentage of first lactation heifers culled ${ }^{\text {E.Hare et al., } 2006}$ & $26.7 \%$ \\
\hline - Percentage of second lactation heifers culled ${ }^{\text {E.Hare et al., } 2006}$ & $49.7 \%$ \\
\hline - Mean culling percentage ${ }^{\text {E.Hare,2006 }}$ & $35.4 \%$ \\
\hline - Mean number of lactations ${ }^{\text {E.Hare et al., } 2006}$ & 2.8 lactations \\
\hline \multicolumn{2}{|l|}{ Pregnancy Rates } \\
\hline \multicolumn{2}{|l|}{ - Heifers } \\
\hline$\circ \quad$ Non-Sexed Semen ${ }^{\text {G. Siedel, } 2003}$ & 0.6 \\
\hline$\circ \quad$ Sexed Semen ${ }^{\text {G. Siedel, } 2003}$ & 0.3 \\
\hline Non-Sexed Semen/ Embryo Transfer ${ }^{\text {J. Hasler, } 2001}$ & 0.597 \\
\hline \multicolumn{2}{|l|}{ - Cows } \\
\hline$\circ \quad$ Non-Sexed Semen WDN, September, 2007 & 0.377 \\
\hline ○ $\quad$ Sexed Semen ${ }^{\text {WDN, September, } 2007}$ & 0.25 \\
\hline$\circ \quad \begin{array}{l}\text { Non-Sexed Semen/ Embryo Transfer into Heifer Recipients } \\
\text { J. Hasler, 2001 }\end{array}$ & 0.597 \\
\hline \multicolumn{2}{|l|}{ Mean Number of Viable Embryos Per Flush } \\
\hline • Heifers ${ }^{\text {Pieppo et al.,2008 }}$ & 5.7 embryos \\
\hline - Cows ${ }^{\text {Pieppo et al.,2008 }}$ & 6.3 embryos \\
\hline \multicolumn{2}{|l|}{ Breeding Costs } \\
\hline - Non-Sexed Semen, per service ${ }^{\text {G. Siedel, } 2003}$ & $\$ 30.00$ \\
\hline - $\quad$ Sexed Semen, per service, assuming $\$ 50.00$ per straw G. Siedel, 2003 & $\$ 80.00$ \\
\hline - $\quad$ Non-Sexed Semen/Embryo Transfer, per calf born J. Grimes, 2008 & $\$ 252.38$ \\
\hline \multicolumn{2}{|l|}{ Gender Proportions } \\
\hline - $\quad$ Non-Sexed Semen ${ }^{\text {G. Siedel, } 2003}$ & Bulls 51\%: Heifers 49\% \\
\hline - $\quad$ Sexed Semen ${ }^{\text {G. Siedel, } 2003}$ & Bulls 10\%: Heifers 90\% \\
\hline - $\quad$ Non-Sexed Semen/Embryo Transfer ${ }^{\text {G. Siedel, } 2003}$ & Bulls 51\%: Heifers $49 \%$ \\
\hline \multicolumn{2}{|l|}{ Calf Loss Rates } \\
\hline - Primiparous cow still birth rate ${ }^{\text {Meyer et al. } 2001}$ & $13.2 \%$ \\
\hline - Multiparous cow still birth rate ${ }^{\text {Meyer et al. } 2001}$ & $6.6 \%$ \\
\hline - Pre-weaning death loss USDA-APHIS, 2007 & $7.8 \%$ \\
\hline - $\quad$ Post-weaning death loss ${ }^{\text {USDA-APHIS, } 2007}$ & $1.8 \%$ \\
\hline \multicolumn{2}{|l|}{ Generation Interval } \\
\hline $\begin{array}{l}\text { Heifers Non-Sexed Semen, Sexed-Semen, Heifers Non-Sexed } \\
\text { Semen/Embryo Transfer, Cows Non-Sexed Semen, Cows Sexed- } \\
\text { Semen }\end{array}$ & 2 years \\
\hline - Cows Non-Sexed Semen/Embryo Transfer to Heifer Recipients & 3 years \\
\hline Genetic Standard Deviation of Net Merit Dollar ${ }^{\text {VanRaden, } 2004}$ & $\$ 191.00$ \\
\hline Genotyping Accuracies for Net Merit Dollar & $35 \%, 53 \%, 85 \%$ \\
\hline Genotyping Costs & $\$ 250.00$ \\
\hline
\end{tabular}




\section{Replacement Females}

The number of replacement females required annually to maintain a production herd size of 1,000 head was calculated by multiplying the annual cull rate with the total number of cows in the herd, both milking and dry.

$$
\mathrm{n}_{\mathrm{r}}=\mathrm{n}_{\mathrm{l}} \times \mathrm{p}_{\mathrm{c}}
$$

Where,

$\mathrm{n}_{\mathrm{r}}=\quad$ the number of replacement females required annually to maintain a constant herd size of 1,000 head;

$\mathrm{n}_{\mathrm{l}}=\quad$ the total number of cows, both those milking and dry;

$\mathrm{p}_{\mathrm{c}}=\quad$ the annual cull rate of cows not including death loss;

For this model, $\mathrm{n}_{\mathrm{l}}=1,000$ head of cows and $\mathrm{p}_{\mathrm{c}}=0.354$ (Hare et al., 2006).

Death loss was omitted from the model as it was sufficiently small compared to $\mathrm{p}_{\mathrm{c}}$, which accounted for the greatest number of cows being removed from the operation.

\section{Quantity of Replacement Females Produced Annually}

First, the net number of replacement heifers produced annually was determined by separately calculating the gross number of calves produced by both primiparous and mutliparous cows. The still birth losses within each group were accounted for. Then using the heifer gender ratio of 0.49 and both pre- and post-weaning death loss percentages, the net number of replacement females produced by both primiparous and multiparous cows was determined. 


$$
\mathrm{n}_{\text {post }(\text { primiparous })}=\mathrm{n}_{\text {pre }} \times\left(1-\mathrm{p}_{\mathrm{o}}\right)
$$

Where,

$\mathrm{n}_{\text {post (primiparous })}=\quad$ the number of replacement females produced by primiparous cows that survived to first calving;

$\mathrm{p}_{\mathrm{o}}=$

post-weaning death loss, the percent of replacement females that expired between eight weeks of age and calving;

$\mathrm{n}_{\text {pre }}=\quad$ the number of heifer calves that survived their first eight weeks of life;

For this model, $\mathrm{p}_{\mathrm{o}}=0.018$ (USDA-APHIS, 2007).

The following equation was used to calculate the number of replacement females that survived their first eight weeks of life,

$$
\mathrm{n}_{\mathrm{pre}}=\mathrm{n}_{\mathrm{s}} \times\left(1-\mathrm{p}_{\mathrm{r}}\right)
$$

Where,

$\mathrm{n}_{\mathrm{s}}=\quad$ the number of replacement females born to primiparous cows that survived their first 24 hours of life;

$\mathrm{p}_{\mathrm{r}}=\quad$ pre-weaning death loss, the percent of replacement females that expired between birth and eight weeks of age;

For this model, $\mathrm{p}_{\mathrm{r}}=0.078$ (USDA-APHIS, 2007).

The following equation was used to calculate the number of replacement females born to primiparous cows that survived their first 24 hours of life $n_{s}$. 


$$
\mathrm{n}_{\mathrm{s}}=\mathrm{c}_{\mathrm{s}} \times \mathrm{g}
$$

Where,

$c_{s}=\quad$ the total number of calves, both bulls and heifers, that survived their first 24 hours of life;

$\mathrm{g}=\quad$ the gender bias corresponding to females;

For this model, $\mathrm{g}=0.49$ (Siedel, 2003).

The following equation was used to determine the total number of calves, both bulls and replacement females, that survived their first 24 hours of life $\left(c_{s}\right)$.

$$
c_{s}=c_{p} \times\left(1-b_{p}\right)
$$

Where,

$c_{p}=\quad$ the total number of calves, both bulls and replacement females, that were produced annually by primiparous cows;

$b_{p}=\quad$ the stillbirth rate for primiparous cows;

For this model, $\mathrm{b}_{\mathrm{p}}=0.132$ with $\mathrm{c}_{\mathrm{p}} \approx \mathrm{n}_{\mathrm{r}}$ (Meyer et al., 2001).

The calculations for determining the net number of replacement females produced from multiparous cows used the same variables and equations as the primiparous computations, except where noted. 


$$
\mathrm{n}_{\text {post }(\text { multiparous })}=\mathrm{n}_{\text {pre }} \times\left(1-\mathrm{p}_{\mathrm{o}}\right)
$$

Where,

$\mathrm{n}_{\text {post(multiparous })}=\quad$ the number of replacement females produced by multiparous cows that survived to first calving.

$$
\mathrm{n}_{\mathrm{pre}}=\mathrm{n} \times\left(1-\mathrm{p}_{\mathrm{r}}\right)
$$

Where,

$\mathrm{n}=$

the number of replacement females born to multiparous cows that survived their first 24 hours of life.

$$
\begin{gathered}
\mathrm{n}=\mathrm{c}_{\mathrm{s}} \times \mathrm{g} \\
\mathrm{c}_{\mathrm{s}}=\mathrm{c}_{\mathrm{m}} \times\left(1-\mathrm{b}_{\mathrm{m}}\right)
\end{gathered}
$$

For this model, cows $b_{m}=0.066$ (Meyer et al., 2001)

$$
\mathrm{c}_{\mathrm{m}}=\times\left(1-\mathrm{p}_{\mathrm{c}}\right)
$$

Where,

$\mathrm{c}_{\mathrm{m}}=\quad$ the total number of calves, both bulls and replacement females, produced annually by multiparous cows.

Net Number of Replacement Females. The following equation was used to calculate the net number of replacement females produced annually. The $\mathrm{n}_{\text {post, }}$ from both primiparous and multiparous cows were summed. 


$$
\mathrm{n}_{\text {net }}=\mathrm{n}_{\text {post(primiparous) }}+\mathrm{n}_{\text {post(mutliparous) }}
$$

Where,

$\mathrm{n}_{\text {net }}=\quad$ the net number of replacement females produced annually that were capable of surviving to calving.

\section{${ }_{b}$ Selection Percentage for Heifer-based Genetic Improvement Strategies}

For heifer-based GIS using AI, the greatest selection intensity value that allowed for at least 354 replacement females was used. Three hundred and fifty four replacement females were required because this value was equivalent to the number of cows culled annually at a rate of 0.354 .

$$
354 \text { Replacements } \geq \mathrm{n}_{\text {net }} \times \mathrm{p}_{\mathrm{x}}
$$

Where,

$\mathrm{p}_{\mathrm{x}}=\quad$ the percentage of replacement females selected to become dams for the next generation.

For HETNS, 0.1 of the replacement heifers representing those of the lowest genetic potential for net merit dollar, as identified by the individual replacement female's genomic estimated breeding value, were removed from $\mathrm{n}_{\text {net }}$ as candidates for donor or recipient status. The average number of viable embryos that resulted from a super-ovulated heifer flush, and the average pregnancy rate for embryo transfer in heifers were used to determine the fewest number 
of elite replacement females capable of producing enough viable embryos to result in the successful impregnation of all recipient replacement females.

Number of Donor Heifers Required when Using a Single Flush. The following equation was used to calculate how many donor replacement females, when flushing each donor once, were required to produce enough viable embryos for the impregnation of recipient replacement females.

$$
\mathrm{n}_{\mathrm{k}}=\mathrm{e}_{\mathrm{r}} / 5.7
$$

Where,

$\mathrm{n}_{\mathrm{k}}=\quad$ the number of replacement females selected as donors when using a single donor flush to produce enough embryos to impregnate the non-elite replacement females;

$\mathrm{e}_{\mathrm{r}}=\quad$ the number of embryos required to impregnate the recipient replacement females;

$5.7=\quad$ the number of viable embryos produced from a replacement female embryo flush.

The following equation was used to determine the number of embryos required to impregnate recipient replacement females $\left(\mathrm{e}_{\mathrm{r}}\right)$.

$$
\mathrm{e}_{\mathrm{r}}=\mathrm{n}_{\mathrm{f}} / .597
$$

Where,

$\mathrm{n}_{\mathrm{f}}=\quad$ the number of replacement females selected as recipients that allowed the herd to maintain its original parity percentages and herd size;

$0.597=$ the pregnancy rate for embryo transfer in heifers. 
Number of Donor Heifers Required when Using a Double Flush. The following equation was used to ascertain how many donor replacement females would be required to impregnate all recipient replacement females when flushing each donor twice.

$$
\mathrm{n}_{\mathrm{j}}=0.5 \mathrm{k}
$$

Where,

$\mathrm{n}_{j}=\quad$ the number of heifers selected as donors when using two donor flushes.

\section{Selection Percentage for Cow-based Genetic Improvement Strategies}

For the CNS100, the number of first lactation females selected for breeding was preestablished at 100 percent. The CNS100 GIS was the baseline for all cow-based GIS as it represented currently used dairy management methods. If selection had occurred, the herd size and demographics would have changed, which would have violated the model's constraints, as well as reduced the program's sustainability.

Number of Donor Cows Required when Using a Single Flush. The fewest number of

first lactation cows capable of producing enough viable embryos for the successful impregnation of the entire replacement female cohort was calculated by using the average number of viable embryos produced by cows and the pregnancy rate for embryo transfer in heifers.

The method behind these equations followed those for determining the number of replacement female embryo donors required. 


$$
\mathrm{n}_{\mathrm{d}}=\mathrm{e}_{\mathrm{r}} / 6.3
$$

Where,

$\mathrm{n}_{\mathrm{d}}=\quad$ when using a single donor flush, the number of first lactation cows selected as donors for the replacement female recipients;

$6.3=$ the number of viable embryos produced from a cow embryo flush.

$$
\mathrm{e}_{\mathrm{r}}=\mathrm{n}_{\mathrm{net}} / 0.597
$$

Number of Donor Cows Required when Using a Double Flush. The number of first lactation females selected as embryo donors, when flushing donors twice, was determined by the following equation. The method behind this equation followed that of HETNS.

$$
\mathrm{n}_{\mathrm{y}}=0.5 \mathrm{n}_{\mathrm{d}}
$$

Where,

$\mathrm{n}_{\mathrm{y}}=\quad$ the number of first lactation cows selected as donors when using two donor flushes.

\section{Genomic Estimated Breeding Value Accuracy Levels}

Three accuracy levels of genomic breeding values were investigated for each proposed GIS: 0.35 ; 0.53 ; and 0.85 . These accuracy levels reflected the use of only genomic information. At the publication date, a 0.35 accuracy of prediction for net merit dollar had been attained (VanRaden, 2008c). Considering the rapidly increasing number of genotyped animals and the resulting re-estimation of individual allele effects (VanRaden, 2008b), a 0.53 accuracy level was nearing attainment. The 0.85 value was included to reflect the hypothesized maximum accuracy 
level predicted by Meuwissen et al. (2001), as well as accepted accuracy level used for traditional sire proofs. While the 0.85 accuracy level had not been achieved, a 0.85 accuracy level for genomic breeding values should be attainable in the near future with development of larger genotyping chips and the re-evaluation of individual SNP effects.

\section{Computation of $\Delta G$}

The rate of genetic change per year $(\Delta \mathrm{G})$, in terms of net merit dollars, was calculated by using the equation presented in Strandberg (2006).

$$
\Delta \mathbf{G}=\frac{\left(\mathbf{i}_{\mathbf{s}} \times \mathbf{r} \times \mathbf{g}_{\text {sd }}\right)}{\mathbf{t}}
$$

Where,

$\Delta \mathrm{G}=\quad$ rate of genetic change per year;

$\mathrm{i}_{\mathrm{s}}=\quad$ selection intensity for small cohort, i.e. less than 500 head (Strandberg et al., 2006);

$$
\mathrm{i}_{\mathrm{s}}=\mathrm{i}_{\text {large herd }}-\frac{(.25)}{\# \text { of head selected }}
$$

Where,

$\mathrm{r}=\quad$ the accuracy of prediction;

$\mathrm{g}_{\mathrm{sd}}=\quad$ the genetic standard deviation of true transmitting ability for a selected trait;

$\mathrm{t}=\quad$ the generation interval;

For this model, $\mathrm{r}=0.35,0.53$, and $0.85, \mathrm{~g}_{\mathrm{sd}}=\$ 191.00$ (Van Raden, 2004), and $\mathrm{t}=2$ and 3 years depending on the GIS being investigated (Table 3.3). 


\section{Determination of Present Value}

Converting income and expenditures to a present value allowed for the comparison of all monies over a 20 -year time horizon. The determination of present value was accomplished by multiplying the discount factor by the monetary factor of interest (Gibson and Dekkers, 2008).

$$
\mathrm{v}_{\mathrm{p}}=\mathrm{dX}
$$

Where,

$\mathrm{v}_{\mathrm{p}}=\quad$ present value;

$\mathrm{X}_{\mathrm{t}}=\quad$ money earned or invested to be discounted during a particular year;

$\mathrm{d}=\quad$ the discount rate

$$
\mathrm{d}=\left(\frac{1}{1+\mathrm{u}}\right)^{\overline{\mathrm{t}}}
$$

$\mathrm{u}=\quad$ the discount factor;

$\rho=\quad$ the number of time periods per year;

For this model, $\mathrm{n}=0.05$ and $\mathrm{m}=1$.

\section{Computational Software}

$\mathrm{R}$ 2.6.2 was used to accomplish the linear algebra required to obtain the discounted returns from the use of each heifer and cow-based GIS. In R, all matrices and vectors were designed or derived (Appendix). 


\section{Discounted Gene Flow}

The discounted gene flow method was used to determine the potential returns made over a fixed time horizon of 20-years for each GIS. The discounted gene flow method, a matrix-based method, accounted for gene flow rate, aging, number of selected animals, value of selected trait and a discount rate (Hill, 1974; Gibson and Dekkers, 2008).

Definition of necessary matrices and vectors were as follows:

P: This 20-by-20 matrix contained the proportion of genes that originated from each age class within the entire population (Gibson and Dekkers, 2008) (Table 3.4). P had the general form:

$$
\left[\begin{array}{ccc}
P_{1,1} & \cdots & P_{1, h+k} \\
\vdots & \ddots & \vdots \\
P_{h+k, 1} & \cdots & P_{h+k, h+k}
\end{array}\right]
$$

To construct $\mathbf{P}, \mathbf{m}_{\mathbf{t}}$ was first defined. Vector $\mathbf{m}_{\mathbf{t}}$ consisted of the proportion of genes from each age class that came from the original group of selected animals at the initiation of the selection (Gibson and Dekkers, 2008). However, unlike Gibson and Dekkers (2008), the $\mathbf{m}_{\mathbf{t}}$ that I used corresponded to the transmission of genes only from the females selected when using each GIS, so that,

$$
\mathrm{m}_{\mathrm{t}}=\mathrm{P} \mathrm{m}_{\mathrm{t}-1}
$$

The first column of $\mathbf{P}$ contained every element of $\mathbf{m}_{\mathbf{t}}$, because the genes from the animals selected during the first implementation period (Table 3.4).

Q: A 20-by-20 transitional matrix that accounted for the movement of individuals from one age class to another, specifically heifers becoming cows (Table 3.5). In $\mathbf{Q}$, an animal's transition from heifer age class to cow age class denoted as a 1. 
R: The reproduction matrix, a 20-by-20 matrix, was created by subtracting the $\mathbf{Q}$ matrix from the $\mathbf{P}$ matrix and therefore accounted for both genetics and aging simultaneously (Table 3.6). Where,

$$
\mathbf{R}=\mathbf{P}-\mathbf{Q}
$$

d: This was a 1-by-20 vector of discounting factors that used equation [4] to determine each of the elements (Table 3.7).

n: Number of animals selected during each time period. The value of this 1-by-20 vector was dependant on the GIS investigated. In this model the period was defined as 1 year (Table 3.8; Table 3.10).

v: A 1-by-20 vector of economic values reflecting the improvement of net merit dollar as a result of the implementation of each GIS (Table 3.9; Table 3.11).

$\mathbf{w}$ : This 1-by-20 vector was derived from the multiplication of $\mathbf{n}$ and $\mathbf{v}$ vectors. The $\mathbf{w}$ vector represented the economic gain from each unit of genetic improvement for all animals produced as a result of GIS implementation.

Where,

$$
\mathbf{w}=\mathbf{n} \mathbf{v}
$$

The element values for $\mathbf{w}$ were presented in the results section.

$\mathbf{y}^{\mathbf{c}}$ : A 1-by-20 vector representing the present value of marginal returns yielded from the continuous use of each proposed GIS over a 20 -year time horizon; $\mathbf{y}_{(\mathbf{t})}^{\mathbf{c}}$ was defined as: 


$$
\mathbf{y}_{(t)}^{\mathbf{c}}=\mathbf{d}_{(\mathbf{t})} \mathbf{w}^{\prime} \mathbf{R}_{(\mathrm{t})}
$$

Present value of cumulative gross marginal returns was obtained by:

$$
1^{\prime} \mathbf{y}^{\mathbf{c}}
$$


Table 3.4: $\mathbf{P}$ where the columns correspond to years one through twenty.

\begin{tabular}{|c|c|c|c|c|c|c|c|c|c|c|c|c|c|c|c|c|c|c|c|}
\hline 1 & 0 & 0 & 0 & 0 & 0 & 0 & 0 & 0 & 0 & 0 & 0 & 0 & 0 & 0 & 0 & 0 & 0 & 0 & 0 \\
\hline 0 & 1 & 0 & 0 & 0 & 0 & 0 & 0 & 0 & 0 & 0 & 0 & 0 & 0 & 0 & 0 & 0 & 0 & 0 & 0 \\
\hline 0.5 & 0 & 1 & 0 & 0 & 0 & 0 & 0 & 0 & 0 & 0 & 0 & 0 & 0 & 0 & 0 & 0 & 0 & 0 & 0 \\
\hline 0.75 & 0.5 & 0.5 & 0 & 1 & & 0 & 0 & 0 & 0 & 0 & 0 & 0 & 0 & 0 & 0 & 0 & 0 & 0 & 0 \\
\hline 0.5 & 0.75 & 0.5 & 0.5 & 0 & 1 & 0 & 0 & 0 & 0 & 0 & 0 & 0 & 0 & 0 & 0 & 0 & 0 & 0 & 0 \\
\hline 0.875 & 0.5 & 0.75 & 0.5 & 0.5 & 0 & 1 & 0 & 0 & 0 & 0 & 0 & 0 & 0 & 0 & 0 & 0 & 0 & 0 & 0 \\
\hline 0.75 & 0.875 & 0.5 & 0.75 & 0.5 & 0.5 & 0 & 1 & 0 & 0 & 0 & 0 & 0 & 0 & 0 & 0 & 0 & 0 & 0 & 0 \\
\hline 0.4375 & 0.75 & 0.875 & 0.5 & 0.75 & 0.5 & 0.5 & 0 & 1 & 0 & 0 & 0 & 0 & 0 & 0 & 0 & 0 & 0 & 0 & 0 \\
\hline 0.375 & 0.4375 & 0.75 & 0.875 & 0.5 & 0.75 & 0.5 & 0.5 & 0 & 1 & 0 & 0 & 0 & 0 & 0 & 0 & 0 & 0 & 0 & 0 \\
\hline 0.3438 & 0.375 & 0.4375 & 0.75 & 0.875 & 0.5 & 0.75 & 0.5 & 0.5 & 0 & 1 & 0 & 0 & 0 & 0 & 0 & 0 & 0 & 0 & 0 \\
\hline 0.1875 & 0.3438 & 0.375 & 0.4375 & 0.75 & 0.875 & 0.5 & 0.75 & 0.5 & 0.5 & 0 & 1 & 0 & 0 & 0 & 0 & 0 & 0 & 0 & 0 \\
\hline 0.1719 & 0.1875 & 0.3438 & 0.375 & 0.4375 & 0.75 & 0.875 & 0.5 & 0.75 & 0.5 & 0.5 & 0 & 1 & 0 & 0 & 0 & 0 & 0 & 0 & 0 \\
\hline 0.0859 & 0.0938 & 0.1719 & 0.1875 & 0.3438 & 0.375 & 0.4375 & 0.75 & 0.875 & 0.5 & 0.75 & 0.5 & 0.5 & 0 & 1 & 0 & 0 & 0 & 0 & 0 \\
\hline 0.0469 & 0.0859 & 0.0938 & 0.1719 & 0.1875 & 0.3438 & 0.375 & 0.4375 & 0.75 & 0.875 & 0.5 & 0.75 & 0.5 & 0.5 & 0 & 1 & & 0 & 0 & 0 \\
\hline 0.0429 & 0.0469 & 0.0859 & 0.0938 & 0.1719 & 0.1875 & 0.3438 & 0.375 & 0.4375 & 0.75 & 0.875 & 0.5 & 0.75 & 0.5 & 0.5 & 0 & 1 & 0 & 0 & 0 \\
\hline 0.0234 & 0.0429 & 0.0469 & 0.0859 & 0.0938 & 0.1719 & 0.1875 & 0.3438 & 0.375 & 0.4375 & 0.75 & 0.875 & 0.5 & 0.75 & 0.5 & 0.5 & 0 & 1 & 0 & 0 \\
\hline 0.0215 & 0.0234 & 0.0429 & 0.0469 & 0.0859 & 0.0938 & 0.1719 & 0.1875 & 0.3438 & 0.375 & 0.4375 & 0.75 & 0.875 & 0.5 & 0.75 & 0.5 & 0.5 & 0 & 1 & 0 \\
\hline 0.0117 & 0.0215 & 0.0234 & 0.0429 & 0.0469 & 0.0859 & 0.0938 & 0.1719 & 0.1875 & 0.3438 & 0.375 & 0.4375 & 0.75 & 0.875 & 0.5 & 0.75 & 0.5 & 0.5 & 0 & 1 \\
\hline
\end{tabular}


Table 3.5: $\mathbf{Q}$ where the columns correspond to years one through twenty.

\begin{tabular}{|c|c|c|c|c|c|c|c|c|c|c|c|c|c|c|c|c|c|}
\hline 0 & 0 & 0 & 0 & 0 & 0 & 0 & 0 & 0 & 0 & 0 & 0 & 0 & 0 & 0 & 0 & 0 & 0 \\
\hline 0 & 0 & 0 & 0 & 0 & 0 & 0 & 0 & 0 & 0 & 0 & 0 & 0 & 0 & 0 & 0 & 0 & 0 \\
\hline 1 & 0 & 0 & 0 & 0 & 0 & 0 & 0 & 0 & 0 & 0 & 0 & 0 & 0 & 0 & 0 & 0 & 0 \\
\hline 0 & 1 & 0 & 0 & 0 & 0 & 0 & 0 & 0 & 0 & 0 & 0 & 0 & 0 & 0 & 0 & 0 & 0 \\
\hline 0 & 0 & 1 & 0 & 0 & 0 & 0 & 0 & 0 & 0 & 0 & 0 & 0 & 0 & 0 & 0 & 0 & 0 \\
\hline 0 & 0 & 0 & 1 & 0 & 0 & 0 & 0 & 0 & 0 & 0 & 0 & 0 & 0 & 0 & 0 & 0 & 0 \\
\hline 0 & 0 & 0 & 0 & 1 & 0 & 0 & 0 & 0 & 0 & 0 & 0 & 0 & 0 & 0 & 0 & 0 & 0 \\
\hline 0 & 0 & 0 & 0 & 0 & 1 & 0 & 0 & 0 & 0 & 0 & 0 & 0 & 0 & 0 & 0 & 0 & 0 \\
\hline 0 & 0 & 0 & 0 & 0 & 0 & 1 & 0 & 0 & 0 & 0 & 0 & 0 & 0 & 0 & 0 & 0 & 0 \\
\hline 0 & 0 & 0 & 0 & 0 & 0 & 0 & 1 & 0 & 0 & 0 & 0 & 0 & 0 & 0 & 0 & 0 & 0 \\
\hline 0 & 0 & 0 & 0 & 0 & 0 & 0 & 0 & 1 & 0 & 0 & 0 & 0 & 0 & 0 & 0 & 0 & 0 \\
\hline 0 & 0 & 0 & 0 & 0 & 0 & 0 & 0 & 0 & 1 & 0 & 0 & 0 & 0 & 0 & 0 & 0 & 0 \\
\hline 0 & 0 & 0 & 0 & 0 & 0 & 0 & 0 & 0 & 0 & 1 & 0 & 0 & 0 & 0 & 0 & 0 & 0 \\
\hline 0 & 0 & 0 & 0 & 0 & 0 & 0 & 0 & 0 & 0 & 0 & 1 & 0 & 0 & 0 & 0 & 0 & 0 \\
\hline 0 & 0 & 0 & 0 & 0 & 0 & 0 & 0 & 0 & 0 & 0 & 0 & 1 & 0 & 0 & 0 & 0 & 0 \\
\hline 0 & 0 & 0 & 0 & 0 & 0 & 0 & 0 & 0 & 0 & 0 & 0 & 0 & 1 & 0 & 0 & 0 & 0 \\
\hline 0 & 0 & 0 & 0 & 0 & 0 & 0 & 0 & 0 & 0 & 0 & 0 & 0 & 0 & 1 & 0 & 0 & 0 \\
\hline 0 & 0 & 0 & 0 & 0 & 0 & 0 & 0 & 0 & 0 & 0 & 0 & 0 & 0 & 0 & 1 & 0 & 0 \\
\hline 0 & 0 & 0 & 0 & 0 & 0 & 0 & 0 & 0 & 0 & 0 & 0 & 0 & 0 & 0 & 0 & 1 & 0 \\
\hline 0 & 0 & 0 & 0 & 0 & 0 & 0 & 0 & 0 & 0 & 0 & 0 & 0 & 0 & 0 & 0 & 0 & 1 \\
\hline
\end{tabular}


Table 3.6: $\mathbf{R}$ where the columns correspond to years one through twenty.

\begin{tabular}{|c|c|c|c|c|c|c|c|c|c|c|c|c|c|c|c|c|c|c|c|}
\hline 1 & 0 & 0 & 0 & 0 & 0 & 0 & 0 & 0 & 0 & 0 & 0 & 0 & 0 & 0 & 0 & 0 & 0 & 0 & 0 \\
\hline 0 & 1 & 0 & 0 & 0 & 0 & 0 & 0 & 0 & 0 & 0 & 0 & 0 & 0 & 0 & 0 & 0 & 0 & 0 & 0 \\
\hline-0.5 & 0 & 1 & 0 & 0 & 0 & 0 & 0 & 0 & 0 & 0 & 0 & 0 & 0 & 0 & 0 & 0 & 0 & 0 & 0 \\
\hline 0.5 & -0.5 & 0 & 1 & 0 & 0 & 0 & 0 & 0 & 0 & 0 & 0 & 0 & 0 & 0 & 0 & 0 & 0 & 0 & 0 \\
\hline 0.75 & 0.5 & -0.5 & 0 & 1 & 0 & 0 & 0 & 0 & 0 & 0 & 0 & 0 & 0 & 0 & 0 & 0 & 0 & 0 & 0 \\
\hline 0.5 & 0.75 & 0.5 & -0.5 & 0 & 1 & 0 & 0 & 0 & 0 & 0 & 0 & 0 & 0 & 0 & 0 & 0 & 0 & 0 & 0 \\
\hline 0.875 & 0.5 & 0.75 & 0.5 & -0.5 & 0 & 1 & 0 & 0 & 0 & 0 & 0 & 0 & 0 & 0 & 0 & 0 & 0 & 0 & 0 \\
\hline 0.75 & 0.875 & 0.5 & 0.75 & 0.5 & -0.5 & 0 & 1 & 0 & & 0 & 0 & 0 & 0 & 0 & 0 & 0 & 0 & 0 & 0 \\
\hline 0.4375 & 0.75 & 0.875 & 0.5 & 0.75 & 0.5 & -0.5 & 0 & 1 & 0 & 0 & 0 & 0 & 0 & 0 & 0 & 0 & 0 & 0 & 0 \\
\hline 0.375 & 0.4375 & 0.75 & 0.875 & 0.5 & 0.75 & 0.5 & -0.5 & 0 & 1 & 0 & 0 & 0 & 0 & 0 & 0 & 0 & 0 & 0 & 0 \\
\hline 0.3438 & 0.375 & 0.4375 & 0.75 & 0.875 & 0.5 & 0.75 & 0.5 & -0.5 & 0 & 1 & 0 & 0 & 0 & 0 & 0 & 0 & 0 & 0 & 0 \\
\hline 0.1875 & 0.3438 & 0.375 & 0.4375 & 0.75 & 0.875 & 0.5 & 0.75 & 0.5 & -0.5 & 0 & 1 & 0 & 0 & 0 & 0 & 0 & 0 & 0 & 0 \\
\hline 0.1719 & 0.1875 & 0.3438 & 0.375 & 0.4375 & 0.75 & 0.875 & 0.5 & 0.75 & 0.5 & -0.5 & 0 & 1 & 0 & 0 & 0 & 0 & 0 & 0 & 0 \\
\hline 0.0938 & 0.1719 & 0.1875 & 0.3438 & 0.375 & 0.4375 & 0.75 & 0.875 & 0.5 & 0.75 & 0.5 & -0.5 & 0 & 1 & 0 & 0 & 0 & 0 & 0 & 0 \\
\hline 0.859 & 0.0938 & 0.1719 & 0.1875 & 0.3438 & 0.375 & 0.4375 & 0.75 & 0.875 & 0.5 & 0.75 & 0.5 & -0.5 & 0 & 1 & 0 & 0 & 0 & 0 & 0 \\
\hline 0.0469 & 0.859 & 0.0938 & 0.1719 & 0.1875 & 0.3438 & 0.375 & 0.4375 & 0.75 & 0.875 & 0.5 & 0.75 & 0.5 & -0.5 & 0 & 1 & 0 & 0 & 0 & 0 \\
\hline 0.0429 & 0.0469 & 0.859 & 0.0938 & 0.1719 & 0.1875 & 0.3438 & 0.375 & 0.4375 & 0.75 & 0.875 & 0.5 & 0.75 & 0.5 & -0.5 & 0 & 1 & 0 & 0 & 0 \\
\hline 0.0234 & 0.0429 & 0.0469 & 0.859 & 0.0938 & 0.1719 & 0.1875 & 0.3438 & 0.375 & 0.4375 & 0.75 & 0.875 & 0.5 & 0.75 & 0.5 & -0.5 & 0 & 1 & 0 & 0 \\
\hline 0.0215 & 0.0234 & 0.0429 & 0.0469 & 0.859 & 0.0938 & 0.1719 & 0.1875 & 0.3438 & 0.375 & 0.4375 & 0.75 & 0.875 & 0.5 & 0.75 & 0.5 & -0.5 & 0 & 1 & 0 \\
\hline 0.0117 & 0.0215 & 0.0234 & 0.0429 & 0.0469 & 0.859 & 0.0938 & 0.1719 & 0.1875 & 0.3438 & 0.375 & 0.4375 & 0.75 & 0.875 & 0.5 & 0.75 & 0.5 & -0.5 & 0 & 1 \\
\hline
\end{tabular}


Table 3.7: $\mathbf{d}$ where each row corresponds to years one through twenty.

\begin{tabular}{|l|}
\hline 0.9523 \\
\hline 0.9069 \\
\hline 0.8636 \\
\hline 0.8224 \\
\hline 0.7832 \\
\hline 0.7458 \\
\hline 0.7103 \\
\hline 0.6764 \\
\hline 0.6441 \\
\hline 0.6134 \\
\hline 0.5841 \\
\hline 0.5563 \\
\hline 0.5297 \\
\hline 0.5045 \\
\hline 0.4804 \\
\hline 0.4575 \\
\hline 0.4357 \\
\hline 0.4149 \\
\hline 0.3951 \\
\hline 0.3762 \\
\hline
\end{tabular}


Table 3.8: $\mathbf{n}$ for heifer-based genetic improvement strategies.

\begin{tabular}{|c|c|c|c|c|}
\hline HNS100 & HNS90 & HSS90 & HETNS23 & HETNS11 \\
\hline 403 & 363 & 363 & 363 & 363 \\
\hline 403 & 363 & 363 & 363 & 363 \\
\hline 403 & 363 & 363 & 363 & 363 \\
\hline 403 & 363 & 363 & 363 & 363 \\
\hline 403 & 363 & 363 & 363 & 363 \\
\hline 403 & 363 & 363 & 363 & 363 \\
\hline 403 & 363 & 363 & 363 & 363 \\
\hline 403 & 363 & 363 & 363 & 363 \\
\hline 403 & 363 & 363 & 363 & 363 \\
\hline 403 & 363 & 363 & 363 & 363 \\
\hline 403 & 363 & 363 & 363 & 363 \\
\hline 403 & 363 & 363 & 363 & 363 \\
\hline 403 & 363 & 363 & 363 & 363 \\
\hline 403 & 363 & 363 & 363 & 363 \\
\hline 403 & 363 & 363 & 363 & 363 \\
\hline 403 & 363 & 363 & 363 & 363 \\
\hline 403 & 363 & 363 & 363 & 363 \\
\hline 403 & 363 & 363 & 363 & 363 \\
\hline 403 & 363 & 363 & 363 & 363 \\
\hline & & & & \\
\hline
\end{tabular}


Table 3.9: $\mathbf{v}$ for heifer-based genetic improvement strategies.

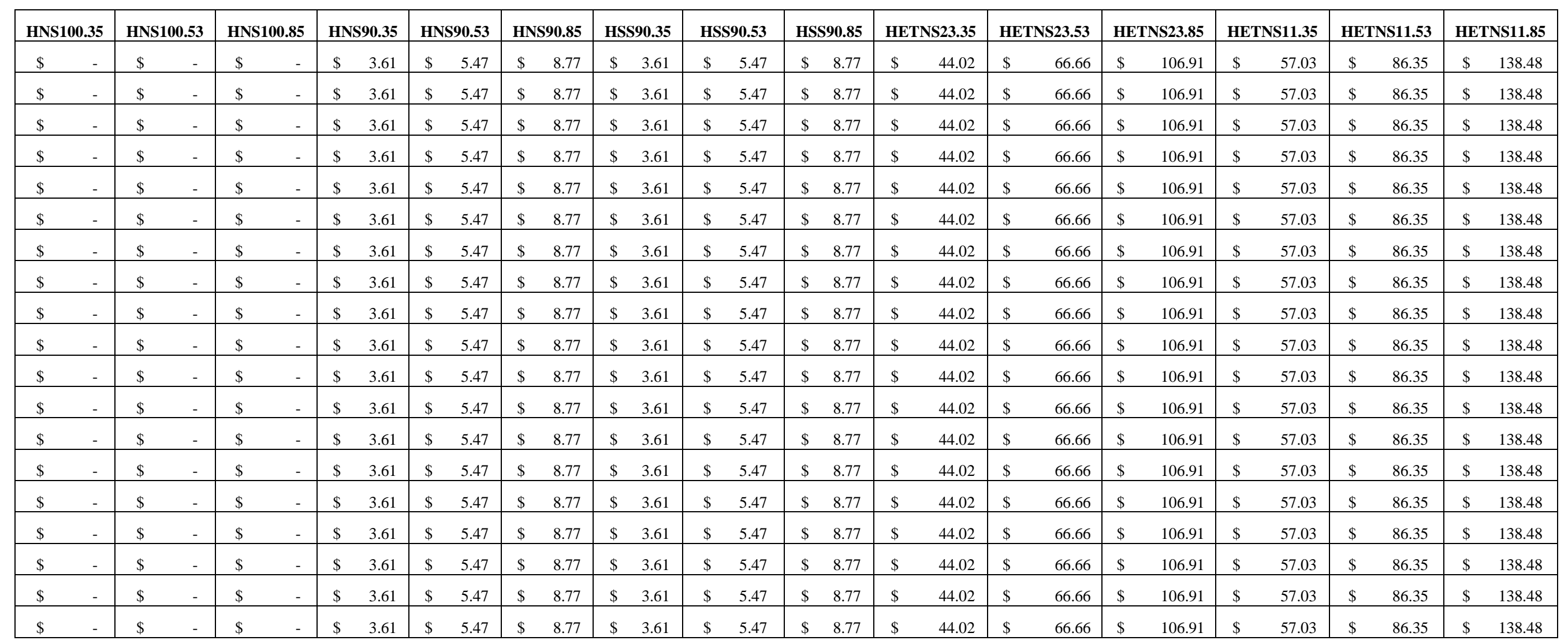


Table 3.10: $\mathbf{n}$ for cow-based genetic improvement strategies.

\begin{tabular}{|c|c|c|}
\hline CNS100 & CETNS42 & CETNS21 \\
\hline 265 & 403 & 403 \\
\hline 265 & 403 & 403 \\
\hline 265 & 403 & 403 \\
\hline 265 & 403 & 403 \\
\hline 265 & 403 & 403 \\
\hline 265 & 403 & 403 \\
\hline 265 & 403 & 403 \\
\hline 265 & 403 & 403 \\
\hline 265 & 403 & 403 \\
\hline 265 & 403 & 403 \\
\hline 265 & 403 & 403 \\
\hline 265 & 403 & 403 \\
\hline 265 & 403 & 403 \\
\hline 265 & 403 & 403 \\
\hline 265 & 403 & 403 \\
\hline 265 & 403 & 403 \\
\hline 265 & 403 & 403 \\
\hline 265 & 403 & 403 \\
\hline 265 & 403 & 403 \\
\hline
\end{tabular}


Table 3.11: $\mathbf{v}$ for cow-based genetic improvement strategies.

\begin{tabular}{|ll|lll|ll|ll|ll|lr|}
\hline \multicolumn{2}{|c|}{ CETNS42.35 } & \multicolumn{2}{|c|}{ CETNS42.53 } & \multicolumn{2}{|c|}{ CETNS42.85 } & \multicolumn{2}{|c|}{ CETNS21.35 } & \multicolumn{2}{l|}{ CETNS21.53 } & \multicolumn{2}{l|}{ CETNS21.85 } \\
\hline$\$$ & 20.70 & $\$$ & 31.35 & $\$$ & 50.27 & $\$$ & 30.46 & $\$$ & 46.13 & $\$$ & 73.98 \\
\hline$\$$ & 20.70 & $\$$ & 31.35 & $\$$ & 50.27 & $\$$ & 30.46 & $\$$ & 46.13 & $\$$ & 73.98 \\
\hline$\$$ & 20.70 & $\$$ & 31.35 & $\$$ & 50.27 & $\$$ & 30.46 & $\$$ & 46.13 & $\$$ & 73.98 \\
\hline$\$$ & 20.70 & $\$$ & 31.35 & $\$$ & 50.27 & $\$$ & 30.46 & $\$$ & 46.13 & $\$$ & 73.98 \\
\hline$\$$ & 20.70 & $\$$ & 31.35 & $\$$ & 50.27 & $\$$ & 30.46 & $\$$ & 46.13 & $\$$ & 73.98 \\
\hline$\$$ & 20.70 & $\$$ & 31.35 & $\$$ & 50.27 & $\$$ & 30.46 & $\$$ & 46.13 & $\$$ & 73.98 \\
\hline$\$$ & 20.70 & $\$$ & 31.35 & $\$$ & 50.27 & $\$$ & 30.46 & $\$$ & 46.13 & $\$$ & 73.98 \\
\hline$\$$ & 20.70 & $\$$ & 31.35 & $\$$ & 50.27 & $\$$ & 30.46 & $\$$ & 46.13 & $\$$ & 73.98 \\
\hline$\$$ & 20.70 & $\$$ & 31.35 & $\$$ & 50.27 & $\$$ & 30.46 & $\$$ & 46.13 & $\$$ & 73.98 \\
\hline$\$$ & 20.70 & $\$$ & 31.35 & $\$$ & 50.27 & $\$$ & 30.46 & $\$$ & 46.13 & $\$$ & 73.98 \\
\hline$\$$ & 20.70 & $\$$ & 31.35 & $\$$ & 50.27 & $\$$ & 30.46 & $\$$ & 46.13 & $\$$ & 73.98 \\
\hline$\$$ & 20.70 & $\$$ & 31.35 & $\$$ & 50.27 & $\$$ & 30.46 & $\$$ & 46.13 & $\$$ & 73.98 \\
\hline$\$$ & 20.70 & $\$$ & 31.35 & $\$$ & 50.27 & $\$$ & 30.46 & $\$$ & 46.13 & $\$$ & 73.98 \\
\hline$\$$ & 20.70 & $\$$ & 31.35 & $\$$ & 50.27 & $\$$ & 30.46 & $\$$ & 46.13 & $\$$ & 73.98 \\
\hline$\$$ & 20.70 & $\$$ & 31.35 & $\$$ & 50.27 & $\$$ & 30.46 & $\$$ & 46.13 & $\$$ & 73.98 \\
\hline$\$$ & 20.70 & $\$$ & 31.35 & $\$$ & 50.27 & $\$$ & 30.46 & $\$$ & 46.13 & $\$$ & 73.98 \\
\hline$\$$ & 20.70 & $\$$ & 31.35 & $\$$ & 50.27 & $\$$ & 30.46 & $\$$ & 46.13 & $\$$ & 73.98 \\
\hline$\$$ & 20.70 & $\$$ & 31.35 & $\$$ & 50.27 & $\$$ & 30.46 & $\$$ & 46.13 & $\$$ & 73.98 \\
\hline$\$$ & 20.70 & $\$$ & 31.35 & $\$$ & 50.27 & $\$$ & 30.46 & $\$$ & 46.13 & $\$$ & 73.98 \\
\hline
\end{tabular}




\section{Present Value of Total Marginal Cost for Each Genetic Improvement Strategy}

The present value of marginal cost of each GIS was defined as the cost for the reproduction method plus the cost of genotyping. Below were the methods used to calculate reproductive method costs for each GIS. The cost of genotyping was $\$ 250.00$ per female genotyped. The cost of implementation for each GIS was converted to present value by using equation [2]

\section{Present Value of Total Marginal Costs for Heifer and Cow-based Genetic}

Improvement Strategies Utilizing Artificial Insemination. The reproductive cost for heifer and cow-based GIS utilizing AI were calculated by dividing the number of females to be bred by the average conception rate to determine the number of breeding events. The calculated number of breeding events was then multiplied by the cost per service.

To determine the number of breeding events required to successfully impregnate a selected female group the following equation was used.

$$
\mathrm{n}_{\mathrm{z}}=\mathrm{n}_{\mathrm{f}} / \mathrm{p}_{\mathrm{y}}
$$

Where,

$\mathrm{n}_{\mathrm{z}}=\quad$ the total number of breeding events required to successfully impregnate the entire cohort group;

$\mathrm{n}_{\mathrm{f}}=\quad$ the number of females within a cohort group;

$p_{y}=\quad$ the pregnancy rate for each AI method (Table3.2). 
To derive the present value of marginal costs for genetic improvement strategies that utilized artificial insemination, the following equation was used.

$$
q=n_{z} \times j[5]
$$

Where,

$\mathrm{q}=\quad$ the total reproduction cost for an AI-based GIS

$\mathrm{j}=\quad$ the breeding cost per AI service

Present Value of Total Marginal Costs for Heifer-based Genetic Improvement Strategies Utilizing Embryo Transfer. To determine the reproductive cost of HETNS GIS, two calculations were used. The gross number of calves produced from non-elite recipient females was multiplied by $\$ 252.38$ (Table 3.3). Equation [5] was used to determine the cost to breed the donor heifers using non-sexed semen AI. The costs resulted from each equation were then summed to yield the total reproductive method cost for HETNS GIS.

Present Value of Total Marginal Costs for Cow-based Genetic Improvement Strategies Utilizing Embryo Transfer. To determine the reproductive cost of CETNS GIS, the total number of heifer recipients was multiplied by the cost of $\$ 252.38$ per resulting calf.

Present Value of Total Marginal Cost per Dollar Increase in $\Delta G$

The cost per dollar increase in $\Delta \mathrm{G}$ was calculated by dividing the present cost per head per year for the implementation of a GIS by the present value of genetic improvement per year. 


$$
\mathrm{v}=\eta_{\mathrm{pv}} / \gamma_{\mathrm{pv}}
$$

Where,

$v=\quad$ the cost per dollar increase in $\Delta \mathrm{G}$;

$\eta_{\mathrm{pv}}=\quad$ the present value of total marginal cost for the implementation of each genetic improvement strategy;

$\gamma_{\mathrm{pv}}=$ the present value of genetic change $(\Delta \mathrm{G})$.

\section{Break Even Cost}

To estimate the breakeven cost for GIS, the strategy with the lowest cost per dollar improvement in $\Delta \mathrm{G}$ and the greatest present value of cumulative gross marginal returns was selected. The cumulative gross marginal returns for the selected GIS were used to approximate the present value of per selected animal. The present value of gross marginal returns per selected animal served as an estimation of the breakeven price for the successful implementation of GIS that incorporated WGS with a reproductive method. 


\section{CHAPTER 4}

\section{RESULTS}

This model required 354 head of replacement females annually to maintain a production herd size of 1,000 cows. Accounting for still birth rate for primiparous and multiparous cows, as well as pre-weaning and post-weaning death loss, the net number of replacement females produced each year was 403 head. The number of replacement females selected, to be bred or used as donors for the remaining females of the replacement cohort, when using each GIS were listed below (Table 4.1).

Table 4.1. Selection level, breeding and calving number for each heifer-based genetic improvement strategy.

\begin{tabular}{|c|c|c|c|}
\hline $\begin{array}{c}\text { Genetic Improvement } \\
\text { Strategy }\end{array}$ & $\begin{array}{c}\text { Selection } \\
\text { \% }\end{array}$ & $\begin{array}{c}\text { Selected Number of } \\
\text { Females Bred }\end{array}$ & $\begin{array}{c}\text { Number of Females to } \\
\text { Calve }\end{array}$ \\
\hline HNS & 100 & 403 & 403 \\
\hline HNS & 90 & 363 & 363 \\
\hline HSS & 90 & 363 & 363 \\
\hline HETNS(Single Flush) & 23 & 91 & 363 \\
\hline HETNS(Double Flush) & 11 & 46 & 363 \\
\hline
\end{tabular}

The number of first lactation females selected, to be bred or used as embryo donors for the replacement cohort, when using each GIS were listed below (Table 4.2). 
Table 4.2. Selection level, breeding and calving number for each cow-based genetic improvement strategy.

\begin{tabular}{|c|c|c|c|}
\hline $\begin{array}{c}\text { Genetic Improvement } \\
\text { Strategy }\end{array}$ & $\begin{array}{c}\text { Selection } \\
\mathbf{\%}\end{array}$ & $\begin{array}{c}\text { Selected Number of } \\
\text { Females Bred }\end{array}$ & $\begin{array}{c}\text { Number of Females to } \\
\text { Calve }\end{array}$ \\
\hline CNS & 100 & 256 & 256 \\
\hline CETNS(Single Flush) & 42 & 108 & 403 \\
\hline CETNS(Double Flush) & 21 & 54 & 403 \\
\hline
\end{tabular}

Value of $\mathbf{w}$. Following the multiplication of $\mathbf{n}$ and $\mathbf{v}, \mathbf{w}$ was determined for each GIS. The calculated present value of total economic returns were the same for each element of a GIS 1-by$20 \mathbf{w}$. The values of w elements for heifer-based GIS were listed below (Table 4.3).

Table 4.3: Values of $\mathbf{w}$ elements for heifer-based genetic improvement strategies.

\begin{tabular}{|c|c|c|}
\hline GIS & Accuracy of EBV & w \\
\hline HNS100 & 35 & $\$ 0$ \\
\hline & 53 & $\$ 0$ \\
\hline HNS90 & 85 & $\$ 0$ \\
\hline & 35 & $\$ 1,310.43$ \\
\hline & 53 & $\$ 1,963.83$ \\
\hline & 85 & $\$ 5,717.25$ \\
\hline & 35 & $\$ 1,310.43$ \\
\hline & 53 & $\$ 1,963.83$ \\
\hline & 85 & $\$ 5,717.25$ \\
\hline & 35 & $\$ 15,979.26$ \\
\hline & 53 & $\$ 24,197.58$ \\
\hline & 85 & $\$ 38.808 .33$ \\
\hline & 35 & $\$ 20,701.89$ \\
\hline & 53 & $\$ 31,345.05$ \\
\hline
\end{tabular}


The values of w elements for cow-based GIS were listed below (Table 4.4).

Table 4.4: Values of $\mathbf{w}$ elements for cow-based genetic improvement strategies.

\begin{tabular}{|c|c|c|}
\hline GIS & Accuracy of EBV & w \\
\hline CNS100 & 35 & $\$ 0$ \\
\hline & 53 & $\$ 0$ \\
\hline CETNS42 & 85 & $\$ 0$ \\
\hline & 35 & $\$ 8,342.10$ \\
\hline & 53 & $\$ 12,634.05$ \\
\hline CETNS21 & 85 & $\$ 20,258.81$ \\
\hline & 35 & $\$ 12,275.30$ \\
\hline & 53 & $\$ 18,590.39$ \\
\hline
\end{tabular}

\section{Estimated $4 G$ per Year}

The rate of genetic change $(\Delta \mathrm{G})$ for net merit dollar was calculated per generation and per year by using equation [1], for each of the three accuracy values, for both heifer-based and cow-based GIS (Table 4.5; Table 4.6). 
Table 4.5: $\Delta \mathrm{G}$ per generation and $\Delta \mathrm{G}$ per year for heifer-based genetic improvement strategies.

\begin{tabular}{|c|c|c|c|}
\hline GIS & Accuracy of EBV & $\Delta$ G per Generation & $\Delta$ G per Year \\
\hline HNS100 & 35 & 0 & 0 \\
\hline & 53 & 0 & 0 \\
\hline HNS90 & 85 & 0 & 0 \\
\hline & 35 & $\$ 7.22$ & $\$ 3.61$ \\
\hline HSS90 & 53 & $\$ 10.93$ & $\$ 5.47$ \\
\hline & 85 & $\$ 17.53$ & $\$ 3.61$ \\
\hline HETNS23 & 35 & $\$ 7.22$ & $\$ 5.47$ \\
\hline & 53 & $\$ 10.93$ & $\$ 8.77$ \\
\hline & 85 & $\$ 17.53$ & $\$ 44.02$ \\
\hline HETNS11 & 35 & $\$ 88.04$ & $\$ 66.66$ \\
\hline & 53 & $\$ 133.32$ & $\$ 106.91$ \\
\hline & 85 & $\$ 213.81$ & $\$ 57.03$ \\
\hline & 35 & $\$ 114.05$ & $\$ 86.35$ \\
\hline
\end{tabular}

Table 4.6: $\Delta \mathrm{G}$ per generation and $\Delta \mathrm{G}$ per year for cow-based genetic improvement strategies.

\begin{tabular}{|c|c|c|c|}
\hline GIS & Accuracy of EBV & $\Delta \mathbf{G}$ per Generation & $\Delta$ G per Year \\
\hline CNS100 & 35 & 0 & 0 \\
\hline & 53 & 0 & 0 \\
\hline CETNS42 & 85 & 0 & 0 \\
\hline & 35 & $\$ 62.10$ & $\$ 20.70$ \\
\hline & 53 & $\$ 94.05$ & $\$ 31.35$ \\
\hline CETNS21 & 85 & $\$ 150.81$ & $\$ 50.27$ \\
\hline & 35 & $\$ 91.38$ & $\$ 30.46$ \\
\hline & 53 & $\$ 138.39$ & $\$ 46.13$ \\
\hline
\end{tabular}

\section{Present Value of Gross Marginal Returns}

All of the GIS investigated followed the same trend throughout the 20-year time horizon, a decline in discounted returns into year three and a peak in discounted returns at year eleven (Figures 4.1, 4.2, 4.3). 
The trough between years one and three was the result of the model design. To simplify the model's representation of the dairy industry, the discounted gene flow model was implemented using a period of one year, which resulted in the discounted returns reported on an annual basis. However, dairy females produced marketable product every day for approximately 305 days of every year they were in lactation.

Additionally, it took approximately two years for a replacement heifer to develop, which resulted in a lag period. During the lag period, the only returns recognized were the asset value of selected replacement females. However, when the selected females started to calve, their transition from heifer to cow resulted in a reduction in asset value.

The reduction in asset value in period three was created by the negative value in the $\mathbf{R}$, which was a result of the subtraction of $\mathbf{Q}$ from $\mathbf{P}$ (Table 4.7). When the selected replacement heifers began to calve, 50 percent of their genes were passed to their progeny, which was represented in $\mathbf{P}$ as 0.5 . However, this transition was not without cost. The transition from heifer to cow age-class was represented as one in $\mathbf{Q}$. Therefore, when $\mathbf{R}$ was derived to account for both gene flow and aging, a negative value during the transition year was generated.

Table 4.7. 5-by-5 excerpt of $\mathbf{R}$.

\begin{tabular}{|c|c|c|c|c|}
\hline 1 & 0 & 0 & 0 & 0 \\
\hline 0 & 1 & 0 & 0 & 0 \\
\hline-0.5 & 0 & 1 & 0 & 0 \\
\hline 0.5 & -0.5 & 0 & 1 & 0 \\
\hline 0.75 & 0.5 & -0.5 & 0 & 1 \\
\hline
\end{tabular}


Following the reduced returns in period three, the income for each GIS increased at a decreasing rate until reaching a peak in returns during period eleven. Following the attainment of the peak revenue, the rate of returns decreased at an increasing rate for two reasons. First, the negative effects of time on present value. Second, after year eleven the number of individuals that were more closely related to the first selected female began to leave the herd, due to aging, at a rate greater than the influx of genetics from succeeding generations of less related replacements.

\section{Present Value of Gross Marginal Returns for Heifer-based Genetic Improvement Strategies}

For analysis, the heifer-based strategies were separated into those using AI and those using embryo transfer. The calculated present value of gross marginal returns for heifer-based GIS using AI were deceiving; returns from using non-sexed and sexed semen were identical (Figure 4.1). This result occurred because the selection intensity for both HNS and HSS were the same, which resulted in the same $\Delta \mathrm{G}$ (a key component in determining $\mathbf{w}$ ). Then, $\mathbf{w}$ was used in equation [5] to determine the present value of gross marginal returns of a GIS. 


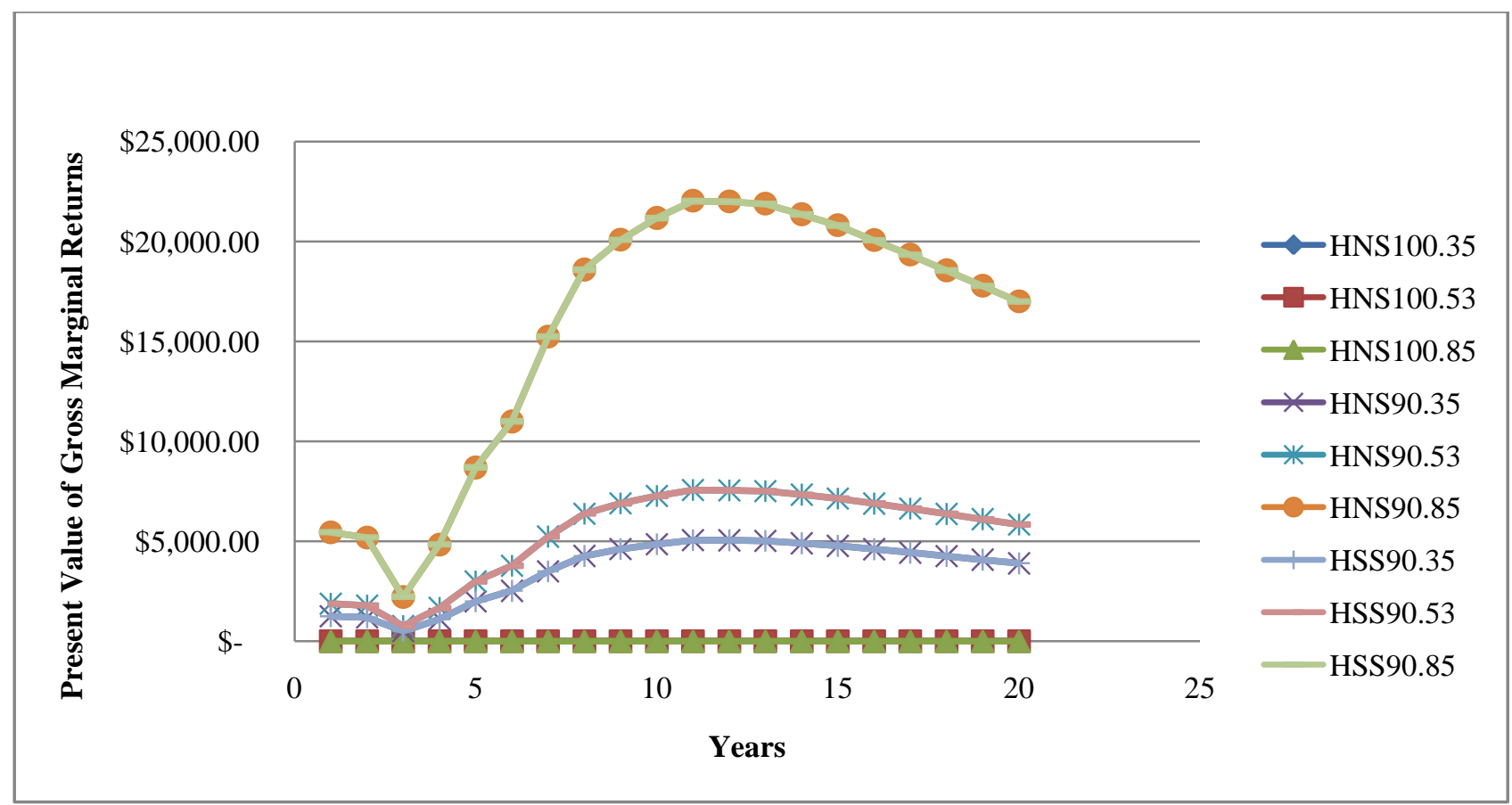

Figure 4.1. Present value of gross marginal returns for heifer-based genetic improvement strategies using artificial insemination by year.

Heifer-based strategies that utilized embryo transfer allowed for the greatest gross marginal returns because the selection intensity was substantially greater (Figure 4.2). Selection intensity and the accuracy of prediction work in synergy to generate greater gross marginal returns, as seen with strategies HETNS11.85 and HETNS23.85. 


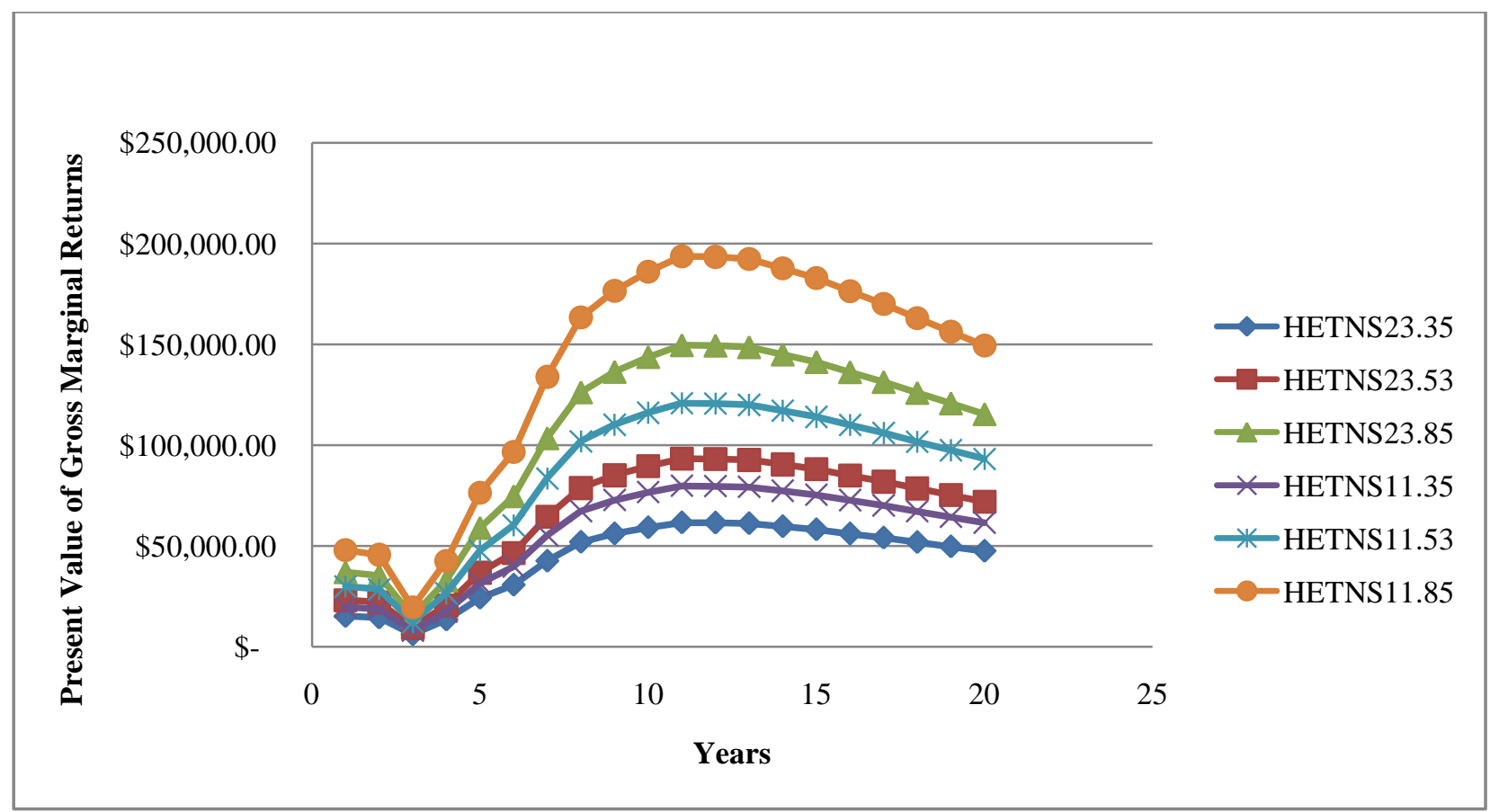

Figure 4.2. Present value of gross marginal returns for heifer-based genetic improvement strategies using embryo transfer by year.

\section{Present Value of Gross Marginal Returns for Cow-based Genetic Improvement Strategies}

Although the present value of gross marginal returns were comparatively less, the present value of annual gross marginal returns for cow-based strategies followed the same pattern as heifer-based methods (Figure 4.3). There were three main reasons for the lesser gross marginal returns:

- the cohort size for the first lactation group was substantially smaller; therefore, had less of an impact on the herd's genetic future;

- first lactation cows could not be selectively removed in addition to normal culling or there would have been insufficient replacement heifers to maintain herd size; 
- and the generation interval was lengthened an additional year, which effectively reduced the rate of genetic gain by one third.

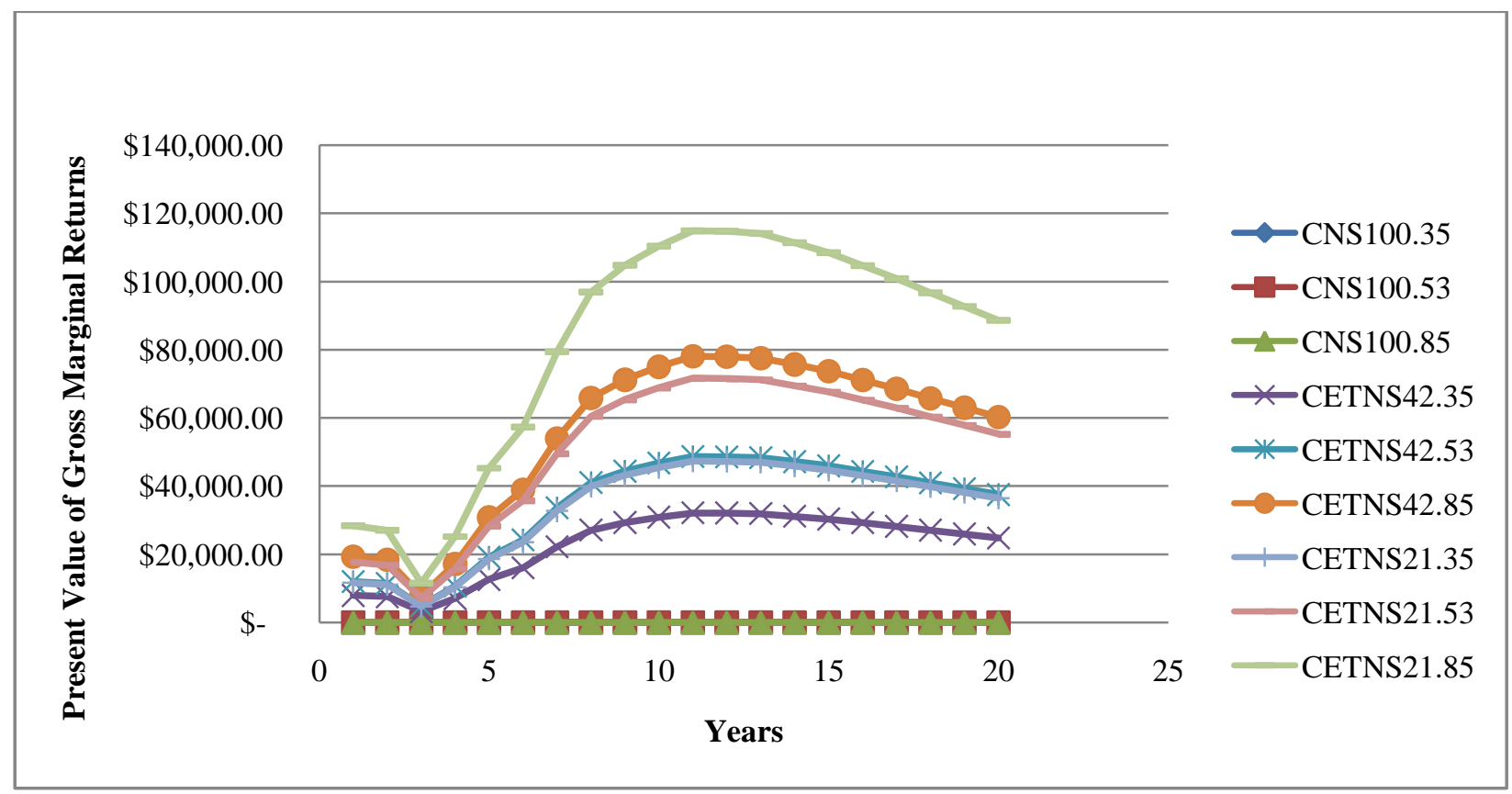

Figure 4.3: Present value of gross marginal returns for cow-based genetic improvement strategies by year.

The present value of gross marginal returns for GIS using artificial insemination were substantially less than those using embryo transfer. The reason for this was due to the increased level of selection achievable when using embryo transfer. Selection intensity was a main component to $\Delta \mathrm{G}$, as seen in equation [2]; selection intensity affected $\Delta \mathrm{G}$ considerably more than the accuracy of prediction. However, with equal selection intensities, the method with the greatest accuracy of prediction would have resulted in the greater increase in $\Delta \mathrm{G}$. 


\section{Present Value of Cumulative Gross Marginal Returns}

The present value of cumulative gross marginal returns for each genetic improvement strategy were determined over a 20 -year time horizon. The GIS with the greatest selection intensity and highest level of accuracy achieved the greatest cumulative gross marginal returns. I

Present Value of Cumulative Gross Marginal Returns for Heifer-based Genetic Improvement Strategies. Of the strategies investigated, heifer-based embryo transfer methods resulted in the highest cumulative gross marginal returns of 2.7 million dollars (Figure 4.4). Furthermore, the positive relationship between selection intensity and accuracy was illustrated by HETNS23 at 0.85 accuracy. Even though the selection intensity for HETNS23 was comparatively less than HETNS11 at 0.85 accuracy, the cumulative gross marginal returns for HETNS23 were substantially greater than those of HETNS11 with 0.35 or 0.53 accuracy of predictions. 


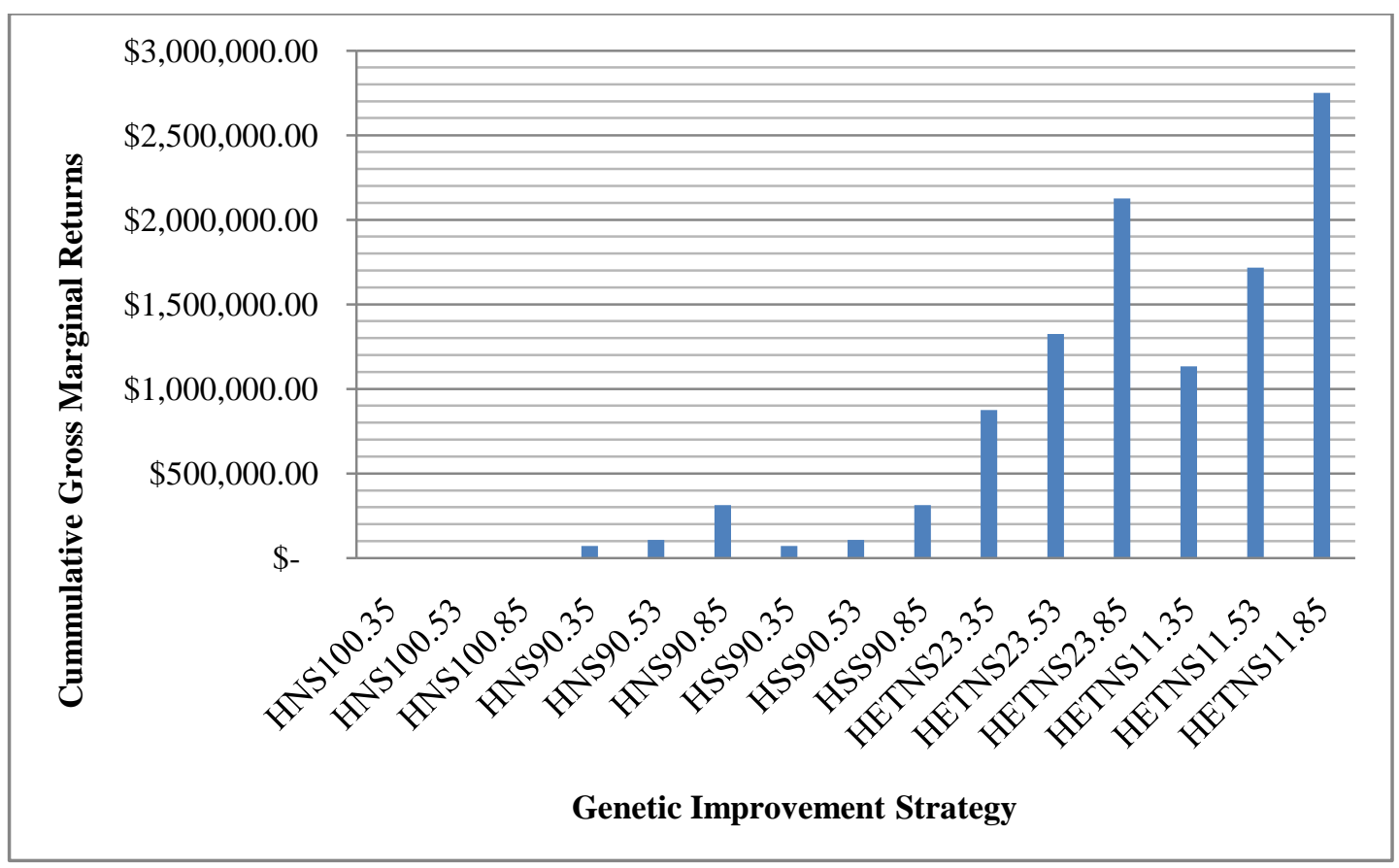

Figure 4.4. Present value of cumulative gross marginal returns for each heifer-based genetic improvement strategy over a 20 -year time horizon.

\section{Present Value of Cumulative Gross Marginal Returns for Cow-based Genetic}

Improvement Strategies. The trend in cumulative gross marginal returns for cow-based GIS was similar than that of heifer-based GIS. However, due to lesser levels of selection intensity, the cumulative gross marginal returns were not nearly as substantial (Figure 4.5). 


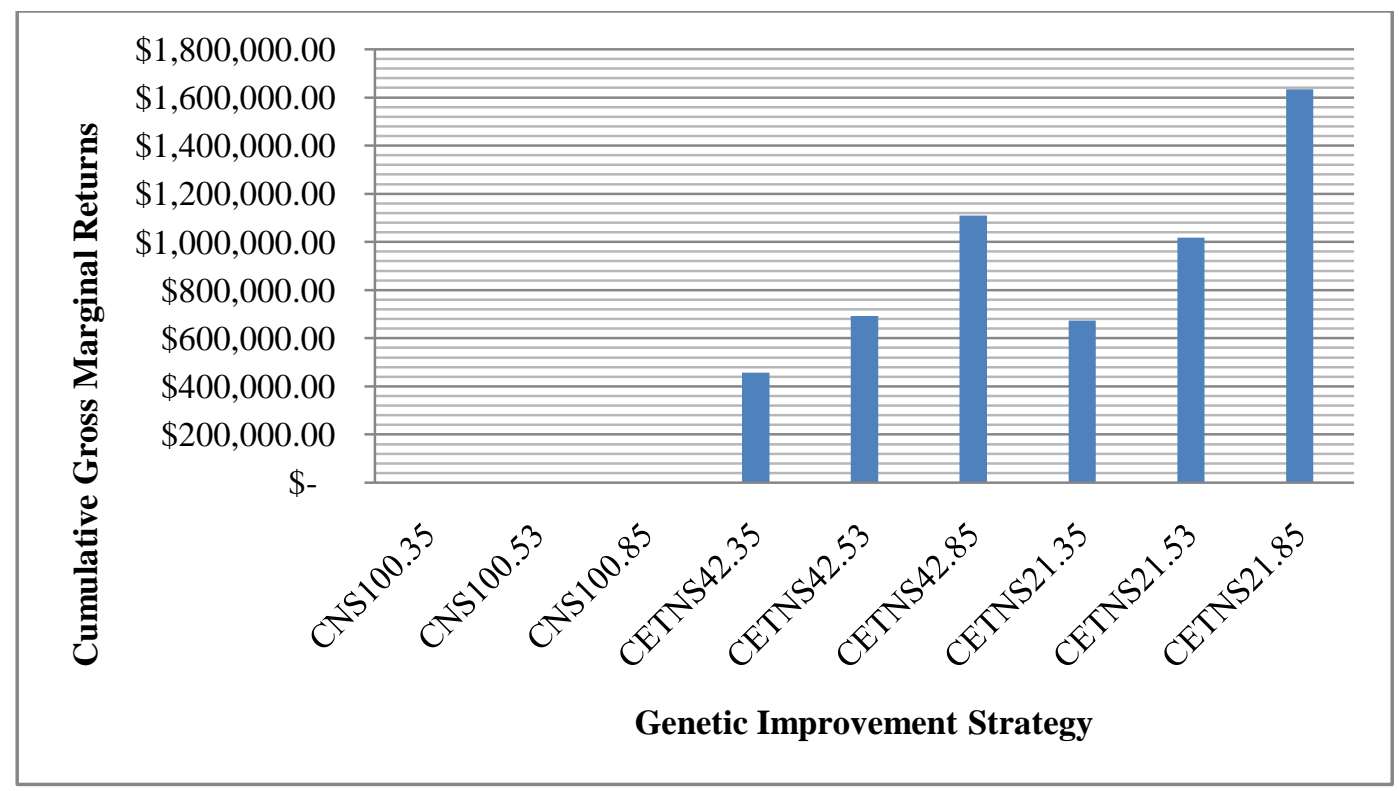

Figure 4.5. Present value of cumulative gross marginal returns for each cow-based genetic improvement strategy over a 20 -year time horizon.

\section{Present Value of Total Marginal Costs for Each Genetic Improvement Strategy}

The present value of total marginal cost of each heifer and cow-based genetic improvement strategy, over a 20-year time horizon, included both a reproduction method and genotyping fees (Table 4.8; Table 4.9).

Table 4.8. Present value of total marginal cost for each heifer-based genetic improvement strategy.

\begin{tabular}{|c|c|c|}
\hline GIS & $\begin{array}{c}\text { Present Value of Total } \\
\text { Marginal Cost }\end{array}$ & $\begin{array}{c}\text { Present Value of Marginal Cost per } \\
\text { Replacement Female }\end{array}$ \\
\hline HNS 100 & $\$ 251,048.45$ & $\$ 31.15$ \\
\hline HNS90 & $\$ 1,480,637.92$ & $\$ 183.70$ \\
\hline HSS90 & $\$ 2,460,050.64$ & $\$ 305.22$ \\
\hline HETNS23 & $\$ 2,166,256.20$ & $\$ 268.77$ \\
\hline HETNS11 & $\$ 2,279,665.12$ & $\$ 282.84$ \\
\hline
\end{tabular}


Table 4.9. Present value of total marginal cost for each cow-based genetic improvement strategy.

\begin{tabular}{|c|c|c|}
\hline GIS & $\begin{array}{c}\text { Present Value of Total } \\
\text { Marginal Cost }\end{array}$ & $\begin{array}{c}\text { Present Value of Marginal Cost per First } \\
\text { Lactation Female }\end{array}$ \\
\hline CNS100 & $\$ 292,142.60$ & $\$ 57.05$ \\
\hline CETNS42 & $\$ 2,063,542.80$ & $\$ 403.04$ \\
\hline CETNS21 & $\$ 2,063,542.80$ & $\$ 403.04$ \\
\hline
\end{tabular}

Present Value of Total Marginal Cost per Dollar Increase in the Present Value of $\Delta G$

In spite of increased implementation costs, GIS with the greatest selection intensities and accuracy levels had the lowest cost per dollar increase in $\Delta \mathrm{G}$ with lower selection intensities and accuracy levels.

To determine the economic efficiency of each heifer-based GIS, the present value of total marginal cost was divided by the present value of $\Delta \mathrm{G}$ per year (Table 4.10). 
Table 4.10. Present value of marginal cost per dollar increase in the present value of $\Delta \mathrm{G}$ per year for heifer-based genetic improvement strategies.

\begin{tabular}{|c|c|}
\hline Genetic Improvement Strategy & $\begin{array}{c}\text { Present Value of Marginal Cost per Dollar } \\
\text { Increase in } \Delta \mathrm{G}\end{array}$ \\
\hline HNS100.35 & $\$ 0$ \\
\hline HNS100.53 & $\$ 0$ \\
\hline HNS100.85 & $\$ 0$ \\
\hline HNS90.35 & $\$ 81.64$ \\
\hline HNS90.53 & $\$ 53.87$ \\
\hline HNS90.85 & $\$ 33.64$ \\
\hline HSS90.35 & $\$ 135.65$ \\
\hline HSS90.85 & $\$ 89.51$ \\
\hline HETNS23.35 & $\$ 55.90$ \\
\hline HETNS23.53 & $\$ 9.81$ \\
\hline HETNS23.85 & $\$ 6.48$ \\
\hline HETNS11.35 & $\$ 4.03$ \\
\hline HETNS11.53 & $\$ 7.97$ \\
\hline HETNS11.85 & $\$ 5.26$ \\
\hline & $\$ 3.28$ \\
\hline
\end{tabular}

To determine the economic efficiency of each cow-based GIS, the present value of total marginal cost was divided by the present value of $\Delta \mathrm{G}$ per year (Table 4.11).

Table 4.11. Present value of marginal cost per dollar increase in the present value of $\Delta \mathrm{G}$ per year for cow-based genetic improvement strategies.

\begin{tabular}{|c|c|}
\hline Genetic Improvement Strategy & $\begin{array}{c}\text { Present Value of Marginal Cost per Dollar } \\
\text { Increase in } \Delta \mathrm{G}\end{array}$ \\
\hline CNS100.35 & $\$ 0$ \\
\hline CNS100.53 & $\$ 0$ \\
\hline CNS100.85 & $\$ 0$ \\
\hline CETNS42.35 & $\$ 19.47$ \\
\hline CETNS42.53 & $\$ 12.86$ \\
\hline CETNS42.85 & $\$ 8.02$ \\
\hline CETNS21.35 & $\$ 13.23$ \\
\hline CETNS21.53 & $\$ 8.74$ \\
\hline
\end{tabular}




\section{Breakeven Cost}

Of the five GIS investigated, HETNS11 at an accuracy level of 0.85 generated the most affordable cost per dollar improvement in $\Delta \mathrm{G}$ and was the only GIS to show long-term profitability. This GIS achieved the present value of cumulative gross marginal returns of $\$ 2,752,053.15$, which was $\$ 472,388.03$ over cumulative marginal costs (Figure 4.12).

While not generating cumulative gross marginal returns greater than total marginal cost, HETNS23 with 0.85 accuracy earned $\$ 2,126,188.83$. This GIS lost the least over the 20-year time horizon (Figure 4.12).

Table 4.12: Cumulative marginal returns for heifer-based genetic improvement strategies

\begin{tabular}{|c|c|c|c|c|}
\hline $\begin{array}{c}\text { Genetic } \\
\text { Improvement } \\
\text { Strategy }\end{array}$ & $\begin{array}{c}\text { Present Value of } \\
\text { Total Marginal } \\
\text { Cost }\end{array}$ & $\begin{array}{c}\text { Present Value of } \\
\text { Cumulative Gross } \\
\text { Marginal Returns }\end{array}$ & $\begin{array}{c}\text { Present Value of } \\
\text { Marginal Returns } \\
\text { per Replacement } \\
\text { Female }\end{array}$ & $\begin{array}{c}\text { Present Value of } \\
\text { Total Marginal } \\
\text { Returns }\end{array}$ \\
\hline HNS100 & $\$ 251,048.45$ & $\$ 0$ & $\$ 0$ & $\$-251,048.45$ \\
\hline HNS90.35 & $\$ 1,480,637.93$ & $\$ 71,794.41$ & $\$ 8.91$ & $\$-1,408,843.52$ \\
\hline HNS90.53 & $\$ 1,480,637.93$ & $\$ 107,592.20$ & $\$ 13.35$ & $\$-1,373,045.73$ \\
\hline HNS90.85 & $\$ 1,480,637.93$ & $\$ 313,230.51$ & $\$ 38.86$ & $\$-1,167,407.42$ \\
\hline HSS90.35 & $\$ 2,460,050.64$ & $\$ 71,794.41$ & $\$ 8.91$ & $\$-2,388,256.23$ \\
\hline HSS90.53 & $\$ 2,460,050.64$ & $\$ 107,592.20$ & $\$ 13.35$ & $\$-2,352,458.44$ \\
\hline HSS90.85 & $\$ 2,460,050.64$ & $\$ 313,230.51$ & $\$ 38.86$ & $\$-2,146,820.13$ \\
\hline HETNS23.35 & $\$ 2,166,256.20$ & $\$ 875,454.41$ & $\$ 120.59$ & $\$-1,290,801.79$ \\
\hline HETNS23.53 & $\$ 2,166,256.20$ & $\$ 1,325,710.87$ & $\$ 182.60$ & $\$-840,545.33$ \\
\hline HETNS23.85 & $\$ 2,166,256.20$ & $\$ 2,126,188.83$ & $\$ 292.86$ & $-\$ 40,067.37$ \\
\hline HETNS11.35 & $\$ 2,279,665.12$ & $\$ 1,134,192.63$ & $\$ 156.22$ & $\$-1,145,472.49$ \\
\hline HETNS11.53 & $\$ 2,279,665.12$ & $\$ 1,717,298.70$ & $\$ 236.54$ & $\$-562,366.42$ \\
\hline HETNS11.85 & $\$ 2,279,665.12$ & $\$ 2,752,053.15$ & $\$ 379.07$ & $+\$ 472,388.03$ \\
\hline
\end{tabular}

To break even, the maximum cost per head for the implementation of the GIS cannot exceed the maximum discounted annual returns. Employing this logic, the breakeven cost for HETNS at the specified selection intensity and accuracy levels would be between $\$ 292.86$ and 
\$379.07 (Figure 4.12). The lower bound of \$292.86 was selected because HETNS23, at 0.85 accuracy, would have produced enough returns to have broken even.

None of the cow-based GIS were viable at this time. The present value of cumulative gross returns for each GIS were not great enough to cover the present value of marginal costs for any of the investigated cow-based GIS (Figure 4.13).

Table 4.13: Cumulative marginal returns for cow-based genetic improvement strategies

\begin{tabular}{|c|c|c|c|c|}
\hline $\begin{array}{c}\text { Genetic } \\
\text { Improvement } \\
\text { Strategy }\end{array}$ & $\begin{array}{c}\text { Present Value of } \\
\text { Total Marginal } \\
\text { Cost }\end{array}$ & $\begin{array}{c}\text { Present Value of } \\
\text { Cumulative Gross } \\
\text { Marginal Returns }\end{array}$ & $\begin{array}{c}\text { Present Value of } \\
\text { Marginal Returns } \\
\text { per Replacement } \\
\text { Female }\end{array}$ & $\begin{array}{c}\text { Present Value of } \\
\text { Total Marginal } \\
\text { Returns }\end{array}$ \\
\hline CNS100 & $\$ 292,142.60$ & $\$ 0$ & $\$ 0$ & $\$ 0$ \\
\hline CETNS42.35 & $\$ 2,063,542.80$ & $\$ 457,037.96$ & $\$ 89.27$ & $\$-1,606,504.84$ \\
\hline CETNS42.53 & $\$ 2,063,542.80$ & $\$ 692,180.66$ & $\$ 135.19$ & $\$-1,371,362.14$ \\
\hline CETNS42.85 & $\$ 2,063,542.80$ & $\$ 1,109,917.78$ & $\$ 216.78$ & $\$-953,625.02$ \\
\hline CETNS21.35 & $\$ 2,063,542.80$ & $\$ 672,530.25$ & $\$ 131.35$ & $\$-1,391,012.55$ \\
\hline CETNS21.53 & $\$ 2,063,542.80$ & $\$ 1,018,510.19$ & $\$ 198.93$ & $\$-1,045,032.61$ \\
\hline CETNS21.85 & $\$ 2,063,542.80$ & $\$ 1,633,413.91$ & $\$ 319.03$ & $\$-430,128.89$ \\
\hline
\end{tabular}




\section{CHAPTER 5}

\section{DISCUSSION}

From the results, it was apparent that, selection intensity had the greatest effect on genetic change and discounted returns compared to accuracy of prediction. However, selection intensity and accuracy of prediction had a synergistic relationship. Genetic improvement strategies (GIS) that combined high selection intensity reproductive methods with high accuracy WGS generated substantially greater rates of genetic gain and discounted annual returns.

Whole genome selection was not a stand-alone technology. To be effectively implemented, WGS had to be combined with a reproduction method that permitted for increased selection intensity. Of the common reproduction methods investigated (non-sexed semen AI, sexed semen AI and embryo transfer using non-sexed semen), embryo transfer permitted the greatest levels of selection intensity.

Between replacement female and first lactation cow cohorts, GIS using embryo transfer harvested the greatest cumulative gross marginal returns when implemented within the replacement female group. The replacement female cohort was the largest single group in this model, as it was with most dairies. The size of the replacement female cohort allowed for the greatest levels of selection within the dams to produce dams selection pathway.

Genetic improvement strategies did not achieve optimum results when implemented with

first lactation cows. The size of the first lactation cow cohort was comparatively smaller than that of replacement females. Due to constraints on herd size and parity demographics, high selection intensity was not possible. 


\section{Limitations}

This model did not reflect any one dairy operation as it was designed using published herd and genetic parameters. Therefore, changing or adding any parameter (i.e. cost of GIS implementation, accuracy of estimated breeding values, or selection intensity) may generate a different outcome.

\section{Strengths}

Whole genomic selection was a technology in its infancy. The feasibility of its application within the commercial dairy sector had not been studied. This thesis served as a preliminary investigation for future research on ways to effectively implement WGS on actual dairy operations.

\section{Implications}

From this initial research, the dairy industry, academic and animal breeding communities now have an idea of how to effectively apply whole genome selection on a commercial dairy operation. Furthermore, the specific predictive accuracy required to make whole genome selection viable was now known. Most importantly, an approximate breakeven cost for implementation was elucidated.

Further research on the implementation of whole genome selection within the commercial dairy sector should focus on the development of new or redevelopment of reproduction methods that allow for the increased selection of future dams, as well as the development of inexpensive, high accuracy genotyping tools. 


\section{Future Research}

Modeling allowed researchers the opportunity to investigate the effects of any genetic improvement, breeding or management strategy before implemented in vivo. Of the numerous scenarios that could be modeled, three stand out as the next logical steps in this research.

To more fully understand a discounted gene flow model representing a commercial dairy operation, an in depth sensitivity analysis should be carried out. Sensitivity analysis would allow researchers to understand which variables substantially affect the model, such as selection intensity, accuracy of predictions, costs of implementation, and generation interval. With this knowledge, animal breeders could more effectively design breeding strategies that use WGS.

Additionally, a model to determine the viability of a GIS using superior 10 to 12 monthold replacement heifers as embryo donors for average quality replacement females should be investigated. This strategy would reduce the generation interval by one year. By decreasing the generation interval, the rate of genetic change should double, compared to strategies with a twoyear generation interval. This increased rate of genetic change may make WGS, with lower accuracies of prediction, viable for use on commercial dairies.

Lastly, future research should develop an additional model to determine the effectiveness and viability of using genomically tested young sire semen in the aforementioned heifer-based GIS. By decreasing the generation intervals in multiple selection pathways, animal breeders should be able to harvest greater amounts of genetic improvement from the use of such a WGS. 


\section{Conclusion}

Genomic selection was a promising new technology investigated for implementation within the commercial dairy sector. Whole genomic selection was not achievable at the current prices for genotyping, reproductive methods, and achievable accuracy levels. With accurate and affordable genotyping solutions combined with reasonably priced high selection intensity reproductive methods, WGS selection could be a powerful genetic improvement tool for the commercial dairy industry. If the development of SNP chips follow Moore's Law, as suggested by Golden et al. (2009), and SNP chip marker density does indeed double every 18 months, it will not be long until the use of WGS is viable. 


\section{REFERENCES}

Aubertot, J.N. 2008. Introduction.

http://www.modelia.org/html/081118_ModellingCoursePoland/pdf/1_Introduction_Aube rtot_20081118.pdf_Accessed May 15, 2008.

Beckman, J. S. and M. Soller. 1983. Restriction fragment length polymorphisms in genetic improvement: methodologies mapping and costs. Theor. Appl. Genet. 67:35-43.

Bird, P. J. W. N. and G. Mitchell. 1980. The choice of discount rate in animal breeding investment appraisal. J. Anim. Breed. Genet. 48:499-505. (Abstract)

Butler, L. J. 2002. The potential for growth in the California dairy/forage industry and implications of the 2002 farm bill. Page 29-38 in Proc. $31^{\text {st }}$ California Alfalfa and Forage Symposium, Modesto, California.

California Department of Food and Agriculture, Dairy Marketing Branch. 2007. Cost of production. Pages 1-55.

Dalton, J. C. 2007. Comparing gender-selected AI semen pregnancy results in heifers and cows. Western Dairy News, Hoard's Dairyman. http://ansci.colostate/content/view/593/ Accessed November 23, 2008.

Dematawewa, C. M. B., P. J. Berger and B. E. Melton. 1998. Optimization of sire selection based on maximization of guaranteed income and risk associated with sire merit. J. Dairy Sci. 81:807-816. 
de Roos, A. P. W., B. J. Hayes, R. J. Spelman and M. E. Goddard. 2008. Linkage disequilibrium and persistence of phase in Holstein-Friesian, Jersey and Angus cattle. Genetics. 179:1503-1512.

Dumas, A., J. Dijkstra, and J. France. 2008. Mathematical modeling in animal nutrition: a century review, J. Agric. Sci. 146:123-142.

Everett, R. W. 1975. Income over investment in semen. J. Dairy Sci. 58:1717-1722.

Foote, R. H. 2002. The history of artificial insemination: selected notes and notables. J. Anim. Sci. 80:1-10.

Freeman, A. E. 1991. C. R. Henderson: contributions to the dairy industry. J. Dairy Sci. 74:40454051.

Garrick, D. J. 2007. Equivalent mixed model equations for genomic selection. J. Dairy Sci. 90(Suppl. 1):376. (Abstract)

Genesis 1500 BC. 30:41-43. The Holy Bible. New Revised Standard Version.

Georges, M., D. Nielsen, M. Mackinnon, A. Mishra, R. Okimoto, A. T. Pasquino, L. S. Sargeant, A. Sorensen, M. R. Steele, X. Zhao, J. E. Womack, and I. Hoeshele. 1995. Mapping quantitative trait loci controlling milk production in dairy cattle by exploiting progeny testing. Genetics. 139:907-920.

Gibson, J. P. and J. C. M. Dekkers. 2008. Design and economics of animal breeding strategies. http://www.une.edu.au/tigb/gibson-book/Chapter8.pdf Accessed January 7, 2009. 
Goddard, M. E. and B. J. Hayes. 2007. Genomic selection. Journal of Animal Breeding and Genetics. 124:323-330.

Golden, B.L., D.J. Garrick, and L.L. Benyshek. 2009. Milestones in beef cattle evaluation. J. Anim. Sci. 87:E3-E10.

Grimes, J. F. 2008. Utilization of embryo transfer in beef cattle. Extension Fact Sheet. The Ohio State University Extension.

Grisart, B., W. Coppieters, and F. Farnir. 2002. Positional candidate cloning of a QTL in dairy cattle: identification of a missense mutation in the bovine DGAT1 gene with major effect on milk yield and composition. Genome Res. 12:222-231.

Grisart, B., F. Farnir, L. Karim, N. Cambisano, J. J. Kim, A. Kvasz, M. Mni, P. Simon, J. M. Frére, W. Coppieters and M. Georges. 2004. Genetic and functional confirmation of the causality of the DGAT1 K232A quantitative trait nucleotide in affecting milk yield and composition. Proc. Natl. Acad. Sci. U.S.A. 101:2398-2403.

Hare, E., H. D. Norman, and J. R. Wright. 2006. Survival rates and productive herd life of dairy cattle in the United States. J. Dairy Sci. 98:3713-3720.

Harris, D. L. and S. Newman. 1994. Breeding for profit: synergism between genetic improvement and livestock production (a review). J. Anim. Sci. 72:2178-2200.

Hasler, J. F. 2001. Factors affecting frozen and fresh embryo transfer pregnancy rates in cattle. Theriogenology. 56:1401-1415.

Hawken, R. J., W. C. Barris, S. M. McWilliam, and B. P. Dalrymple. 2004. An interactive bovine in silico SNP database (IBISS). Mamm. Genome. 15:819-827. 
Hinds, D. A., L. L. Stuve, G. B. Nilsen, E. Halperin, E. Eskin, D. G. Ballinger, K. A. Frazer, and D. R. Cox. 2005. Whole-genome patterns of common DNA variation in three human populations. Science. 307:1072-1079.

Hill, W. G. 1974. Prediction and evaluation of response to selection with overlapping generations. Anim. Prod. 18:117-139.

Human Genome Sequencing Center. 2009. Bovine Genome Project. http://www.hgsc.bcm.tmc.edu/project-species-m-Bovine.hgsc?pageLocation=Bovine Accessed March 3, 2009.

Illumina. 2008. BovineSNP50 genotyping beadchip. Genome-wide DNA analysis beadchip. http://www.illumina.com/pages.ilmn?ID=256 Accessed October 14, 2008.

In Silico Biology, An International Journal on Computational Molecular Biology. 2008. http:// www.bioinfo.de/isb/aims.html Accessed February 17, 2009.

Johansson, I. 1959. Progeny testing methods in Europe. Page 706-713 Proc. in American Dairy Science Associations Meeting, University of Illinois, Urbana.

Kolbehdari, D., Z. Wang, J. R. Grant, B. Murdoch, A. Prasad, Z. Xiu, E. Marques, P. Stothard, and S. S. Moore. 2008. A whole-genome scan to map quantitative trait loci for confirmation and functional traits in Canadian Holstein bulls. J. Dairy Sci. 91:2844-2856.

Lambert, D. K. 2008. The expected utility of genetic information in beef cattle production. Agriculture Systems, 99:44-52.

Lande, R. and R. Thompson. 1990. Efficiency of marker-assisted selection in the improvement of quantitative traits. Genetics. 124:743-756. 
Lush, J. L. 1959. Improving dairy cattle by breeding. I. Current status and outlook. Page 702-706 in Proc. The American Dairy Science Association's Meeting, University of Illinois, Urbana.

McKay, S. D., R. D. Schnabel, B. M. Murdoc, L. K. Matukumalli, J. Aerts, W. Coppieters, D. Krews, E. D. Neto, C. A. Gill, C. Gao, H. Mannen, P. Stothard, Z. Wang, C. P. Van Tassell, J. L. Williams, J. F. Taylor, and S. S. Moore. 2007. Whole genome linkage disequilibrium maps in cattle. BMC Genet. doi:10.1186/1471-2156-8-74.

McKay, S. D., R. D. Schnabel, B. M. Murdoc, L. K. Matukumalli, J. Aerts, W. Coppieters, D. Krews, E. D. Neto, C. A. Gill, C. Gao, H. Mannen, Z. Wang, C. P. Van Tassell, J. L. Williams, J. F. Taylor, and S. S. Moore. 2008. An assessment of population structure in eight breeds of cattle using whole genome SNP panel. BMC Genet. doi:10.1186/14712156-9-37.

Makowski, D. 2008. Basic concepts illustrated with simple static model. http://www.modelia.org/html/081118_ModellingCoursePoland/pdf/2_UseSimpleModels _Makowski_20081118.pdf_Accessed May 15, 2008.

Meuwissen, T. H. E., B. J. Hayes, and M. E. Goddard. 2001. Prediction of total genetic value using genome-wide dense marker maps. Genetics. 157:1819-1829.

Meyer, C. L., P. J. Berger, K. J. Koehler, J. R. Thompson, and C. G. Sattler. 2001. Phenotypic trends in incidence of stillbirth for Holsteins in the United States. J. Dairy Sci. 84:515523. 
National Human Genome Research Institute. 2009. Online education kit: understanding the human genome project. http://www.genome.gov/25019887 Accessed December 20, 2008.

Norman, H. D., R. L. Powell and F. N. Dickinson. 1976. Modified contemporary and herd mate comparisons in sire summary. J. Dairy Sci. 59:2155-2161.

Pieppo, J., K. Vartia, K. Cananen-Anttila, M. Räty, K. Korhonen, T. Hurme, H. Myllymäki, A. Sairanen, and A. Mäki Tanila. 2008. Embryo production from superovulated HolsteinFriesian dairy heifers and cows after insemination with frozen-thawed sex-sorted exsperm atozoa or unsorted semen. Anim. Reprod. Sci. doi:10.1016/j.anireprosci.2008.02.002.

Powell, R. L. and H. D. Norman. 2006. Major advances in genetic evaluation techniques. J. Dairy Sci. 89:1337-1348.

Putnam, D. N., G. A. Bowling, and C. T. Conklin. 1943. The use of first records versus the average of all records in dam-daughter comparisons when proving sires. J. Dairy Sci. 26:959-965.

Rendel, J. M. and A. Robertson. 1950. The use of progeny testing with artificial insemination in dairy cattle. J. Genet. 50:21-31. 
Riguet, J., W. Coppieters, N. Cambisano, J. J. Arranz, P. Berzi, S. K. Davis, B. Grisart, F. Farnir, L. Karim, M. Mni, P. Simon, J. F. Taylor, P. Vanmanshoven, D. Wagenaar, J. E. Womack, and M. Georges. 1999. Fine-mapping of quantitative trait loci by identity by decent in outbred populations: application to milk production in dairy cattle. Proc. Natl. Acad. Science. U.S.A. 96:9252-9257.

Ron, M. and J. I. Weller. 2007. From QTL to QTN identification in livestock - winning by points rather than knock-out: a review. Animal Genet. 38:429-439.

Schaefer, L. R. 2006. Strategy for applying genome-wide selection in dairy cattle. J. Anim. Breed. Genet. 123:218-223.

Schrooten, C., H. Bovenhuis, G. A. M. van Arendonk and P. Bijma. 2005. Genetic progress in multistage dairy cattle breeding schemes using genetic markers. J. Dairy Sci. 88:15691581.

Seidel Jr., G. E. 2003. Economics for selecting for sex: the most important genetic trait. Theriogenology, 59:585-598.

Slatko, B. E., L. M. Albright, S. Tabor and J. Ju. 2001. DNA sequencing by the dideoxy method. Curr. Protoc. Mol. Biol. doi:10.1002/0471142727.mb0704as47.

Snelling, W. M., E. Casas, R. T. Stone, J. W. Keele, G. P. Harhey, G. L. Bennett, and T. P. L. Smith. 2005. Linkage mapping bovine EST-based SNP. BMC Genomics. doi:10.1186/1471-2164-6-74 
Sonstegard, T. 2008. Design and application of the bovine SNP50.

http://www.illumina.com/usermeeting/archive/Sonstegard_SanDiego_18April08.pdf. Accessed December 5, 2008.

Strandberg, E. and B. Malmfors. 2006. Compendium selection and genetic change. http://agtr.ilri.cgiar.org/Compendia/Doc/Comp\%20Selection.pdf Accessed Dec 3, 2008.

United States Department of Agriculture, Animal and Plant Health Inspection Service. 2007. Highlights of dairy 2007 part 1: reference of dairy cattle health and management practices in the United States, 2007. http://nahms.aphis.usda.gov Accessed November 22, 2008.

van der Beek, S. 2007. Effect of genomic selection on national and international genetic evaluations. Interbull Bull, 37:111-114.

VanRaden, P. M. 2004. Invited review: selection on net merit to improve lifetime profit. J. Dairy Sci. $87: 3125-3131$.

VanRaden, P. M. 2007. Efficient estimation of breeding values from dense genomic data. J. Dairy Sci. 90(Suppl. 1):374. (Abstract)

VanRaden, P. M. 2008a. Efficient methods to compute genomic predictions. J. Dairy Sci. 91:4414-4423.

VanRaden, P. M., C. P. Van Tassell, G. R. Wiggans, T. S. Sonstegard, R. D. Schnabel, and F. Schenkel. 2008b. Reliability of genomic predictions for North American dairy bulls. J. Dairy Sci., 91(Suppl. 1):305. (Abstract) 
VanRaden, P. M., C. P. Van Tassell, G. R. Wiggans, T. S. Sonstegard, R. D. Schnabel, J. F. Taylor, and F. Schenkel. 2008c. Genomic data and cooperation result in faster progress. Proc. Interbull Annual Meeting, Niagara Falls, New York.

VanRaden, P. M., G. R. Wiggans, C. P. Van Tassell, T. S. Sonstegard, and L. Walton. $2008 d$. Changes to evaluation system. http://aipl.arsusda.gov/reference/changes/eval0804.html Accessed November 23, 2008.

Van Vleck, L. D. 1963. Regression of records on herd mate averages. J. Dairy Sci. 46:846-849.

Van Vleck, L. D. and R. W. Everett. 1975. Genetic value of sex semen to produce dairy heifers. J. Dairy Sci. 59:1802-1807.

Voelker, D. E. 1981. Dairy herd improvement associations. J. Dairy Sci. 64:1269-1277.

Wiggans, G.R. and I. Misztal, 1987. Supercomputer for animal model evaluation of Ayrshire yield. J. Dairy Sci. 70:1906-1912.

Wiltshire, T., M. T. Pletcher, S. Batalov, S. W. Barnes, L. M. Tarantino, M. P. Cooke, H. Wu, K. Smylie, A. Santrosyan, N. G. Copeland, N. A. Jenkins, F. Calush, R. J. Mural, R. J. Glynne, S. A. Kay, M. D. Adams, and C. F. Fletcher. 2003. Genome-wide singlenucleotide polymorphism analysis defines haplotype patterns in mouse. Proc. Natl. Acad. Sci. U.S.A. 100:3380-3385.

Yalcin, B., J. Flint, R. Mott. 2005. Using progenitor strain information to identify quantitative trait nucleotides in outbred mice. Genetics Society of America. 171:673:681. 
APPENDICES 


\section{Appendix A}

R-commands to Compute Present Value of Total Marginal, Present Value of Cumulative Gross Marginal Returns, Present Value of $\Delta G$ and Present Value of Total Marginal Costs 
\#\#\#\#\#\#\#\#\#\#\#\#\#\#\#\#\#\#\#\#\#\#\#\#\#\#\#\#\#\#

P-matrix

\#\#\#\#\#\#\#\#\#\#\#\#\#\#\#\#\#\#\#\#\#\#\#\#\#\#\#\# -

p1 <- c $(1,0, .5, .5, .75, .5, .875, .75, .4375, .375, .3438, .1875, .1719, .0938, .0859, .0469, .0429, .0234, .0215, .0117)$

$\mathrm{p} 2<-\mathrm{c}(0,1,0, .5, .5, .75, .5, .875, .75, .4375, .375, .3438, .1875, .1719, .0938, .0859, .0469, .0429, .0234, .0215)$

p3 <- c $(0,0,1,0, .5, .5, .75, .5, .875, .75, .4375, .375, .3438, .1875, .1719, .0938, .0859, .0469, .0429, .0234)$

p4 <- c $(0,0,0,1,0, .5, .5, .75, .5, .875, .75, .4375, .375, .3438, .1875, .1719, .0938, .0859, .0469, .0429)$

p5 <- c $(0,0,0,0,1,0, .5, .5, .75, .5, .875, .75, .4375, .375, .3438, .1875, .1719, .0938, .0859, .0469)$

p6 <- c $(0,0,0,0,0,1,0, .5, .5, .75, .5, .875, .75, .4375, .375, .3438, .1875, .1719, .0938, .0859)$

p7 <- c( $0,0,0,0,0,0,1,0, .5, .5, .75, .5, .875, .75, .4375, .375, .3438, .1875, .1719, .0938)$

p8 <- c $(0,0,0,0,0,0,0,1,0, .5, .5, .75, .5, .875, .75, .4375, .375, .3438, .1875, .1719)$

p9 <- c $(0,0,0,0,0,0,0,0,1,0, .5, .5, .75, .5, .875, .75, .4375, .375, .3438, .1875)$

$\mathrm{p} 10<-\mathrm{c}(0,0,0,0,0,0,0,0,0,1,0, .5, .5, .75, .5, .875, .75, .4375, .375, .3438)$

$\mathrm{p} 11<-\mathrm{c}(0,0,0,0,0,0,0,0,0,0,1,0, .5, .5, .75, .5, .875, .75, .4375, .375)$

$\mathrm{p} 12<-\mathrm{c}(0,0,0,0,0,0,0,0,0,0,0,1,0, .5, .5, .75, .5, .875, .75, .4375)$

$\mathrm{p} 13<-\mathrm{c}(0,0,0,0,0,0,0,0,0,0,0,0,1,0, .5, .5, .75, .5, .875, .75)$

p14 <- c $(0,0,0,0,0,0,0,0,0,0,0,0,0,1,0, .5, .5, .75, .5, .875)$

$\mathrm{p} 15<-\mathrm{c}(0,0,0,0,0,0,0,0,0,0,0,0,0,0,1,0, .5, .5, .75, .5)$

p16 <- c $(0,0,0,0,0,0,0,0,0,0,0,0,0,0,0,1,0, .5, .5, .75)$

$\mathrm{p} 17<-\mathrm{c}(0,0,0,0,0,0,0,0,0,0,0,0,0,0,0,0,1,0, .5, .5)$ 


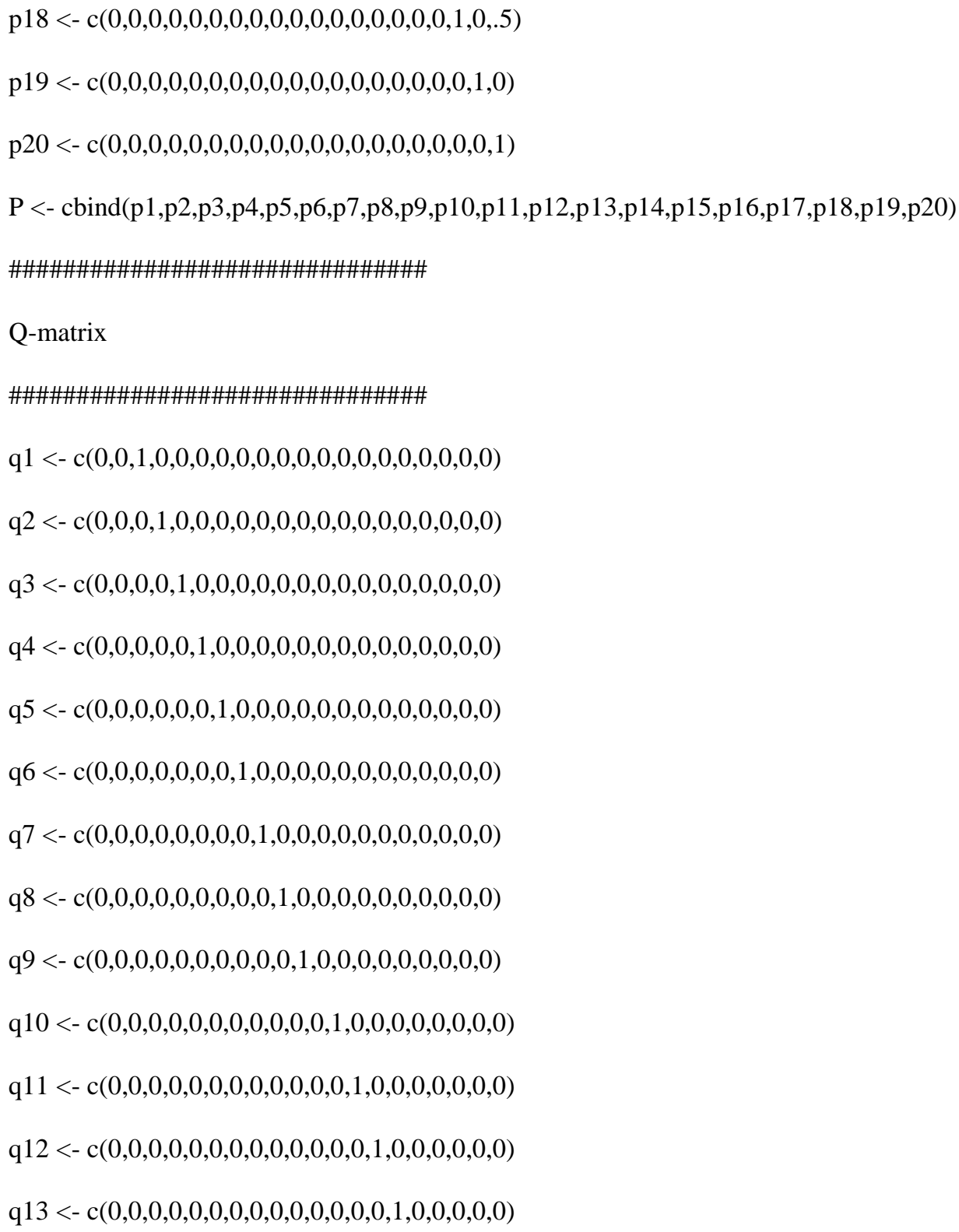


$\mathrm{q} 14<-\mathrm{c}(0,0,0,0,0,0,0,0,0,0,0,0,0,0,0,1,0,0,0,0)$

$\mathrm{q} 15<-\mathrm{c}(0,0,0,0,0,0,0,0,0,0,0,0,0,0,0,0,1,0,0,0)$

$\mathrm{q} 16<-\mathrm{c}(0,0,0,0,0,0,0,0,0,0,0,0,0,0,0,0,0,1,0,0)$

$\mathrm{q} 17<-\mathrm{c}(0,0,0,0,0,0,0,0,0,0,0,0,0,0,0,0,0,0,1,0)$

$\mathrm{q} 18<-\mathrm{c}(0,0,0,0,0,0,0,0,0,0,0,0,0,0,0,0,0,0,0,1)$

$\mathrm{q} 19<-\mathrm{c}(0,0,0,0,0,0,0,0,0,0,0,0,0,0,0,0,0,0,0,0)$

q20 <- c $(0,0,0,0,0,0,0,0,0,0,0,0,0,0,0,0,0,0,0,0)$

$\mathrm{Q}<-\operatorname{cbind}(\mathrm{q} 1, \mathrm{q} 2, \mathrm{q} 3, \mathrm{q} 4, \mathrm{q} 5, \mathrm{q} 6, \mathrm{q} 7, \mathrm{q} 8, \mathrm{q} 9, \mathrm{q} 10, \mathrm{q} 11, \mathrm{q} 12, \mathrm{q} 13, \mathrm{q} 14, \mathrm{q} 15, \mathrm{q} 16, \mathrm{q} 17, \mathrm{q} 18, \mathrm{q} 19, \mathrm{q} 20)$

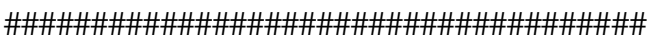

R-matrix

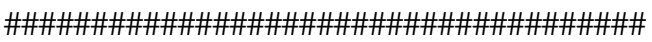

$\mathrm{R}<-\mathrm{P}-\mathrm{Q}$

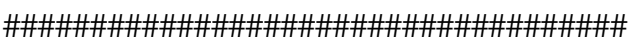

d-vector

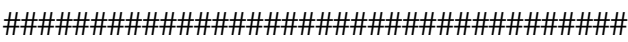

d1 <-(0.9523)

d2 <-(0.9069)

d3 <-(0.8636)

d4 <-(0.8224) 


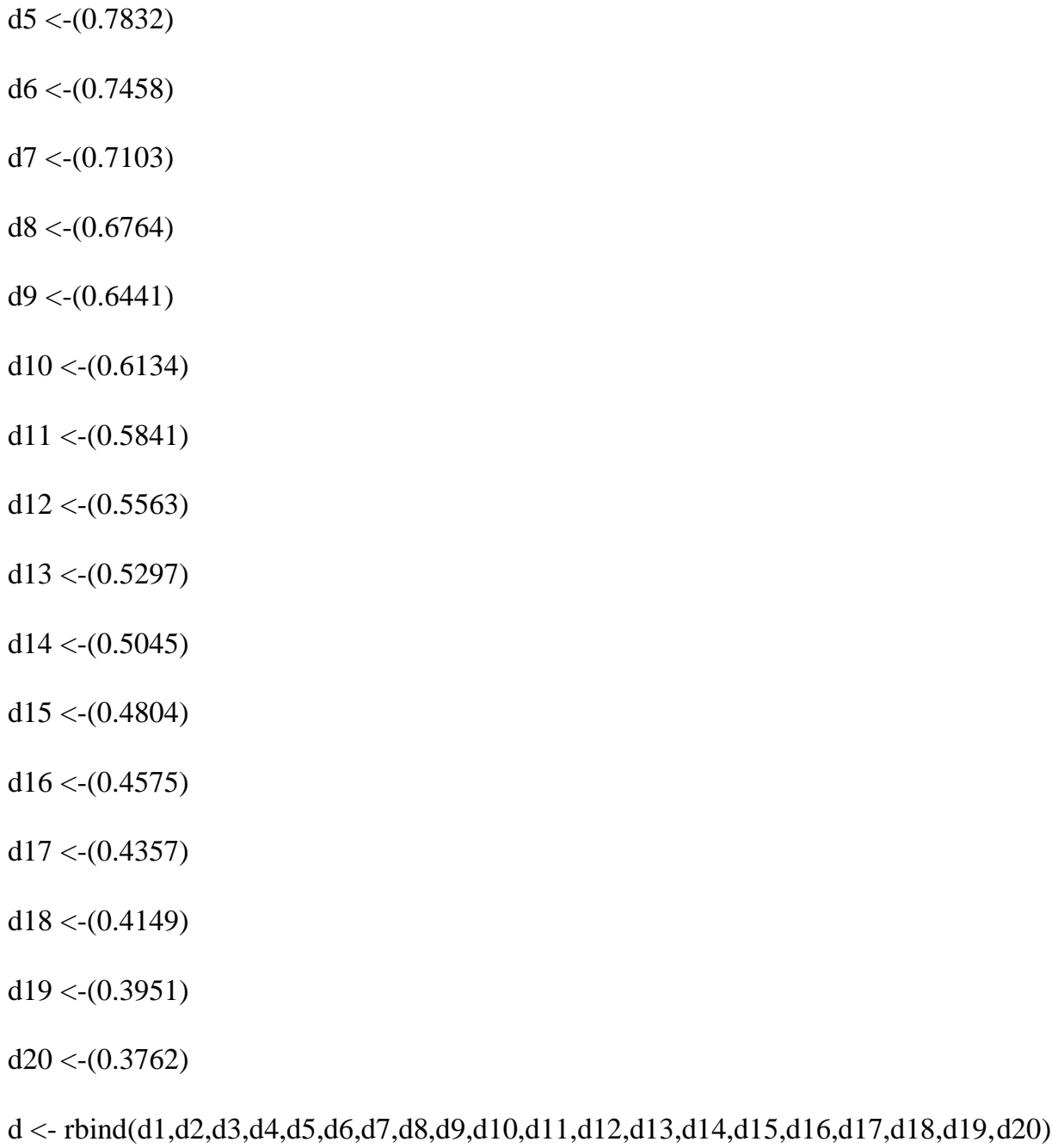




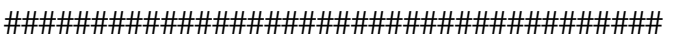

n-vector

\#\#\#\#\#\#\#\#\#\#\#\#\#\#\#\#\#\#\#\#\#\#\#\#\#\#\#\#\#\#\#\#\#

\#Heifers NS

HNS100 <- c(403,403,403,403,403,403,403,403,403,403,403,403,403,403,403,403,403,403,403,403)

HNS90 <- c(363,363,363,363,363,363,363,363,363,363,363,363,363,363,363,363,363,363,363,363)

\#Heifers SS

HSS90 <- c(363,363,363,363,363,363,363,363,363,363,363,363,363,363,363,363,363,363,363,363)

\#Heifers ETNS

HETNS23 <- c(363,363,363,363,363,363,363,363,363,363,363,363,363,363,363,363,363,363,363,363)

HETNS11 <- c(363,363,363,363,363,363,363,363,363,363,363,363,363,363,363,363,363,363,363,363)

\#Cows NS

CNS100 <- c(265,265,265,265,265,265,265,265,265,265,265,265,265,265,265,265,265,265,265,265)

\#Cows SS

CSS90 <- c(266,266,266,266,266,266,266,266,266,266,266,266,266,266,266,266,266,266,266,266)

\#Cows ETNS

CETNS42 <- c(403,403,403,403,403,403,403,403,403,403,403,403,403,403,403,403,403,403,403,403)

CETNS21 <- c(403,403,403,403,403,403,403,403,403,403,403,403,403,403,403,403,403,403,403,403) 
\#\#\#\#\#\#\#\#\#\#\#\#\#\#\#\#\#\#\#\#\#\#\#\#\#\#\#\#\#\#\#\#\#

v-vector

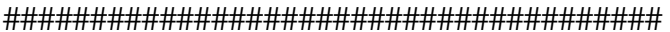

\#Heifers NS

HNS100.35 <- c $(0,0,0,0,0,0,0,0,0,0,0,0,0,0,0,0,0,0,0,0)$

HNS90.35 <- c(3.61,3.61,3.61,3.61,3.61,3.61,3.61,3.61,3.61,3.61,3.61,3.61,3.61,3.61,3.61,3.61,3.61, 3.61,3.61,3.61)

HNS100.53 <- c $(0,0,0,0,0,0,0,0,0,0,0,0,0,0,0,0,0,0,0,0)$

HNS90.53 <- c(5.41,5.41,5.41,5.41,5.41,5.41,5.41,5.41,5.41,5.41,5.41,5.41,5.41,5.41,5.41,5.41,5.41, 5.41,5.41,5.41)

HNS100.85 <- c $(0,0,0,0,0,0,0,0,0,0,0,0,0,0,0,0,0,0,0,0)$

HNS90.85 <- c(15.75,15.75,15.75,15.75,15.75,15.75,15.75,15.75,15.75,15.75,15.75,15.75,15.75,15.75,

$15.75,15.75,15.75,15.75,15.75,15.75)$

\#Heifers SS

HSS90.35 <- c(3.61,3.61,3.61,3.61,3.61,3.61,3.61,3.61,3.61,3.61,3.61,3.61,3.61,3.61,3.61,3.61,3.61,

$3.61,3.61,3.61)$

HSS90.53 <- c(5.41,5.41,5.41,5.41,5.41,5.41,5.41,5.41,5.41,5.41,5.41,5.41,5.41,5.41,5.41,5.41,5.41,

$5.41,5.41,5.41)$

HSS90.85 <- c( $15.75,15.75,15.75,15.75,15.75,15.75,15.75,15.75,15.75,15.75,15.75,15.75,15.75,15.75$

$15.75,15.75,15.75,15.75,15.75,15.75)$

\#Heifers ETNS

HETNS23.35 <- c(44.02,44.02,44.02,44.02,44.02,44.02,44.02,44.02,44.02,44.02,44.02,44.02,44.02,44.02,44.02,44.02,44.02,44.02,44.02,44.02) 
HETNS11.35 <- c(57.03,57.03,57.03,57.03,57.03,57.03,57.03,57.03,57.03,57.03,57.03,57.03,57.03,57.03,57.03,57.03,57.03,57.03,57.03,57.03)

HETNS23.53 <- c(66.66,66.66,66.66,66.66,66.66,66.66,66.66,66.66,66.66,66.66,66.66,66.66,66.66,66.66,66.66,66.66,66.66,66.66,66.66,66.66)

HETNS11.53 <- c $(86.35,86.35,86.35,86.35,86.35,86.35,86.35,86.35,86.35,86.35,86.35,86.35,86.35,86.35,86.35,86.35,86.35,86.35,86.35,86.35)$

HETNS23.85 <-

c(106.91,106.91,106.91,106.91,106.91,106.91,106.91,106.91,106.91,106.91,106.91,106.91,106.91,106.91,106.91,106.91,106.91,106.91,106.91,106.91)

HETNS11.85 <- c(138.38,138.38,138.38,138.38,138.38,138.38,138.38,138.38,138.38,138.38,138.38,138.38,138.38,138.38,138.38,138.38,138.38,138.38,

$138.38,138.38)$

\#Cows NS

CNS100.35 - $-c(0,0,0,0,0,0,0,0,0,0,0,0,0,0,0,0,0,0,0,0)$

CNS100.53 <- c $(0,0,0,0,0,0,0,0,0,0,0,0,0,0,0,0,0,0,0,0)$

CNS100.85 <- c $(0,0,0,0,0,0,0,0,0,0,0,0,0,0,0,0,0,0,0,0)$

\#Cows ETNS

CETNS42.35 <- c(20.70,20.70,20.70,20.70,20.70,20.70,20.70,20.70,20.70,20.70,20.70,20.70,20.70,20.70,20.70,20.70,20.70,20.70,20.70,20.70)

CETNS42.53 <- c(31.35,31.35,31.35,31.35,31.35,31.35,31.35,31.35,31.35,31.35,31.35,31.35,31.35,31.35,31.35,31.35,31.35,31.35,31.35,31.35)

CETNS42.85 <- c(50.27,50.27,50.27,50.27,50.27,50.27,50.27,50.27,50.27,50.27,50.27,50.27,50.27,50.27,50.27,50.27,50.27,50.27,50.27,50.27)

CETNS21.35 <- c(30.46,30.46,30.46,30.46,30.46,30.46,30.46,30.46,30.46,30.46,30.46,30.46,30.46,30.46,30.46,30.46,30.46,30.46,30.46,30.46)

CETNS21.53 <- c(46.13,46.13,46.13,46.13,46.13,46.13,46.13,46.13,46.13,46.13,46.13,46.13,46.13,46.13,46.13,46.13,46.13,46.13,46.13,46.13)

CETNS21.85 <- c(73.98,73.98,73.98,73.98,73.98,73.98,73.98,73.98,73.98,73.98,73.98,73.98,73.98,73.98,73.98,73.98,73.98,73.98,73.98,73.98) 
\#\#\#\#\#\#\#\#\#\#\#\#\#\#\#\#\#\#\#\#\#\#\#\#\#\#\#\#\#\#\#\#\#

w-vector

\#\#\#\#\#\#\#\#\#\#\#\#\#\#\#\#\#\#\#\#\#\#\#\#\#\#\#\#\#\#\#\#\#\#\#\#

wHNS100.35 <- HNS100*HNS100.35

wHNS100.53 <- HNS100*HNS100.53

wHNS100.85 <- HNS100*HNS100.85

wHNS90.35 <- HNS90*HNS90.35

wHNS90.53 <- HNS90*HNS90.53

wHNS90.85 <- HNS90*HNS90.85

wHSS90.35 <- HSS90*HSS90.35

wHSS90.53 <- HSS90*HSS90.53

wHSS90.85 <- HSS90*HSS90.85

wHETNS23.35 <- HETNS23*HETNS23.35

wHETNS23.53 <- HETNS23*HETNS23.53

wHETNS23.85 <- HETNS23*HETNS23.85

wHETNS11.35 <- HETNS11*HETNS11.35

wHETNS11.53 <- HETNS11*HETNS11.53 
wHETNS11.85 <- HETNS11*HETNS11.85

wCNS100.35 <- CNS100*CNS100.35

wCNS100.53 <- CNS100*CNS100.53

wCNS100.85 <- CNS100*CNS100.85

wCETNS42.35 <- CETNS42*CETNS42.35

wCETNS42.53 <- CETNS42 2 CETNS42.53

wCETNS42.85 <- CETNS42*CETNS42.85

wCETNS21.35 <- CETNS2 $1 *$ CETNS21.35

wCETNS21.53 <- CETNS2 $1 *$ CETNS21.53

wCETNS21.85 <- CETNS2 1 *CETNS21.85

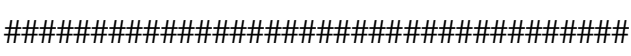

$\mathrm{d} X \mathrm{w}$

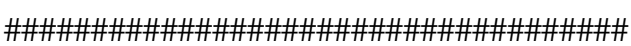

HNS100.35dw <- d*(wHNS100.35)

HNS100.53dw <- d*(wHNS100.53)

HNS100.85dw <- d*(wHNS100.85) 
HNS $90.35 \mathrm{dw}<-\mathrm{d}^{*}($ wHNS 90.35$)$

HNS90.53dw <- d*(wHNS90.53)

HNS $90.85 \mathrm{dw}<-\mathrm{d}^{*}($ wHNS 90.85$)$

HSS $90.35 \mathrm{dw}<-\mathrm{d} *($ wHSS 90.35$)$

HSS90.53dw <- d*(wHSS90.53)

HSS $90.85 \mathrm{dw}<-\mathrm{d}^{*}($ wHSS 90.85$)$

HETNS23.35dw <- d*(wHETNS23.35)

HETNS23.53dw <- d*(wHETNS23.53)

HETNS23.85dw <- d*(wHETNS23.85)

HETNS11.35dw <- d*(wHETNS11.35)

HETNS11.53dw <- d*(wHETNS11.53)

HETNS11.85dw <- d*(wHETNS11.85)

CNS100.35dw <- d*(wCNS100.35)

CNS100.53dw <- d*(wCNS100.53)

CNS100.85dw <- d*(wCNS100.85)

CETNS42.35dw <- d*(wCETNS42.35) 
CETNS42.53dw <- d*(wCETNS42.53)

CETNS42.85dw <- d*(wCETNS42.85)

CETNS21.35dw <- d*(wCETNS21.35)

CETNS21.53dw <- d*(wCETNS21.53)

CETNS21.85dw <- d*(wCETNS21.85)

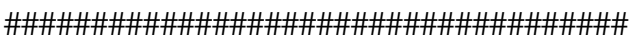

Annual Y

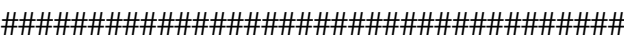

yHNS100.35 <- R\%*\%HNS100.35dw

yHNS100.53 <- R\%*\%HNS100.53dw

yHNS100.85 <- R\%*\%HNS100.85dw

yHNS90.35 <- R\%*\%HNS90.35dw

yHNS90.53 <- R\%*\%HNS90.53dw

yHNS90.85 <- R\%*\%HNS90.85dw

yHSS90.35 <- R\%*\%HSS90.35dw

yHSS90.53 <- R\%*\%HSS90.53dw

yHSS90.85 <- R\%*\%HSS90.85dw 
yHETNS23.35 <- R\%*\%HETNS23.35dw yHETNS23.53 <- R\%*\%HETNS23.53dw yHETNS23.85 <- R\%*\%HETNS23.85dw yHETNS11.35 <- R\%*\%HETNS11.35dw yHETNS11.53 <- R\%*\%HETNS11.53dw yHETNS11.85 <- R\%*\%HETNS11.85dw

$\mathrm{yCNS} 100.35<-\mathrm{R} \% * \% \mathrm{CNS} 100.35 \mathrm{dw}$ $\mathrm{yCNS} 100.53<-\mathrm{R} \% * \% \mathrm{CNS} 100.53 \mathrm{dw}$ $\mathrm{yCNS} 100.85<-\mathrm{R} \% * \% \mathrm{CNS} 100.85 \mathrm{dw}$

yCETNS42.35 <- R\%*\%CETNS42.35dw yCETNS42.53 <- R\%*\%CETNS42.53dw yCETNS42.85 <- R\%*\%CETNS42.85dw yCETNS21.35 <- R\%*\%CETNS21.35dw yCETNS21.53 <- R\%*\%CETNS21.53dw yCETNS21.85 <- R\%*\%CETNS21.85dw 
\#\#\#\#\#\#\#\#\#\#\#\#\#\#\#\#\#\#\#\#\#\#\#\#\#\#\#\#\#

Cumulative $Y$

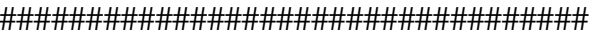

cumsum(yHNS100.35)

cumsum(yHNS100.53)

cumsum(yHNS100.85)

cumsum(yHNS90.35)

cumsum(yHNS90.53)

cumsum(yHNS90.85)

cumsum(yHSS90.35)

cumsum(yHSS90.53)

cumsum(yHSS90.85)

cumsum(yHETNS23.35)

cumsum(yHETNS23.53)

cumsum(yHETNS23.85)

cumsum(yHETNS11.35)

cumsum(yHETNS11.53) 
cumsum(yHETNS11.85)

cumsum(yCNS100.35)

cumsum(yCNS100.53)

cumsum(yCNS100.85)

cumsum(yCETNS42.35)

cumsum(yCETNS42.53)

cumsum(yCETNS42.85)

cumsum(yCETNS21.35)

cumsum(yCETNS21.53)

cumsum(yCETNS21.85)

\#\#\#\#\#\#\#\#\#\#\#\#\#\#\#\#\#\#\#\#\#\#\#\#\#\#\#\#\#\#\#

PRESENT VALUE OF DELTA G

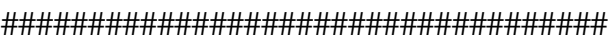

gHNS100 <- c $(0,0,0,0,0,0,0,0,0,0,0,0,0,0,0,0,0,0,0,0)$

gHNSS90.35 <- c(3.61,3.61,3.61,3.61,3.61,3.61,3.61,3.61,3.61,3.61,3.61,3.61,3.61,3.61,3.61,3.61,3.61,3.61,3.61,3.61)

gHNSS90.53 <- c(5.47,5.47,5.47,5.47,5.47,5.47,5.47,5.47,5.47,5.47,5.47,5.47,5.47,5.47,5.47,5.47,5.47,5.47,5.47,5.47) 
gHNSS90.85 <- c $(8.77,8.77,8.77,8.77,8.77,8.77,8.77,8.77,8.77,8.77,8.77,8.77,8.77,8.77,8.77,8.77,8.77,8.77,8.77,8.77)$

gHETNS23.35 <- c(44.02,44.02,44.02,44.02,44.02,44.02,44.02,44.02,44.02,44.02,44.02,44.02,44.02,44.02,44.02,44.02,44.02,44.02,44.02,44.02)

gHETNS23.53 <- c(66.66,66.66,66.66,66.66,66.66,66.66,66.66,66.66,66.66,66.66,66.66,66.66,66.66,66.66,66.66,66.66,66.66,66.66,66.66,66.66) gHETNS23.85 <- c(106.91,106.91,106.91,106.91,106.91,106.91,106.91,106.91,106.91,106.91,106.91,106.91,106.91,106.91,106.91,106.91,106.91,106.91, $106.91,106.91)$

gHETNS11.35 <- c(57.03,57.03,57.03,57.03,57.03,57.03,57.03,57.03,57.03,57.03,57.03,57.03,57.03,57.03,57.03,57.03,57.03,57.03,57.03,57.03) gHETNS11.53 <- c(86.35,86.35,86.35,86.35,86.35,86.35,86.35,86.35,86.35,86.35,86.35,86.35,86.35,86.35,86.35,86.35,86.35,86.35,86.35,86.35) gHETNS11.85 <- c(138.48,138.48,138.48,138.48,138.48,138.48,138.48,138.48,138.48,138.48,138.48,138.48,138.48,138.48,138.48,138.48,138.48,138.48, $138.48,138.48)$

$\mathrm{gCNS} 100<-\mathrm{c}(0,0,0,0,0,0,0,0,0,0,0,0,0,0,0,0,0,0,0,0)$

gCETNS42.35 <- c(20.70,20.70,20.70,20.70,20.70,20.70,20.70,20.70,20.70,20.70,20.70,20.70,20.70,20.70,20.70,20.70,20.70,20.70,20.70,20.70) gCETNS42.53 <- c(31.35,31.35,31.35,31.35,31.35,31.35,31.35,31.35,31.35,31.35,31.35,31.35,31.35,31.35,31.35,31.35,31.35,31.35,31.35,31.35) gCETNS42.85 <- c $(50.27,50.27,50.27,50.27,50.27,50.27,50.27,50.27,50.27,50.27,50.27,50 \cdot 27,50 \cdot 27,50.27,50.27,50.27,50.27,50.27,50.27,50.27)$ gCETNS21.35 <- c(30.46,30.46,30.46,30.46,30.46,30.46,30.46,30.46,30.46,30.46,30.46,30.46,30.46,30.46,30.46,30.46,30.46,30.46,30.46,30.46) gCETNS21.53 <- c(46.13,46.13,46.13,46.13,46.13,46.13,46.13,46.13,46.13,46.13,46.13,46.13,46.13,46.13,46.13,46.13,46.13,46.13,46.13,46.13) gCETNS21.85 <- c(73.98,73.98,73.98,73.98,73.98,73.98,73.98,73.98,73.98,73.98,73.98,73.98,73.98,73.98,73.98,73.98,73.98,73.98,73.98,73.98)

dgHNS100 <- gHNS100*d

dgHNSS90.35 <- gHNSS90.35*d

dgHNSS90.53 <- gHNSS90.53*d 
dgHNSS90.85 <- gHNSS90.85*d

dgHETNS23.35 <- gHETNS23.35*d

dgHETNS23.53 <- gHETNS23.53*d

dgHETNS23.85 <- gHETNS23.85*d

dgHETNS11.35 <- gHETNS11.35*d

dgHETNS11.53 <- gHETNS11.53*d

dgHETNS11.85 <- gHETNS11.85*d

$\operatorname{dgCNS} 100<-$ gCNS100*d

dgCETNS42.35 <- gCETNS42.35*d

dgCETNS42.53 <- gCETNS42.53*d

dgCETNS42.85 <- gCETNS42.85*d

dgCETNS21.35 <- gCETNS21.35*d

dgCETNS21.53 <- gCETNS21.53*d

$\operatorname{dgCETNS21.85<-~gCETNS21.85*d~}$

cumsum(dgHNS100)

cumsum(dgHNSS90.35)

cumsum(dgHNSS90.53)

cumsum(dgHNSS90.85)

cumsum(dgHETNS23.35) 
cumsum(dgHETNS23.53)

cumsum(dgHETNS23.85)

cumsum(dgHETNS11.35)

cumsum(dgHETNS11.53)

cumsum(dgHETNS11.85)

cumsum(dgCNS100)

cumsum(dgCETNS42.35)

cumsum(dgCETNS42.53)

cumsum(dgCETNS42.85)

cumsum(dgCETNS21.35)

cumsum(dgCETNS21.53)

cumsum(dgCETNS21.85)

\#\#\#\#\#\#\#\#\#\#\#\#\#\#\#\#\#\#\#\#\#\#\#\#\#\#\#\#\#

PRESENT VALUE OF COSTS

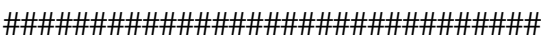

CHNS100 <- c(20160,20160,20160,20160,20160,20160,20160,20160,20160,20160,20160,20160,20160,20160,20160, 20160,20160,20160,20160,20160)

CHNS90 <- c(118900,118900,118900,118900,118900,118900,118900,118900,118900,118900,118900,118900,118900,118900,118900,118900,118900,

$118900,118900,118900)$ 
CHSS90 <- c(197550,197550,197550,197550,197550,197550,197550,197550,197550,197550,197550,197550,197550,197550,197550,197550,197550, $197550,197550,197550)$

CHETNS23 <- c(173957.36,173957.36,173957.36,173957.36,173957.36,173957.36,173957.36,173957.36,173957.36,173957.36,173957.36,173957.36, $173957.36,173957.36,173957.36,173957.36,173957.36,173957.36,173957.36,173957.36)$

CHETNS11 <- c(183064.46,183064.46,183064.46,183064.46,183064.46,183064.46,183064.46,183064.46,183064.46,183064.46,183064.46,183064.46,183064.46, $183064.46,183064.46,183064.46,183064.46,183064.46,183064.46,183064.46)$

CCNS100 <- c(23460,23460,23460,23460,23460,23460,23460,23460,23460,23460,23460,23460,23460,23460,23460, 23460,23460,23460,23460,23460) CCETNS42 <- c(165709.14,165709.14,165709.14,165709.14,165709.14,165709.14,165709.14,165709.14,165709.14,165709.14,165709.14,165709.14, $165709.14,165709.14,165709.14,165709.14,165709.14,165709.14,165709.14,165709.14)$

CCETNS21 <- c(165709.14,165709.14,165709.14,165709.14,165709.14,165709.14,165709.14,165709.14,165709.14,165709.14,165709.14,165709.14, $165709.14,165709.14,165709.14,165709.14,165709.14,165709.14,165709.14,165709.14)$

\author{
dCHNS100 <- CHNS100*d \\ dCHNS90 <- CHNS90*d \\ dCHSS90 <- CHSS90*d \\ dCHETNS23 <- CHETNS23*d \\ dCHETNS11 <- CHETNS11*d \\ dCCNS100 <- CCNS100*d \\ dCCETNS42 <- CCETNS42*d \\ dCCETNS2 1 <- CCETNS21*d
}


cumsum(dCHNS100)

cumsum(dCHNS90)

cumsum(dCHSS90)

cumsum(dCHETNS23)

cumsum(dCHETNS11)

cumsum(dCCNS100)

cumsum(dCCETNS42)

cumsum(dCCETNS21) 


\section{Appendix B}

Present Value of Total Marginal Costs (annual) and Present Value of Total Gross Marginal Returns (cumulative) for each Genetic Improvement Strategy 


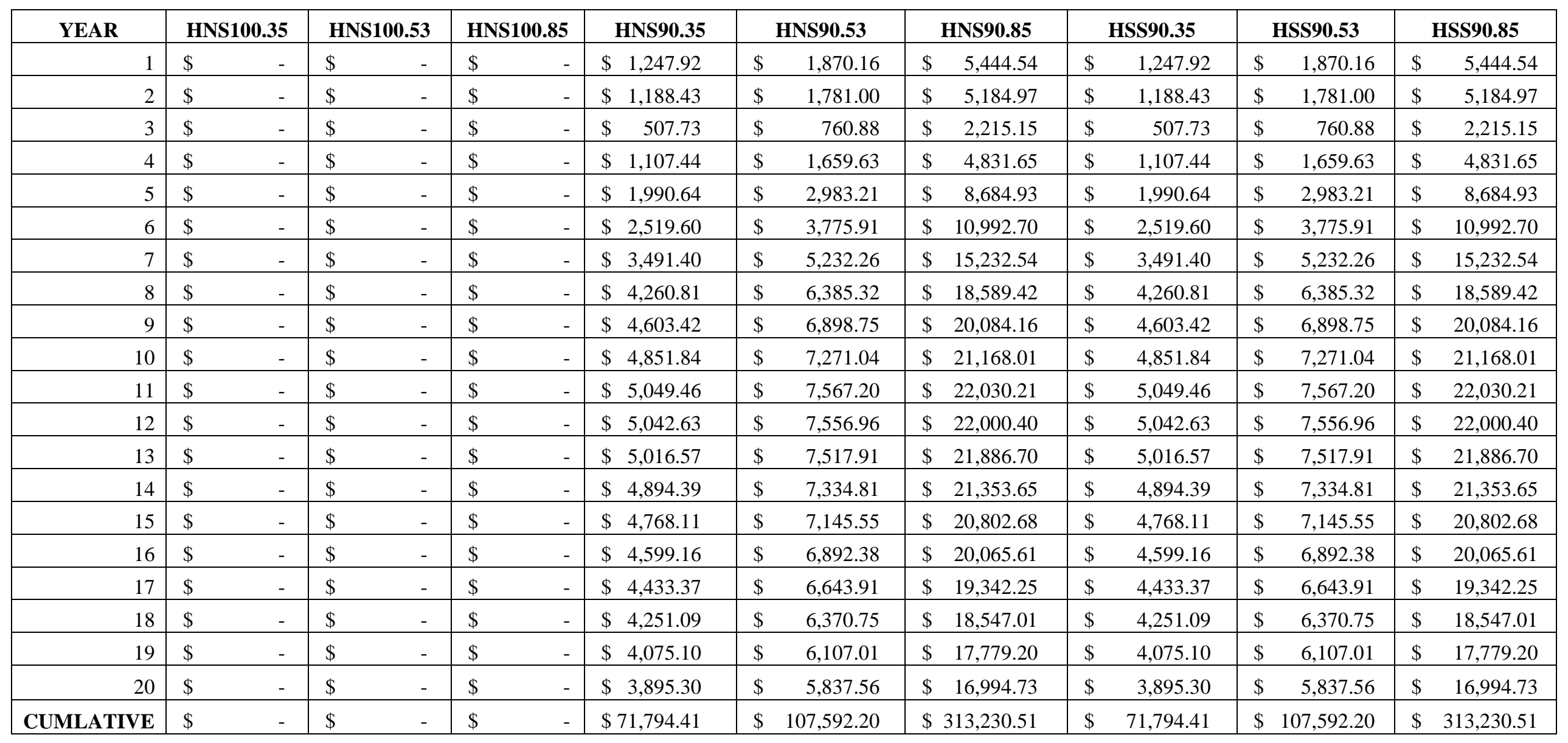




\begin{tabular}{|c|c|c|c|c|c|c|c|c|c|c|c|c|}
\hline YEAR & \multicolumn{2}{|c|}{ HETNS23.35 } & \multicolumn{2}{|c|}{ HETNS23.53 } & \multicolumn{2}{|c|}{ HETNS23.85 } & \multicolumn{2}{|c|}{ HETNS11.35 } & \multicolumn{2}{|c|}{ HETNS11.53 } & \multicolumn{2}{|c|}{ HETNS11.85 } \\
\hline 1 & $\$$ & $15,217.05$ & $\$$ & $23,043.36$ & $\$$ & $36,957.17$ & $\$$ & $19,714.41$ & $\$$ & $29,849.89$ & $\$$ & $47,835.88$ \\
\hline 2 & $\$$ & $14,491.59$ & $\$$ & $21,944.79$ & $\$$ & $35,195.27$ & $\$$ & $18,774.54$ & $\$$ & $28,426.83$ & $\$$ & $45,555.35$ \\
\hline 3 & $\$$ & $6,191.16$ & $\$$ & $9,375.35$ & $\$$ & $15,036.29$ & $\$$ & $8,020.95$ & $\$$ & $12,144.64$ & $\$$ & $19,462.37$ \\
\hline 4 & $\$$ & $13,504.07$ & $\$$ & $20,449.38$ & $\$$ & $32,796.92$ & $\$$ & $17,495.17$ & $\$$ & $26,489.70$ & $\$$ & $42,451.01$ \\
\hline 5 & $\$$ & $24,273.69$ & $\$$ & $36,757.94$ & $\$$ & $58,952.76$ & $\$$ & $31,447.72$ & $\$$ & $47,615.48$ & $\$$ & $76,306.08$ \\
\hline 6 & $\$$ & $30,723.72$ & $\$$ & $46,525.29$ & $\$$ & $74,617.75$ & $\$$ & $39,804.04$ & $\$$ & $60,267.91$ & $\$$ & $96,582.21$ \\
\hline 7 & $\$$ & $42,573.74$ & $\$$ & $64,469.92$ & $\$$ & $103,397.52$ & $\$$ & $55,156.20$ & $\$$ & $83,513.01$ & $\$$ & $133,833.59$ \\
\hline 8 & $\$$ & $51,955.97$ & $\$$ & $78,677.52$ & $\$$ & $126,183.83$ & $\$$ & $67,311.42$ & $\$$ & $101,917.25$ & $\$$ & $163,327.27$ \\
\hline 9 & $\$$ & $56,133.64$ & $\$$ & $85,003.83$ & $\$$ & $136,330.03$ & $\$$ & $72,723.80$ & $\$$ & $110,112.22$ & $\$$ & $176,460.10$ \\
\hline 10 & $\$$ & $59,162.91$ & $\$$ & $89,591.09$ & $\$$ & $143,687.11$ & $\$$ & $76,648.36$ & $\$$ & $116,054.46$ & $\$$ & $185,982.82$ \\
\hline 11 & $\$$ & $61,572.70$ & $\$$ & $93,240.25$ & $\$$ & $149,539.68$ & $\$$ & $79,770.35$ & $\$$ & $120,781.51$ & $\$$ & $193,558.14$ \\
\hline 12 & $\$$ & $61,489.37$ & $\$$ & $93,114.07$ & $\$$ & $149,337.31$ & $\$$ & $79,662.39$ & $\$$ & $120,618.06$ & $\$$ & $193,296.20$ \\
\hline 13 & $\$$ & $61,171.60$ & $\$$ & $92,632.87$ & $\$$ & $148,565.56$ & $\$$ & $79,250.71$ & $\$$ & $119,994.72$ & $\$$ & $192,297.27$ \\
\hline 14 & $\$$ & $59,681.75$ & $\$$ & $90,376.76$ & $\$$ & $144,947.19$ & $\$$ & $77,320.53$ & $\$$ & $117,072.21$ & $\$$ & $187,613.81$ \\
\hline 15 & $\$$ & $58,141.82$ & $\$$ & $88,044.84$ & $\$$ & $141,207.23$ & $\$$ & $75,325.49$ & $\$$ & $114,051.49$ & $\$$ & $182,772.96$ \\
\hline 16 & $\$$ & $56,081.78$ & $\$$ & $84,925.29$ & $\$$ & $136,204.06$ & $\$$ & $72,656.60$ & $\$$ & $110,010.48$ & $\$$ & $176,297.05$ \\
\hline 17 & $\$$ & $54,060.05$ & $\$$ & $81,863.77$ & $\$$ & $131,293.96$ & $\$$ & $70,037.36$ & $\$$ & $106,044.65$ & $\$$ & $169,941.62$ \\
\hline 18 & $\$$ & $51,837.42$ & $\$$ & $78,498.02$ & $\$$ & $125,895.93$ & $\$$ & $67,157.84$ & $\$$ & $101,684.72$ & $\$$ & $162,954.63$ \\
\hline 19 & $\$$ & $49,691.44$ & $\$$ & $75,248.33$ & $\$$ & $120,684.06$ & $\$$ & $64,377.62$ & $\$$ & $97,475.15$ & $\$$ & $156,208.59$ \\
\hline 20 & $\$$ & $47,498.94$ & $\$$ & $71,928.20$ & $\$$ & $115,359.20$ & $\$$ & $61,537.13$ & $\$$ & $93,174.32$ & $\$$ & $149,316.20$ \\
\hline CUMULATIVE & $\$$ & $875,454.41$ & $\$$ & $1,325,710.87$ & $\$$ & $2,126,188.83$ & $\$$ & $1,134,192.63$ & $\$$ & $1,717,298.70$ & $\$$ & $2,752,053.15$ \\
\hline
\end{tabular}




\begin{tabular}{|r|rr|rr|rr|}
\hline YEAR & \multicolumn{2}{|c|}{ CNS100.35 } & \multicolumn{2}{|c|}{ CNS100.53 } & \multicolumn{2}{|c|}{ CNS100.85 } \\
\hline 1 & $\$$ & - & $\$$ & - & $\$$ & - \\
\hline 2 & $\$$ & - & $\$$ & - & $\$$ & - \\
\hline 3 & $\$$ & - & $\$$ & - & $\$$ & - \\
\hline 4 & $\$$ & - & $\$$ & - & $\$$ & - \\
\hline 5 & $\$$ & - & $\$$ & - & $\$$ & - \\
\hline 6 & $\$$ & - & $\$$ & - & $\$$ & - \\
\hline 7 & $\$$ & - & $\$$ & - & $\$$ & - \\
\hline 8 & $\$$ & - & $\$$ & - & $\$$ & - \\
\hline 9 & $\$$ & - & $\$$ & - & $\$$ & - \\
\hline 10 & $\$$ & - & $\$$ & - & $\$$ & - \\
\hline 11 & $\$$ & - & $\$$ & - & $\$$ & - \\
\hline 12 & $\$$ & - & $\$$ & - & $\$$ & - \\
\hline 13 & $\$$ & - & $\$$ & - & $\$$ & - \\
\hline 14 & $\$$ & - & $\$$ & - & $\$$ & - \\
\hline 15 & $\$$ & - & $\$$ & - & $\$$ & - \\
\hline 16 & $\$$ & - & $\$$ & - & $\$$ & - \\
\hline 17 & $\$$ & - & $\$$ & - & $\$$ & - \\
\hline 18 & $\$$ & - & $\$$ & - & $\$$ & - \\
\hline 19 & $\$$ & - & $\$$ & - & $\$$ & - \\
\hline 20 & $\$$ & - & $\$$ & - & $\$$ & - \\
\hline & & & & $\$$ & - \\
\hline
\end{tabular}




\begin{tabular}{|c|c|c|c|c|c|c|c|c|c|c|c|c|}
\hline \multirow{2}{*}{$\begin{array}{ll}\text { YEAR } & \\
& 1\end{array}$} & \multicolumn{2}{|c|}{ CETNS42.35 } & \multicolumn{2}{|c|}{ CETNS42.53 } & \multicolumn{2}{|c|}{ CETNS42.85 } & \multicolumn{2}{|c|}{ CETNS21.35 } & \multicolumn{2}{|c|}{ CETNS21.53 } & \multicolumn{2}{|c|}{ CETNS21.85 } \\
\hline & $\$$ & $7,944.18$ & $\$$ & $12,031.41$ & $\$$ & $19,292.47$ & $\$$ & $11,689.84$ & $\$$ & $17,703.63$ & $\$$ & $28,391.82$ \\
\hline 2 & $\$$ & $7,565.45$ & $\$$ & $11,457.82$ & $\$$ & $18,372.72$ & $\$$ & $11,132.54$ & $\$$ & $16,859.63$ & $\$$ & $27,038.26$ \\
\hline 3 & $\$$ & $3,232.15$ & $\$$ & $4,895.06$ & $\$$ & $7,849.28$ & $\$$ & $4,756.10$ & $\$$ & $7,202.85$ & $\$$ & $11,551.41$ \\
\hline 4 & $\$$ & $7,049.91$ & $\$$ & $10,677.04$ & $\$$ & $17,120.72$ & $\$$ & $10,373.92$ & $\$$ & $15,710.74$ & $\$$ & $25,195.76$ \\
\hline 5 & $\$$ & $12,672.28$ & $\$$ & $19,192.07$ & $\$$ & $30,774.65$ & $\$$ & $18,647.22$ & $\$$ & $28,240.20$ & $\$$ & $45,289.61$ \\
\hline 6 & $\$$ & $16,039.56$ & $\$$ & $24,291.80$ & $\$$ & $38,952.12$ & $\$$ & $23,602.18$ & $\$$ & $35,744.21$ & $\$$ & $57,324.01$ \\
\hline 7 & $\$$ & $22,225.96$ & $\$$ & $33,661.06$ & $\$$ & $53,975.80$ & $\$$ & $32,705.45$ & $\$$ & $49,530.61$ & $\$$ & $79,433.65$ \\
\hline 8 & $\$$ & $27,124.03$ & $\$$ & $41,079.14$ & $\$$ & $65,870.76$ & $\$$ & $39,912.94$ & $\$$ & $60,445.96$ & $\$$ & $96,938.91$ \\
\hline 9 & $\$$ & $29,305.02$ & $\$$ & $44,382.23$ & $\$$ & $71,167.30$ & $\$$ & $43,122.26$ & $\$$ & $65,306.30$ & $\$$ & $104,733.58$ \\
\hline 10 & $\$$ & $30,886.47$ & $\$$ & $46,777.33$ & $\$$ & $75,007.86$ & $\$$ & $45,449.36$ & $\$$ & $68,830.57$ & $\$$ & $110,385.55$ \\
\hline 11 & $\$$ & $32,144.52$ & $\$$ & $48,682.64$ & $\$$ & $78,063.03$ & $\$$ & $47,300.58$ & $\$$ & $71,634.13$ & $\$$ & $114,881.70$ \\
\hline 12 & $\$$ & $32,101.01$ & $\$$ & $48,616.75$ & $\$$ & $77,957.39$ & $\$$ & $47,236.56$ & $\$$ & $71,537.19$ & $\$$ & $114,726.23$ \\
\hline 13 & $\$$ & $31,935.12$ & $\$$ & $48,365.51$ & $\$$ & $77,554.52$ & $\$$ & $46,992.45$ & $\$$ & $71,167.50$ & $\$$ & $114,133.35$ \\
\hline 14 & $\$$ & $31,157.33$ & $\$$ & $47,187.55$ & $\$$ & $75,665.65$ & $\$$ & $45,847.94$ & $\$$ & $69,434.19$ & $\$$ & $111,353.59$ \\
\hline 15 & $\$$ & $30,353.40$ & $\$$ & $45,970.00$ & $\$$ & $73,713.31$ & $\$$ & $44,664.96$ & $\$$ & $67,642.63$ & $\$$ & $108,480.42$ \\
\hline 16 & $\$$ & $29,277.94$ & $\$$ & $44,341.22$ & $\$$ & $71,101.54$ & $\$$ & $43,082.42$ & $\$$ & $65,245.96$ & $\$$ & $104,636.80$ \\
\hline 17 & $\$$ & $28,222.48$ & $\$$ & $42,742.74$ & $\$$ & $68,538.36$ & $\$$ & $41,529.31$ & $\$$ & $62,893.87$ & $\$$ & $100,864.69$ \\
\hline 18 & $\$$ & $27,062.14$ & $\$$ & $40,985.42$ & $\$$ & $65,720.47$ & $\$$ & $39,821.87$ & $\$$ & $60,308.05$ & $\$$ & $96,717.74$ \\
\hline 19 & $\$$ & $25,941.81$ & $\$$ & $39,288.69$ & $\$$ & $62,999.76$ & $\$$ & $38,173.32$ & $\$$ & $57,811.40$ & $\$$ & $92,713.79$ \\
\hline 20 & $\$$ & $24,797.20$ & $\$$ & $37,555.18$ & $\$$ & $60,220.06$ & $\$$ & $36,489.02$ & $\$$ & $55,260.62$ & $\$$ & $88,623.04$ \\
\hline CUMULATIVE & $\$$ & $457,037.96$ & $\$$ & $692,180.66$ & $\$$ & $1,109,917.78$ & $\$$ & $672,530.25$ & $\$$ & $1,018,510.19$ & $\$$ & $1,633,413.91$ \\
\hline
\end{tabular}


Appendix C

Selection Intensity for each Genetic Improvement Strategy 


\begin{tabular}{|c|c|c|c|c|}
\hline GIS & $\begin{array}{c}\text { \% } \\
\text { Selected }\end{array}$ & $\begin{array}{c}\# \\
\text { Selected }\end{array}$ & $\begin{array}{c}\text { i for large } \\
\text { samples }\end{array}$ & $\begin{array}{c}\text { i for small } \\
\text { samples }\end{array}$ \\
\hline HNS & 100 & 403 & 0 & 0 \\
\hline & 90 & 363 & 0.109 & 0.108 \\
\hline HSS & 90 & 363 & 0.109 & 0.108 \\
\hline HETNS & 23 & 91 & 1.320 & 1.317 \\
\hline & 11 & 46 & 1.709 & 1.706 \\
\hline CNS & 100 & 256 & 0 & 0 \\
\hline CETNS & 42 & 108 & 0.931 & 0.929 \\
\hline & 21 & 54 & 1.367 & 1.367 \\
\hline
\end{tabular}


Appendix D

$\Delta \mathrm{G}$ per Generation and per Year 


\begin{tabular}{|c|c|c|c|cc|cr|}
\hline GIS & $\mathbf{r}$ & $\mathbf{i}$ & $\mathbf{g}_{\text {sd }}$ & \multicolumn{1}{|c|}{$\boldsymbol{\Delta G}$ Per Generation } & \multicolumn{2}{|c|}{$\Delta \mathbf{G}$ Per Year } \\
\hline HNS 100 & 35 & 0 & $\$ 191$ & $\$$ & - & $\$$ & - \\
\hline & 53 & 0 & $\$ 191$ & $\$$ & - & $\$$ & - \\
\hline & 85 & 0 & $\$ 191$ & $\$$ & - & $\$$ & - \\
\hline HNS90 & 35 & 0.11 & $\$ 191$ & $\$$ & 7.22 & $\$$ & 3.61 \\
\hline & 53 & 0.11 & $\$ 191$ & $\$$ & 10.93 & $\$$ & 5.47 \\
\hline & 85 & 0.11 & $\$ 191$ & $\$$ & 17.53 & $\$$ & 8.77 \\
\hline HSS90 & 35 & 0.11 & $\$ 191$ & $\$$ & 7.22 & $\$$ & 3.61 \\
\hline & 53 & 0.11 & $\$ 191$ & $\$$ & 10.93 & $\$$ & 5.47 \\
\hline & 85 & 0.11 & $\$ 191$ & $\$$ & 17.53 & $\$$ & 8.77 \\
\hline HETNS23 & 35 & 1.32 & $\$ 191$ & $\$$ & 88.04 & $\$$ & 44.02 \\
\hline & 53 & 1.32 & $\$ 191$ & $\$$ & 133.32 & $\$$ & 66.66 \\
\hline & 85 & 1.32 & $\$ 191$ & $\$$ & 213.81 & $\$$ & 106.91 \\
\hline HETNS11 & 35 & 1.71 & $\$ 191$ & $\$$ & 114.05 & $\$$ & 57.03 \\
\hline & 53 & 1.71 & $\$ 191$ & $\$$ & 172.70 & $\$$ & 86.35 \\
\hline & 85 & 1.71 & $\$ 191$ & $\$$ & 276.97 & $\$$ & 138.48 \\
\hline CNS100 & 35 & 0 & $\$ 191$ & $\$$ & - & $\$$ & - \\
\hline & 53 & 0 & $\$ 191$ & $\$$ & - & $\$$ & - \\
\hline & 85 & 0 & $\$ 191$ & $\$$ & - & $\$$ & - \\
\hline CETNS42 & 35 & 0.93 & $\$ 191$ & $\$$ & 62.10 & $\$$ & 20.70 \\
\hline & 53 & 0.93 & $\$ 191$ & $\$$ & 94.05 & $\$$ & 31.35 \\
\hline & 85 & 0.93 & $\$ 191$ & $\$$ & 150.81 & $\$$ & 50.27 \\
\hline CETNS21 & 35 & 1.37 & $\$ 191$ & $\$$ & 91.38 & $\$$ & 30.46 \\
\hline & 53 & 1.37 & $\$ 191$ & $\$$ & 138.39 & $\$$ & 46.13 \\
\hline & 85 & 1.37 & $\$ 191$ & $\$$ & 221.94 & $\$$ & 73.98 \\
\hline & & & & & & & \\
\hline
\end{tabular}

